U.S. Department of the Interior

U.S. Geological Survey

\title{
Depth Profiles of Temperature, Specific Conductance, and Oxygen Concentration in Lake Powell, Arizona-Utah, 1992-95
}

By G. Richard Marzolf, Robert J. Hart, and Doyle W. Stephens

U.S. GEOLOGICAL SURVEY

Open-File Report 97-835

Prepared in cooperation with the BUREAUOF RECLAMATION

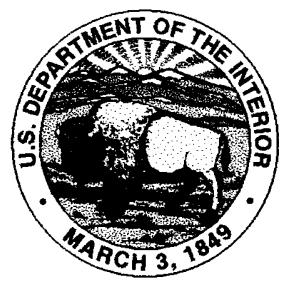




\title{
U.S. DEPARTMENT OF THE INTERIOR \\ BRUCE BABBITT, Secretary
}

\author{
U.S. GEOLOGICAL SURVEY
}

Mark Schaefer, Acting Director

The use of firm, trade, and brand names in this report is for identification purposes only and does not constitute endorsement by the U.S. Geological Survey

For additional information write to:

Richard Marzolf

U.S. Geological Survey, WRD, MS432

12201 Sunrise Valley Drive

Reston, VA 20192
Copies of this report can be purchased from:

U.S. Geological Survey

Information Services

Box 25286

Federal Center

Denver, CO 80225 


\section{CONTENTS}

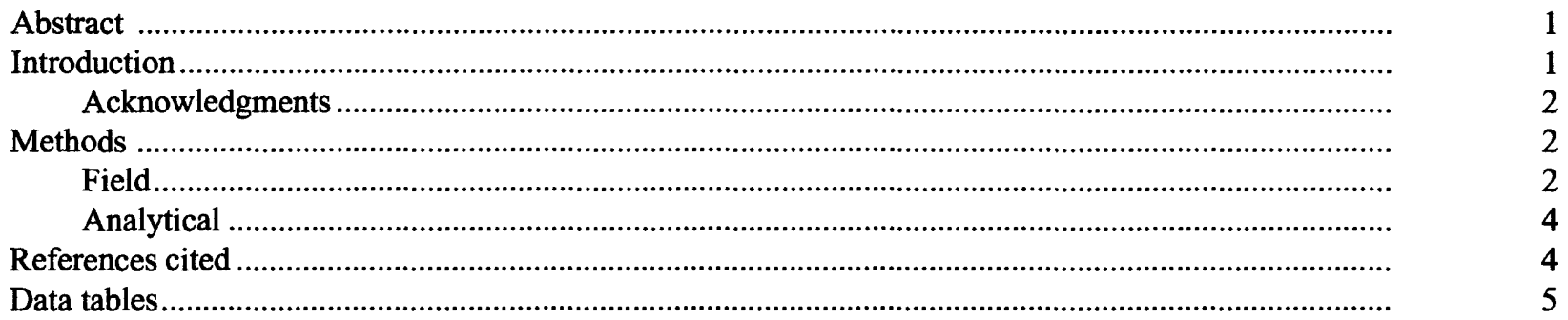

\section{FIGURES}

1. Map showing distribution of sampling sites on Lake Powell.

2. Graph showing longitudinal-depth plot of specific conductance distribution in Lake Powell in July 1995.

\section{CONVERSION FACTORS}

\begin{tabular}{lll}
\hline Multiply & By & To obtain \\
\hline foot (ft) & 0.3048 & meter \\
mile (mi) & 1.609 & kilometer \\
\hline
\end{tabular}

In this report, water temperatures are given in degrees Celsius $\left({ }^{\circ} \mathrm{C}\right)$, which can be converted to degrees Fahrenheit $\left({ }^{\circ} \mathrm{F}\right)$ by the following equation:

$$
{ }^{\circ} \mathrm{F}=1.8\left({ }^{\circ} \mathrm{C}\right)+32
$$

Sea level: In this report sea level refers to the National Geodetic Vertical Datum of 1929-A geodetic datum derived from a general adjustment of the first-order level nets of the United States and Canada, formerly called Sea Level Datum of 1929. 


\title{
Depth Profiles of Temperature, Specific Conductance, and Oxygen Concentration in Lake Powell, Arizona-Utah, 1992-95
}

\author{
By G. Richard Marzolf, Robert J. Hart, and Doyle W. Stephens
}

\section{Abstract}

The depth distribution of temperature in lakes and reservoirs establishes vertical-density gradients that regulate the distribution of a wide array of chemical and biological features. In Lake Powell, the depth at which inflowing river water enters the reservoir is controlled by the water temperature of the river compared to the vertical-thermal structure of the reservoir in late spring and early summer. The measurements reported here document the longitudinal and vertical pattern of temperature, specific conductance, and oxygen concentration on several dates in 1992, 1994, and 1995.

\section{INTRODUCTION}

The interaction of lake surfaces with solar radiation (heating) and atmospheric conditions (wind, cloud cover, and composition) drives the development of major depth-variant patterns in lakes. The seasonal variation in the vertical profile of temperature has been one of the most descriptive features for comparison of lakes for most of this century (Forel, 1895). The thermal structure sets the pattern for subsequent development of mixing patterns by wind, consequent gas exchange with atmosphere, and vertical chemical patterns in deep water below the barriers to wind-mixed contact with the atmosphere. Thus, the vertical or depth patterns of a great many physical properties are instructive about the basic, independent, physical processes that control the distribution of living or nonliving materials dissolved or suspended in lakes.

For example, the mixed upper layer (or epilimnion) results mostly from thermal control of density; water warmed from the surface is characterized as containing the lighted zone (euphotic) that defines the spatial extent of photosynthesis. In water deeper than the mixed layer (or hypolimnion) where light is limited, chemical and biological processes (reduction and respiration) proceed without the influence of atmospheric exchange or oxygen-producing photosynthesis. More complete discussion of the rudiments of these processes can be found in basic limnology references such as Hutchinson (1957) or Wetzel (1983).

Lake Powell is influenced strongly by the hydrologic regime of the Colorado River that was impounded by Glen Canyon Dam in 1957-63. Lake Powell was filled for the first time in 1981. The annual high inflow period is from snowmelt on the west slope of the Rocky Mountains during the late spring and early summer (April until July). The inflow water during this period generally is low in salt concentration. In the late summer and fall, the lower inflow carries higher salt concentrations because the influence of tributaries draining arid portions of the drainage basin is greater and irrigation return flow from agricultural lands carries salts (Iorns and others, 1965).

Reservoirs typically exhibit longitudinal variation caused by the hydrologic regime and the water quality of the river that was impounded to form 
them (Thornton and others, 1990). The advective transport of water and materials into Lake Powell from the Colorado River was thought, therefore, to impose longitudinal patterns in temperature and conductivity that, when superimposed upon the vertical structure driven by processes mentioned above, would help explain much of the spatial variability of water quality that has been observed.

Some of these patterns have been described by Merritt and Johnson (1977) and Johnson and Merritt (1979) during the period when Lake Powell was filling. The data were few and oxygen concentration was not among the profiles that were measured. Technology for gathering and handling profile data improved with the development of field dataloggers. The objective for data collection was to understand better the physical basis for the vertical and longitudinal variations in water quality. The study design employed to achieve that objective included: (1) repetition of the profile measurements 30 years after Lake Powell was filled, (2) sample according to a more dense spatial design in both longitudinal and vertical dimensions, and (3) include measurements of oxygen concentration as an indicator of biotic and chemical processes.

The data reported in this report (tables $1-5$ at the end of this report) resulted from this study.

\section{Acknowledgments}

Financial support for this work was provided by the Bureau of Reclamation (BOR) through the Glen Canyon Environmental Studies, David L. Wegner, Program Manager (Interagency Agreement \#9-AA-40-07910). The field work in 1992 was possible because of the valuable help provided by Bill Verniey, Robert Radtke, Richard Lechleitner, and Jean Korn, BOR's Glen Canyon Environmental Studies; and Richard Leitner, Calvin Leach, and Clarence Herron, the crew of the BOR's service boat. We appreciated the help of James Pfeiffer, Arizona State University, in 1994 for field assistance. John Ritenour, Norman Henderson, and Susan Dodson, National Park Service, Glen Canyon National Recreation Area, were always helpful with logistic needs and facilities at the Wahweap Marina.

\section{METHODS}

\section{Field}

In 1992, there were 13 sampling sites on the mainstem of Lake Powell. These are the same sites that were used by the BOR in their routine monitoring program. In 1994-95, a 14th mainstem site was added at the mouth of the San Juan River. The site names, the two letter codes with which we identify data files, the site locations in river kilometers, and the latitudes and longitudes are shown on figure 1 .

Locations in the field were accomplished through dead reckoning in 1992 and with Satellite geopositioning instruments in 1994-95. Depths were measured with sonic equipment, traversing transects to find the pre-existing river channel, and verifying latitude and longitude coordinates. The same sonic fathometer was used to follow the profiling instrument on the downcast in order to approach the bottom closely without embedding the instruments in the sediments.

The profile measurements were made with a Sea-Bird Electronics, Seacat SBE 19-03. The temperature and conductivity sensors were calibrated annually by the manufacturer and found to be stable and accurate. The calibration coefficient of the pressure transducer was revised on each field excursion to accommodate changes in reservoir levels. The oxygen probe was cleaned and calibrated at 0 percent and 100 percent saturation before and after each field excursion. During any excursion, there was no measurable departure from the calibrated voltages. A thermistor in the oxygen probe failed on the April 1992 trip perhaps because of some extreme thermal variations. Oxygen data are not included from that trip. Subsequently, the instrument was kept submerged in a tub between sites and casts to minimize rapid thermal changes.

The datalogger on the instrument was programmed to scan the sensors at 0.5 second intervals. The data are logged as raw voltages from the sensors in hexadecimal format. At this sampling interval, the profiler sampled each sensor two or three times per meter and profiles were accomplished in 2 to 15 minutes depending on the depth. Downcasts were controlled to a descent rate of less than free fall (0.5-1.0 meters per second). 


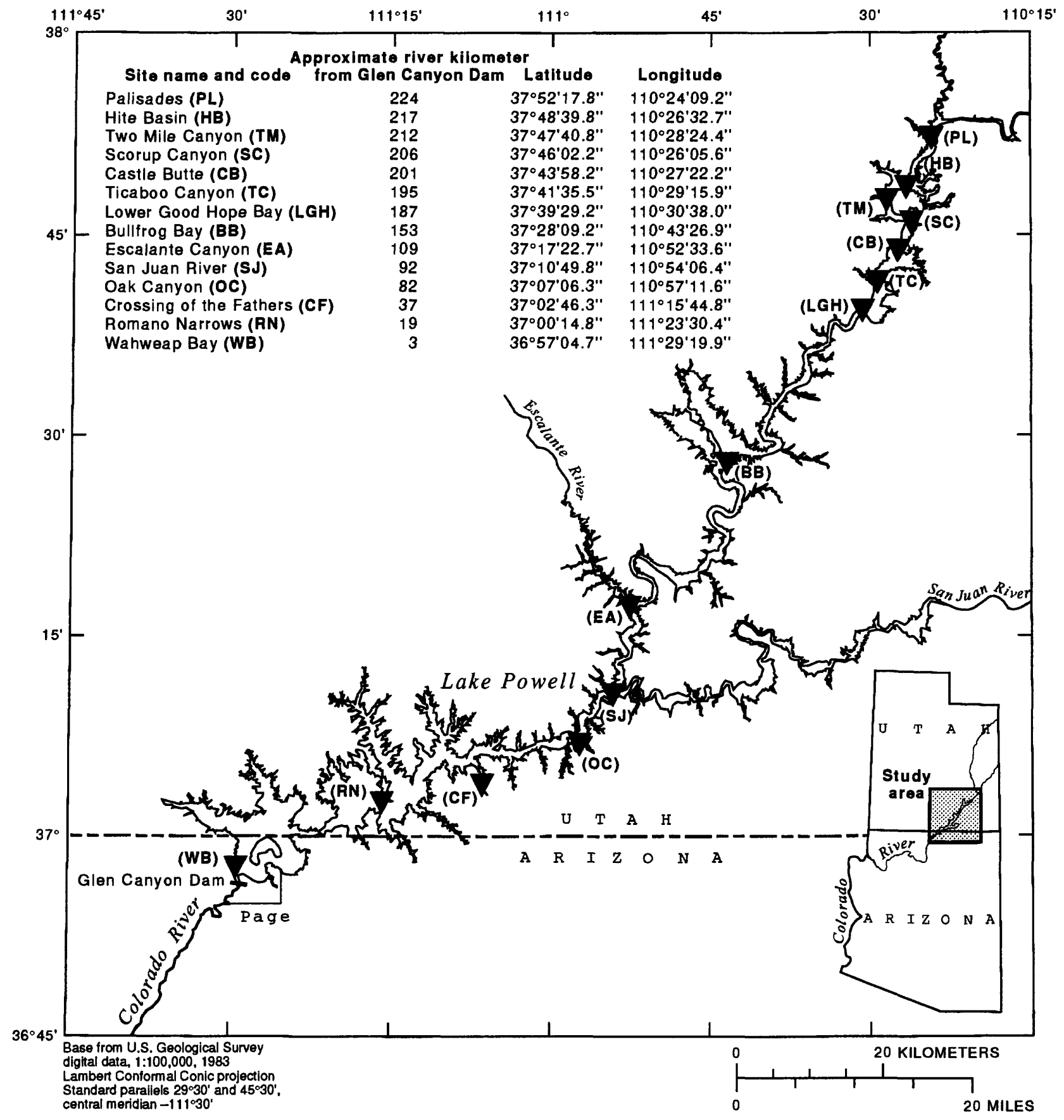

Figure 1. Distribution of sampling sites on Lake Powell.

The time at the start of each cast was recorded to link the file in the datalogger to notes identifying the location and dates on which they were made. Immediately upon retrieval of the profiler, it was connected to a field laptop computer so that specific headers of date, location, and coded file name of the cast could be added to the file. The file was also downloaded on to a hard disc and backed up on a floppy disc at that time. These raw data are available from the senior author if necessary but this report presents only derived, converted, and average values from this raw data set. 


\section{Analytical}

The files were manipulated later with the manufacturer's software (Seasoft version 4.0 in 1992, version 4.024 in 1994, and versions 4.011 and 4.212 in 1995). These data were first converted into derived values of depth, temperature, specific conductance, and oxygen concentrations as ASCII numbers in engineering format from the hexadecimal format and then averaged into 0.5 meter "bins" in 1992 and 1994 and into 1.0 meter "bins" in 1995.

Files were then imported into spreadsheets for inspection and edited and into graphics software for preparation of three-dimensional contour plots (see figure 2 for example).

The entire data sets offered in this report are available in spreadsheet form (Quattro Pro for Windows or Quattro Pro for DOS) from the U.S. Geological Survey, Arizona District, 520 North Park Avenue, Suite 221, Tucson, Arizona 85719-5035. These data sets also are in the data base at the U.S. Geological Survey office at 2255 N. Gemini Drive, Flagstaff, Arizona 86001.

\section{REFERENCES CITED}

Forel, F.-A., 1895, Le Leman: Monograpphie Limnologique, Tome II, Lausanne, F. Rouge (Reprinted Geneve, Slatkine Reprints, 1969).

Hutchinson, G.E., 1957, A treatise on limnology, v. I: New York, John Wiley and Sons, Inc., 1,015 p.

Iorns, W.V., Hembree, C.H., and Oakland, G.L., 1965, Water resources of the Upper Colorado River Basin-Technical report: U.S. Geological Survey Professional Paper 441, 370 p.

Johnson, N.M., and Merritt, D.H., 1979, Convective and advective circulation of Lake Powell, Utah-Arizona during 1972-1975: Water Resources Research, v. 5 , no. 4 , p. $873-884$.

Merritt, D.H., and Johnson, N.M., 1977, Advective circulation in Lake Powell, Utah-Arizona: Lake Powell Research Project Bulletin No. 61, National Science Foundation.

Thorton, K.W., Kimmel, B.L., and Payne, F.E., 1990, Reservoir limnology: New York, John Wiley Interscience, $246 \mathrm{p}$.

Wetzel, R.G., 1983, Limnology: New York, John Wiley and Sons, Inc., $767 \mathrm{p}$.

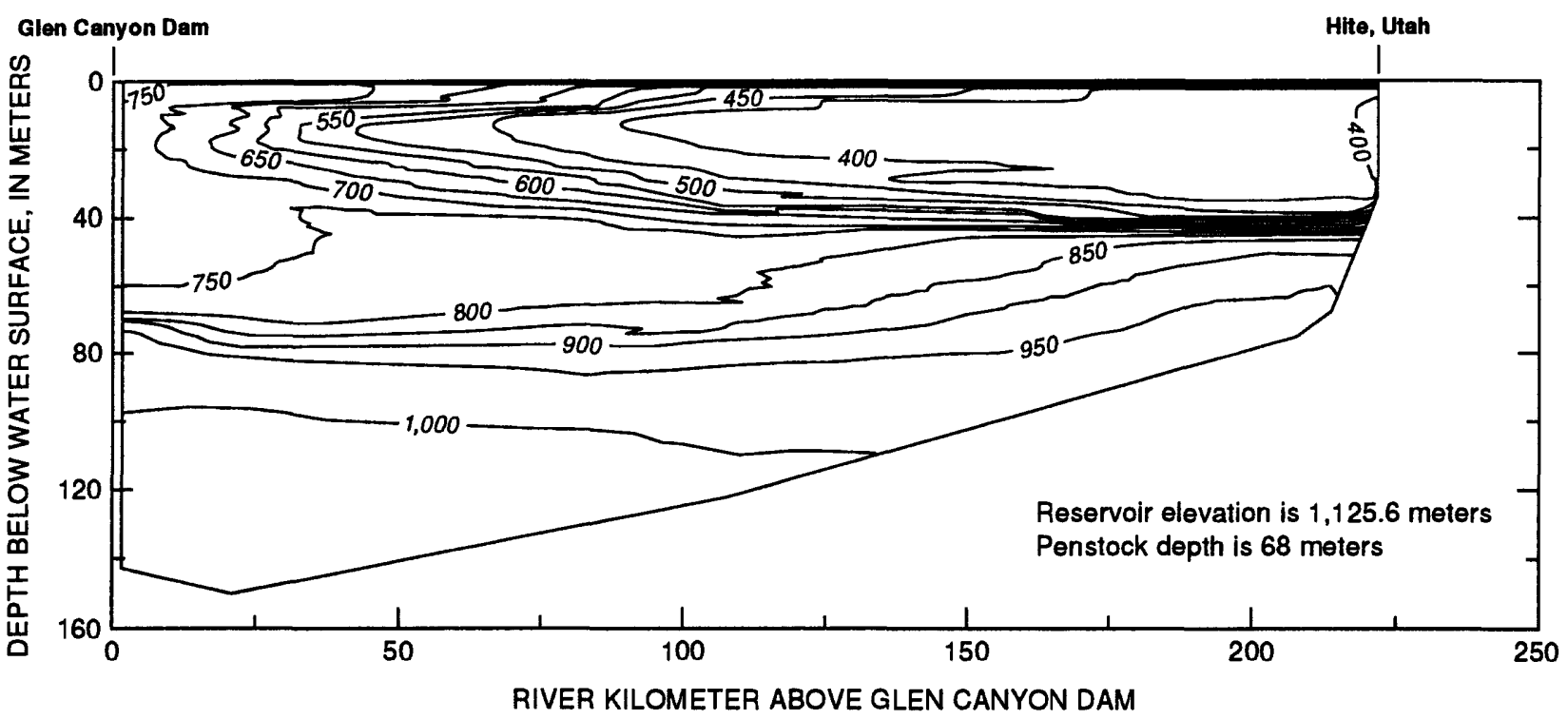

Figure 2. Longitudinal-depth plot of specific conductance distribution in Lake Powell in July 1995 . The distribution of low conductivity water of the spring flow of the Colorado River from Hite, Utah, to approximately 175 kilometers that then extends as a subsurface advective plume almost to Glen Canyon Dam. 


\section{BASIC DATA}

Tables 1-5 


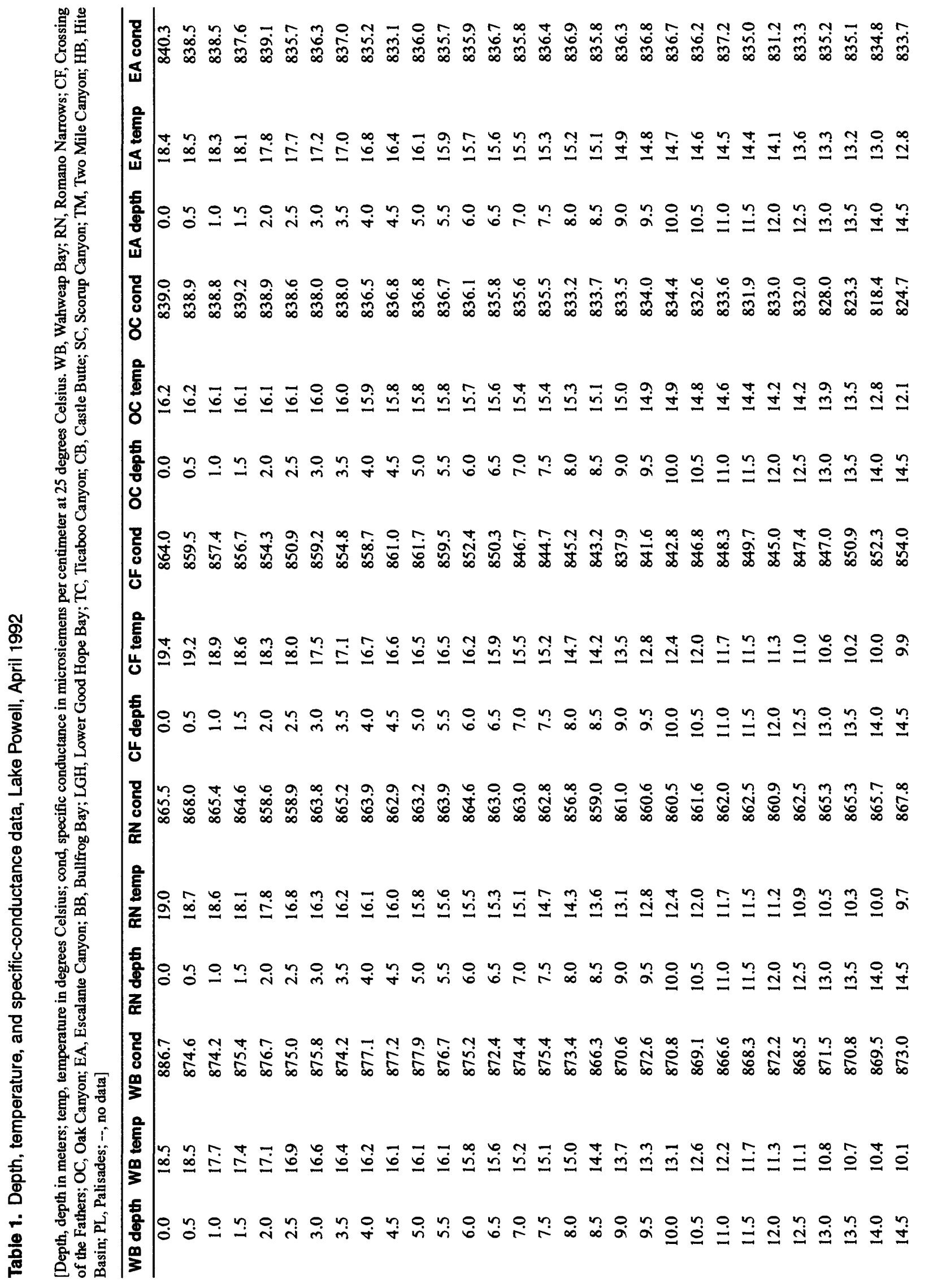




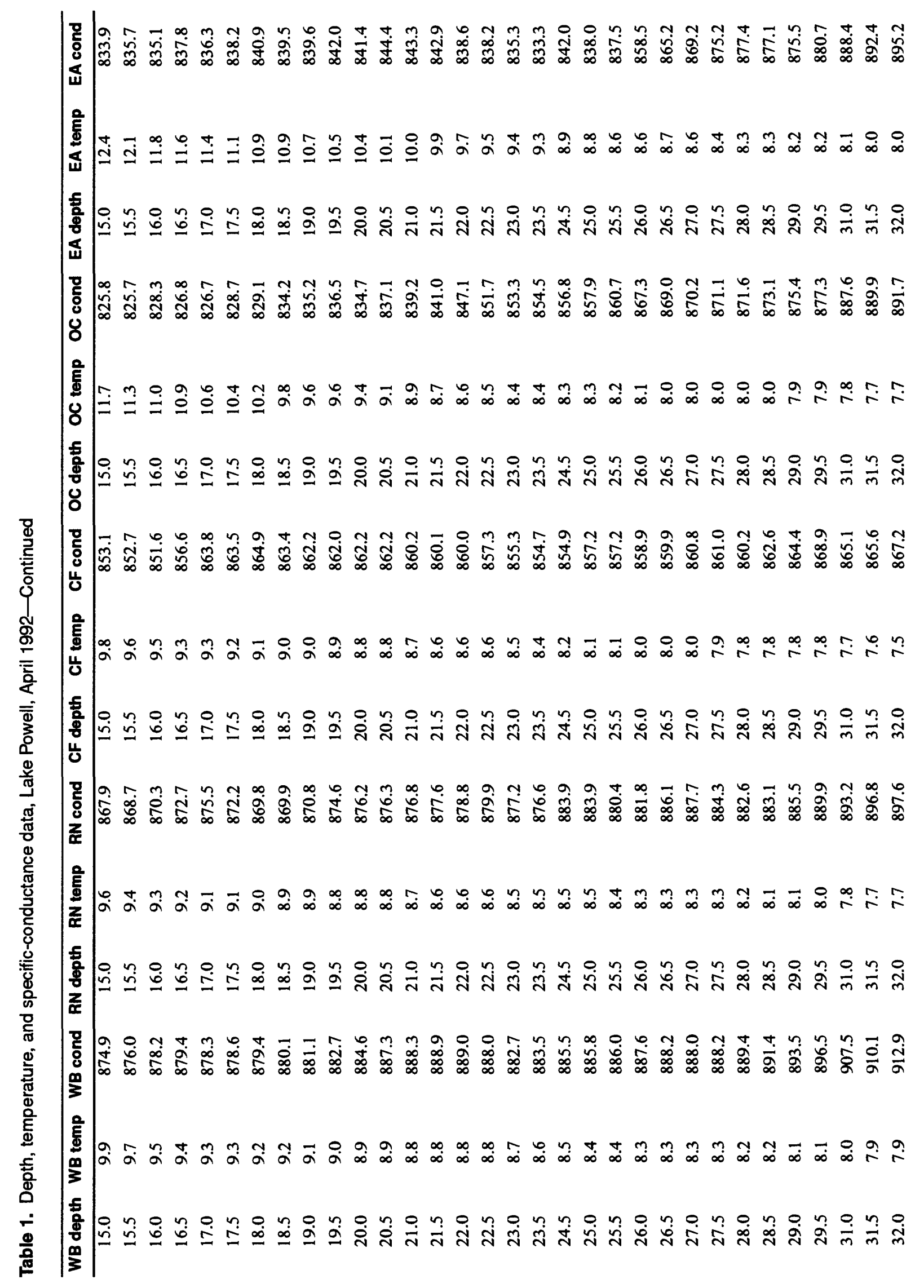

8 Depth Profiles of Temperature, Specific Conductance, and Oxygen Concentration in Lake Powell, Az-Utah, $1992-95$ 


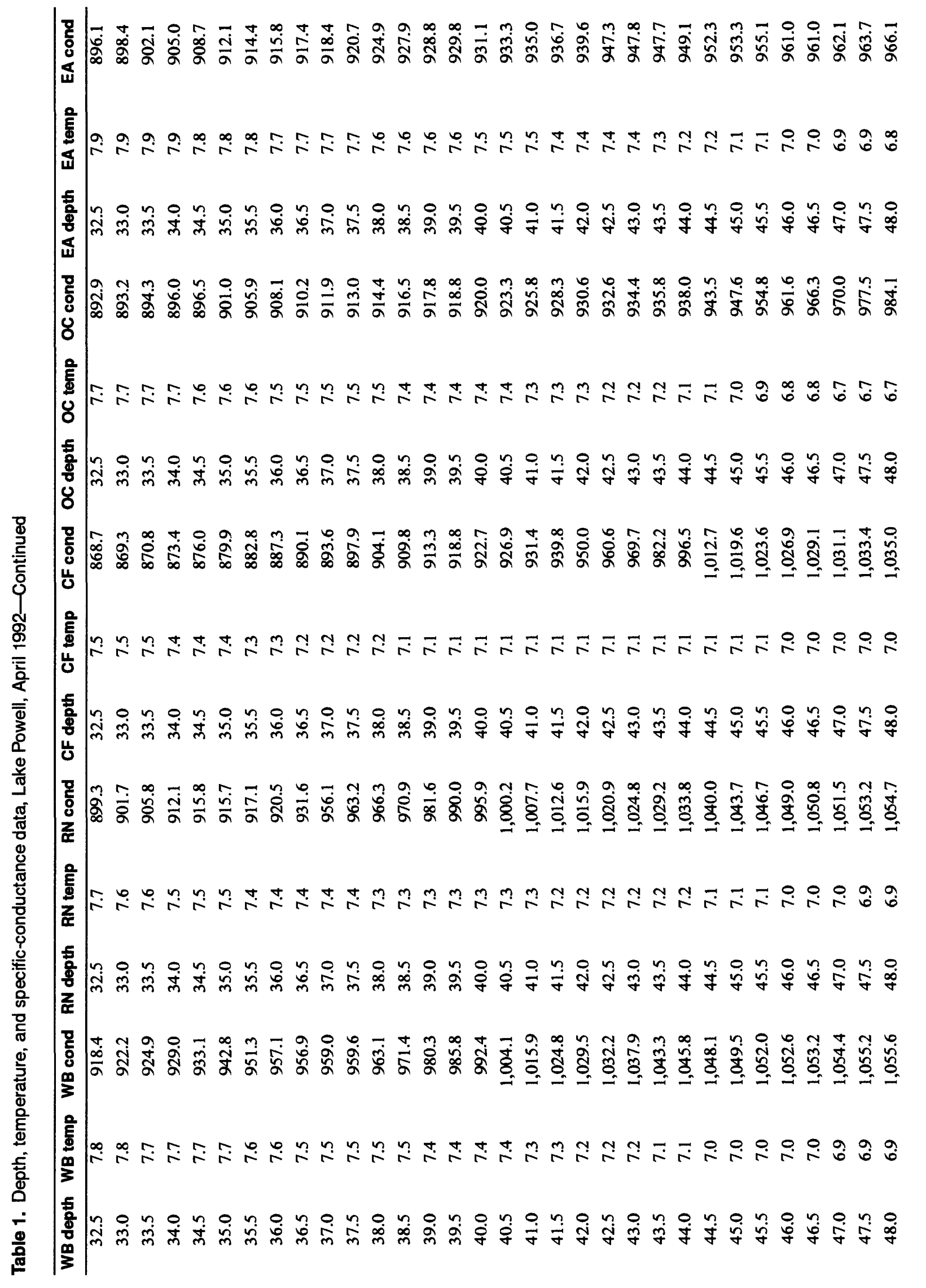




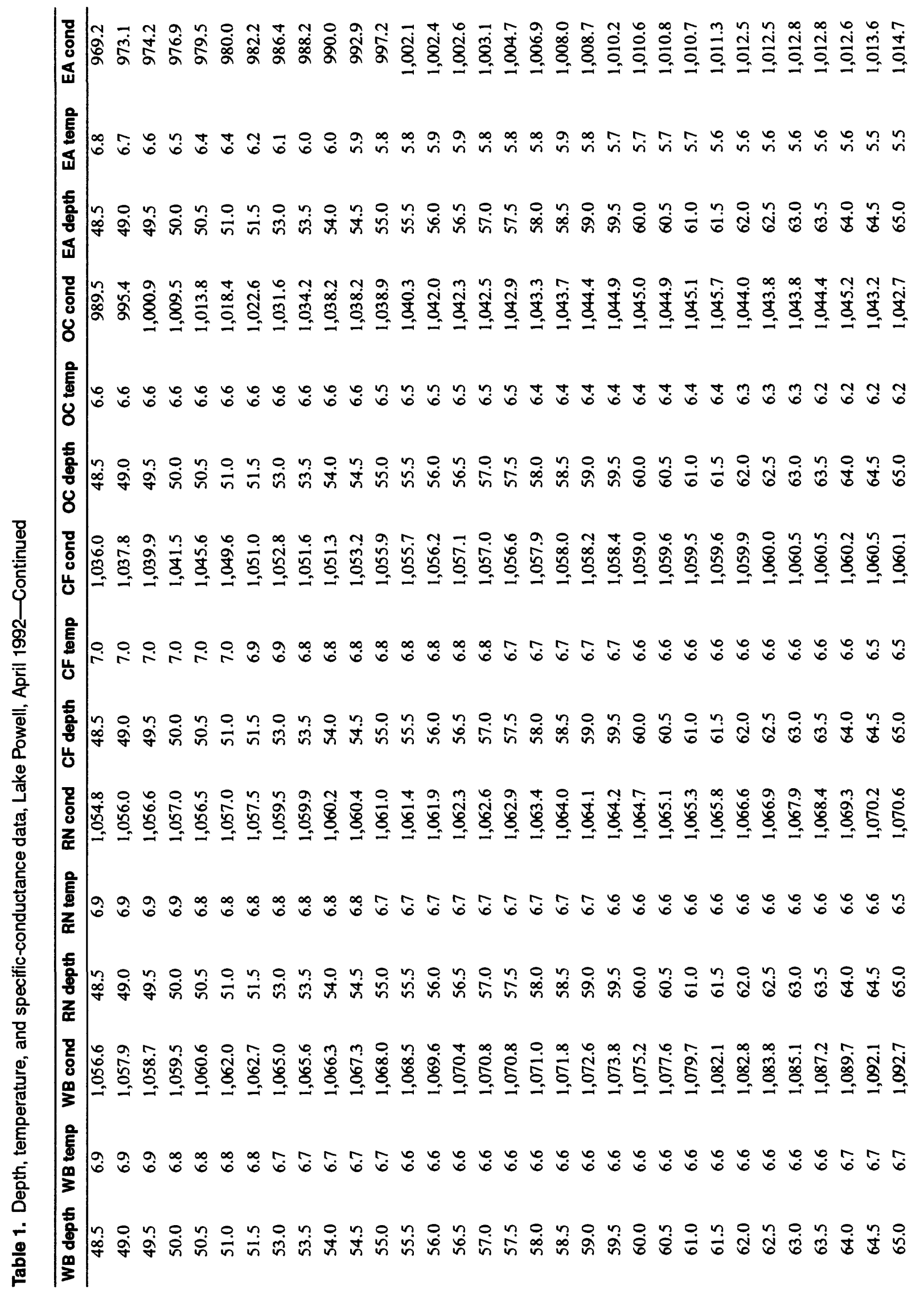




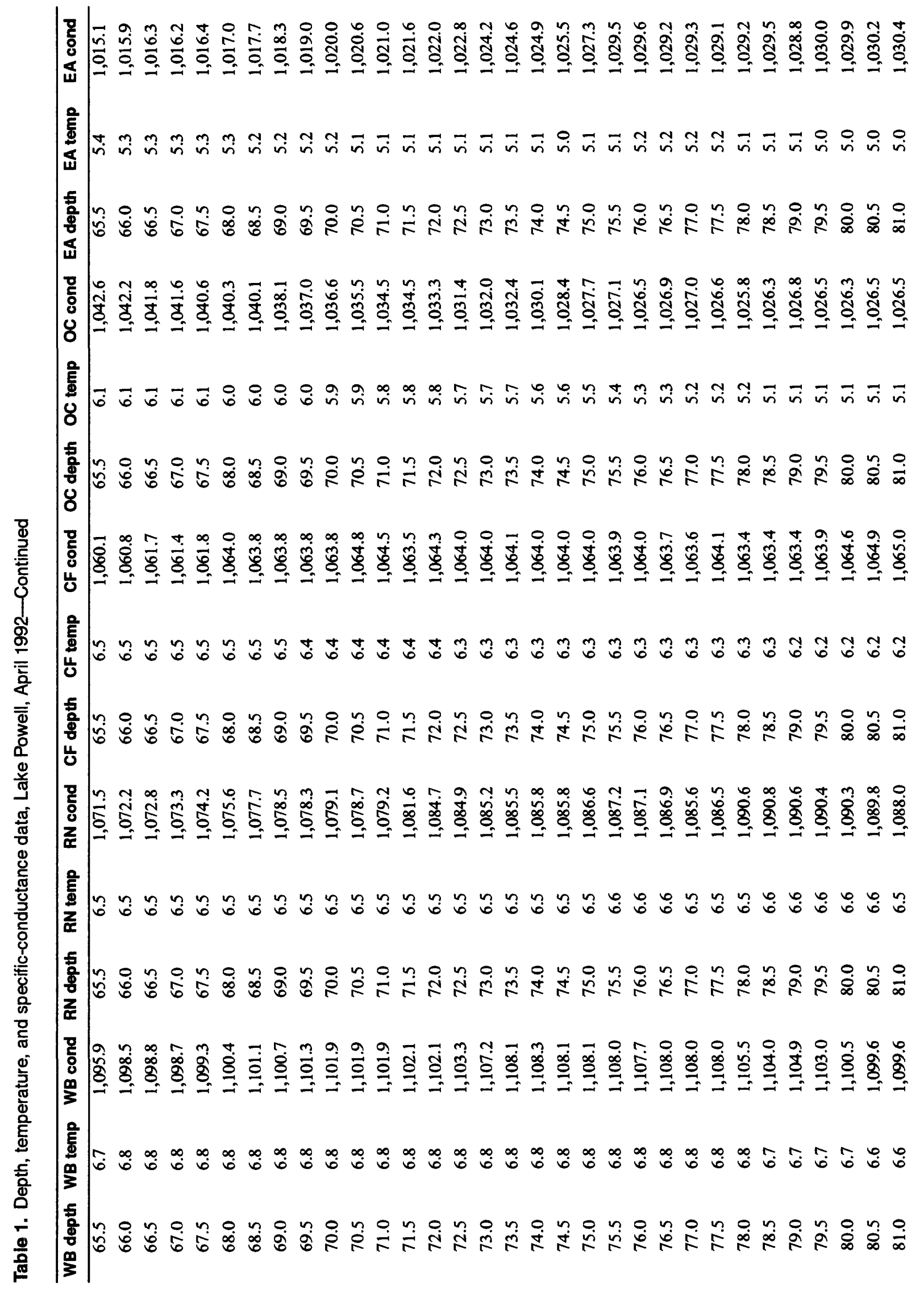




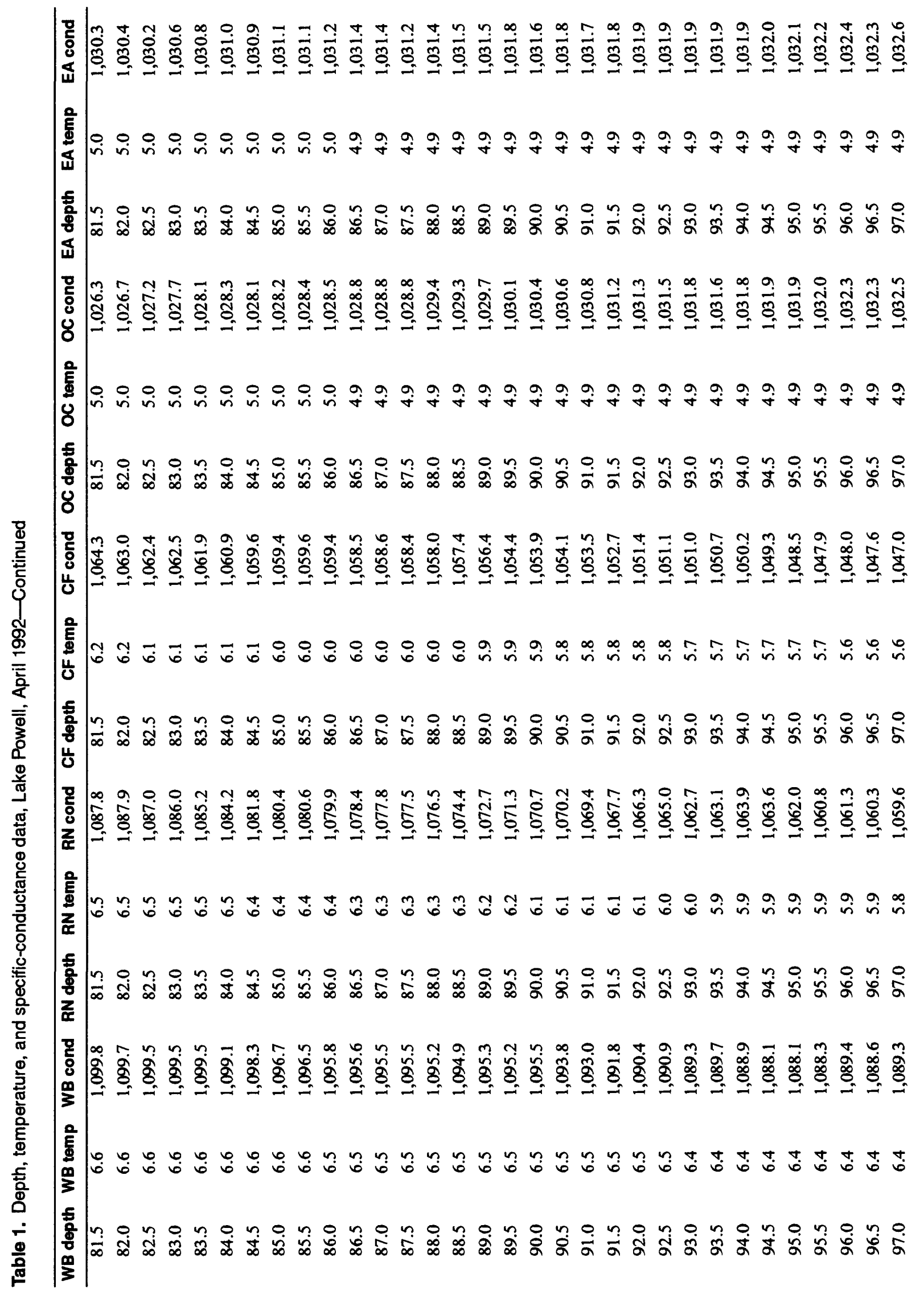




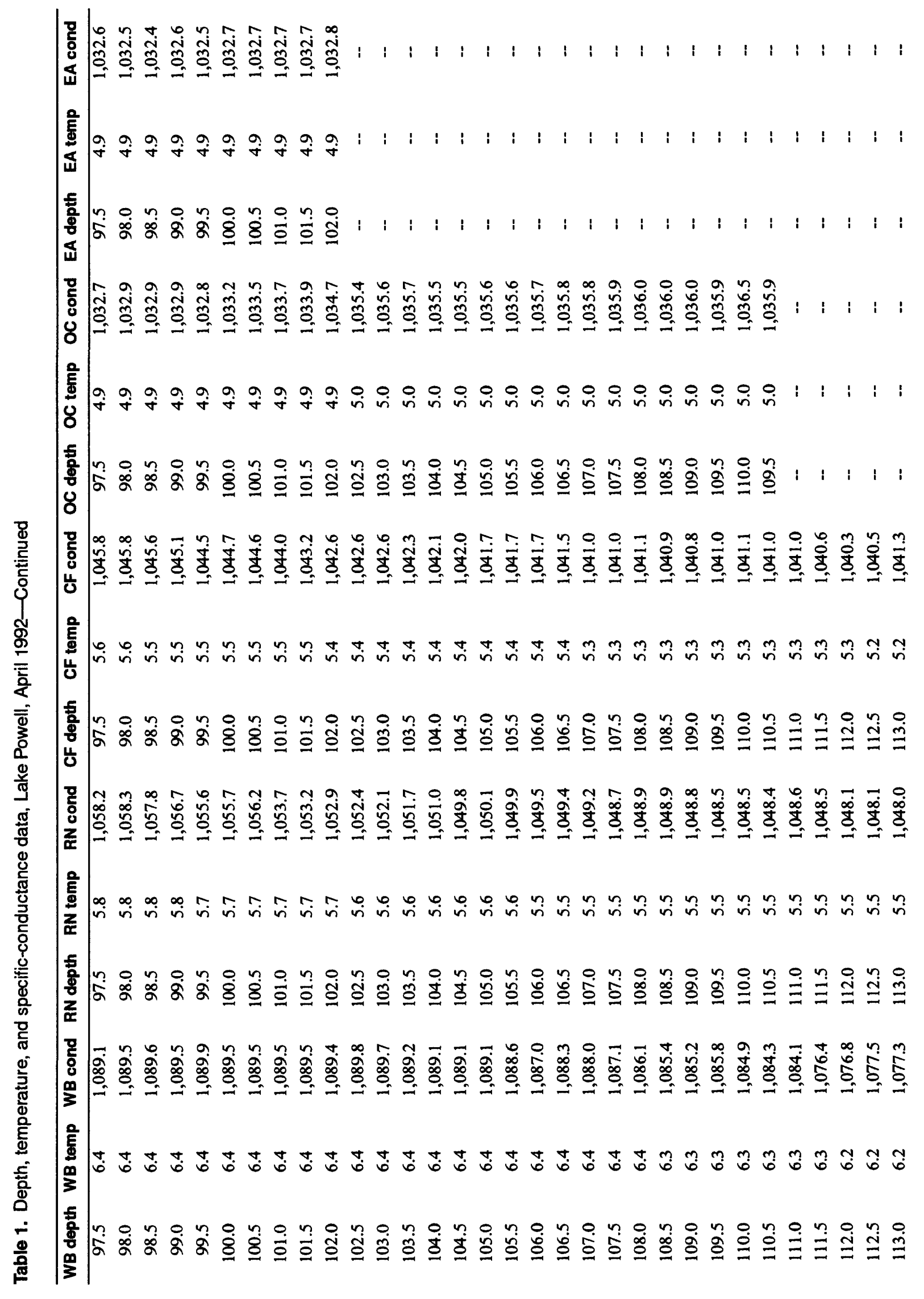




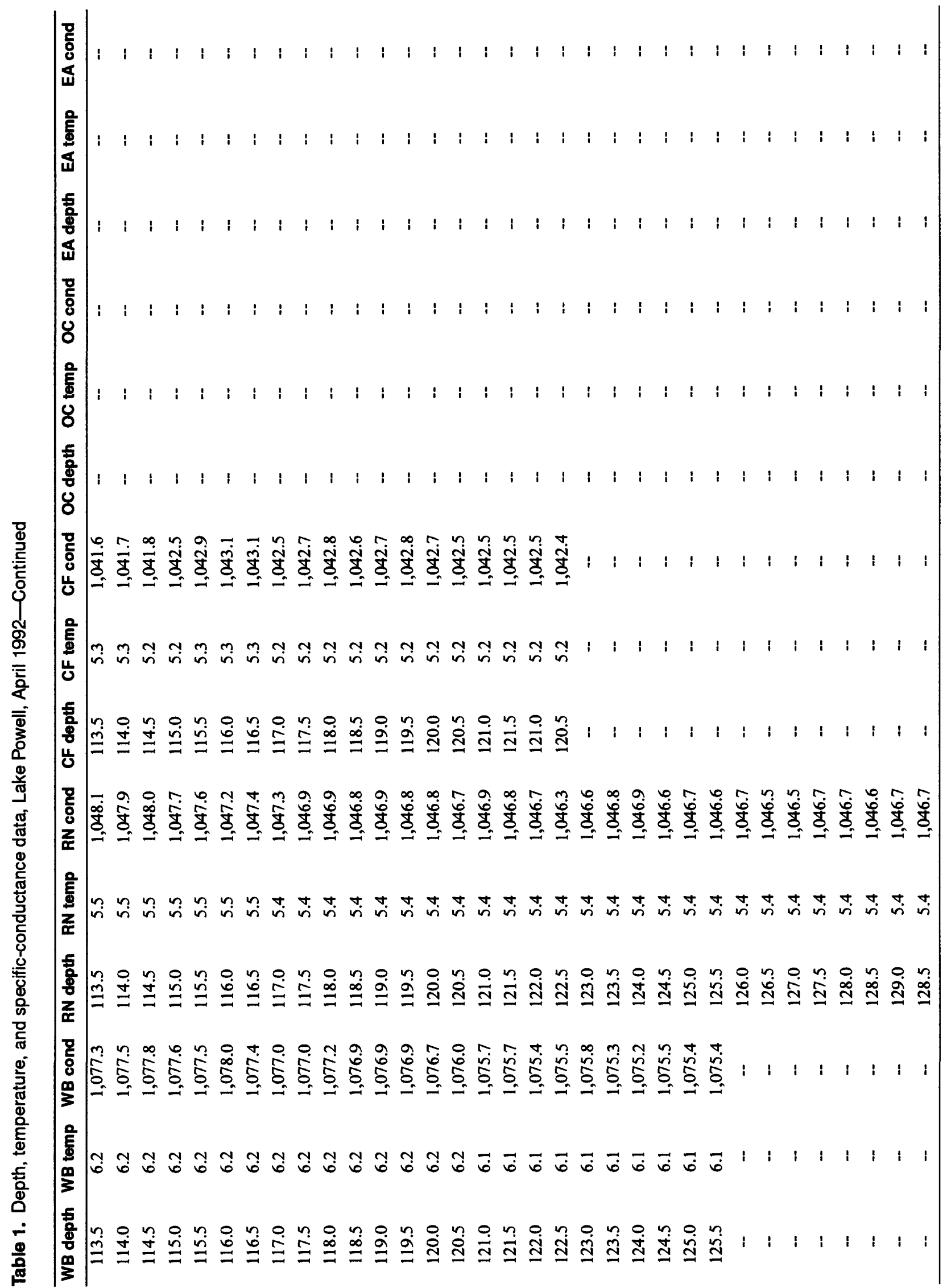




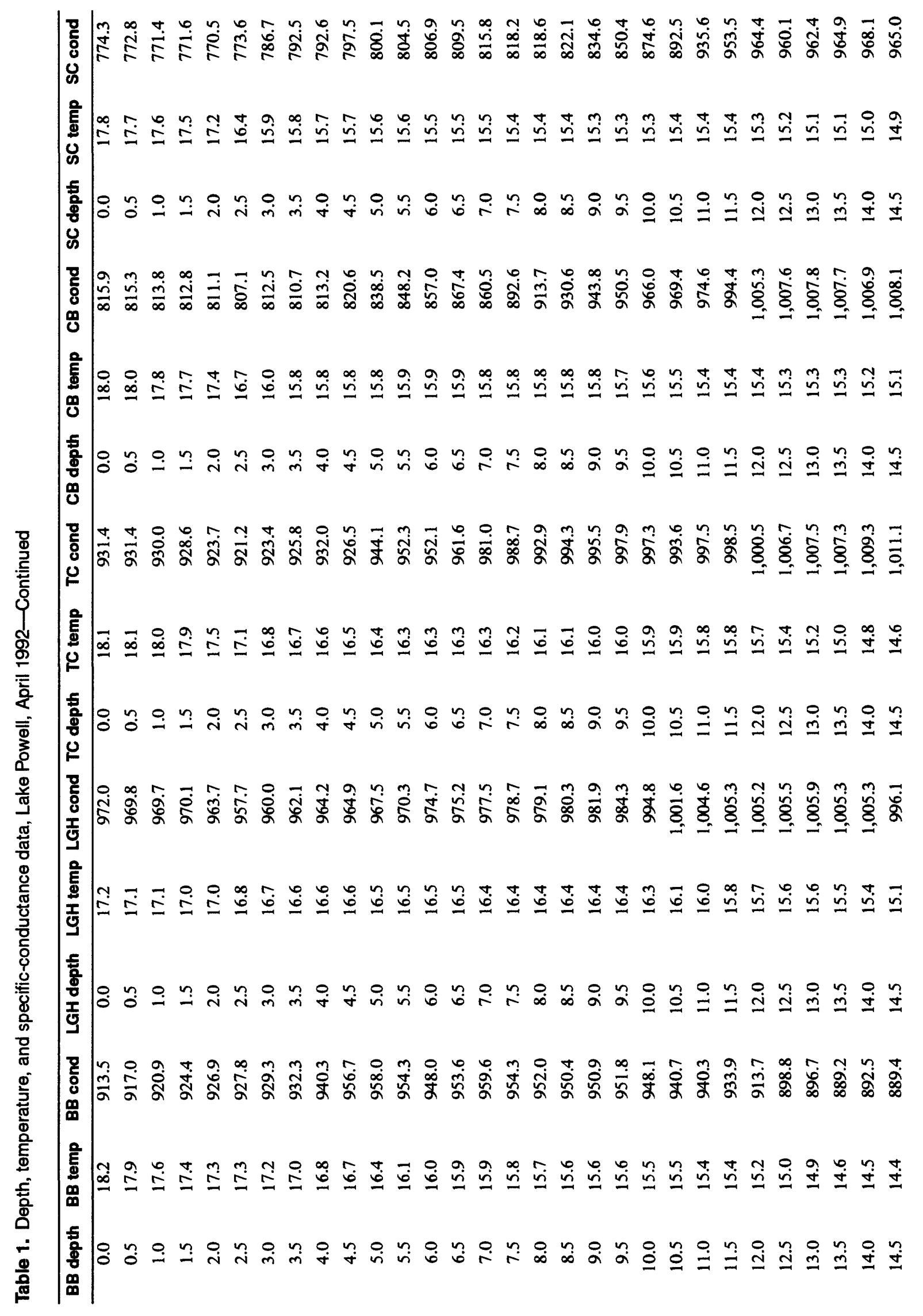




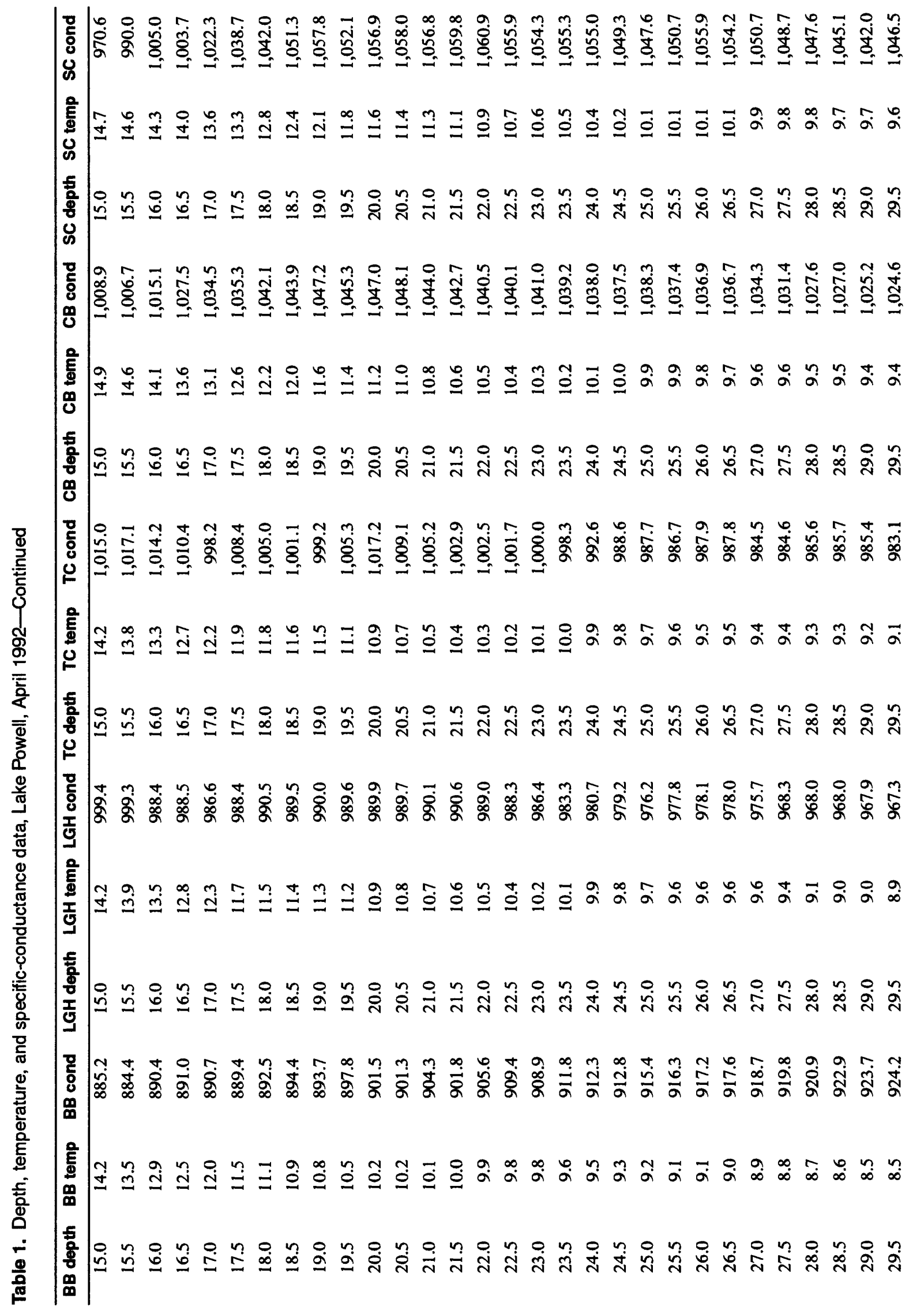




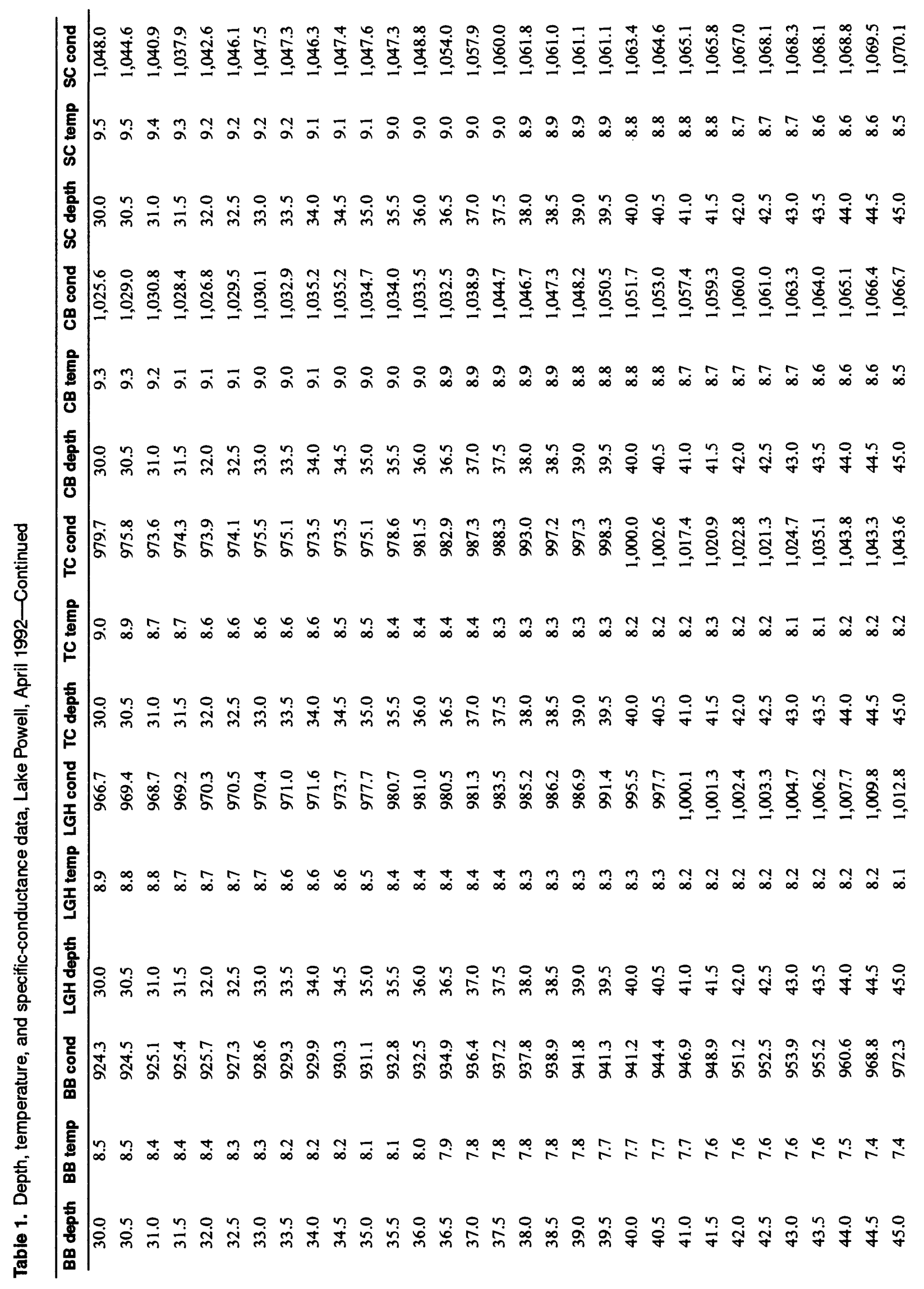




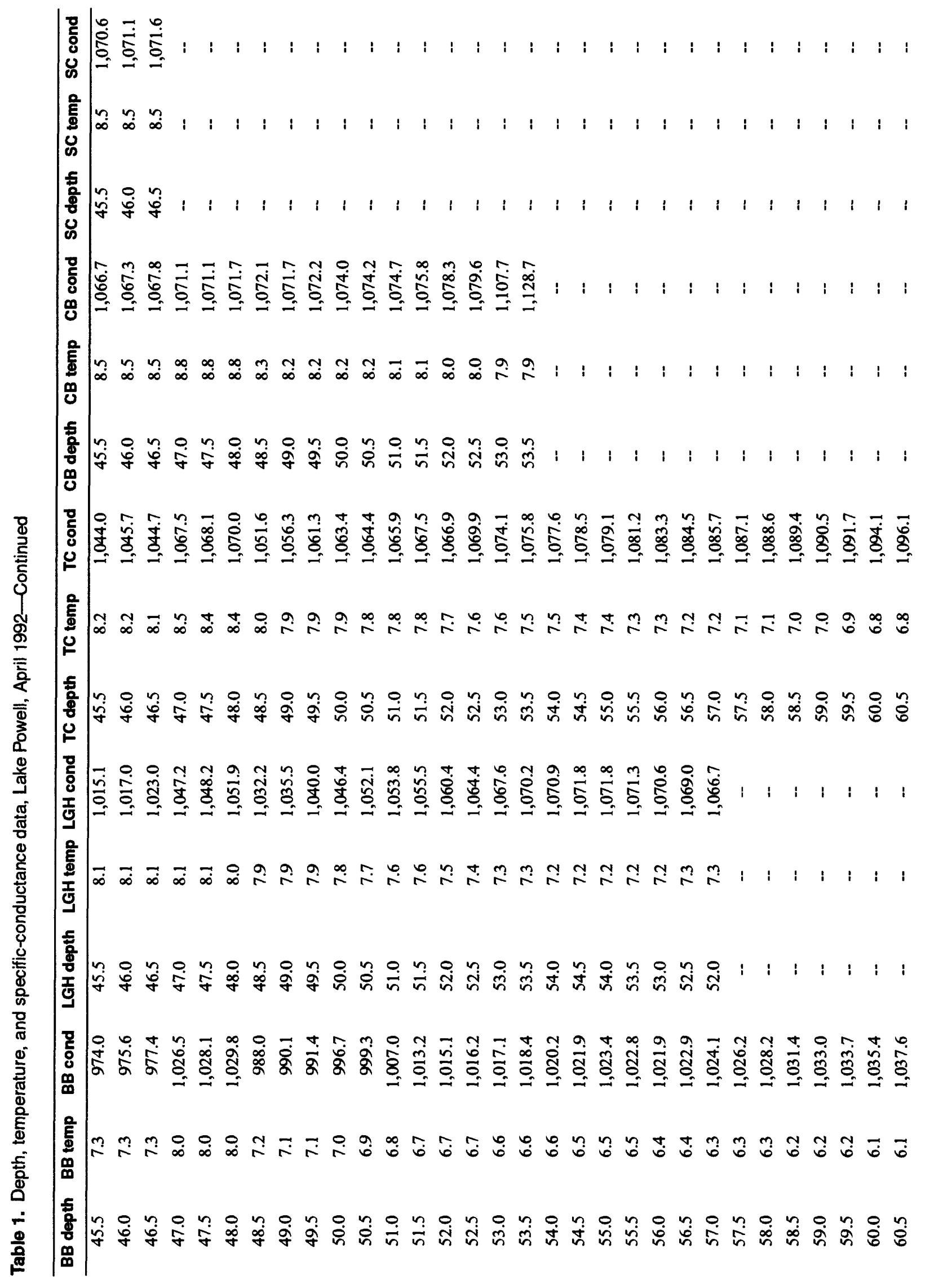




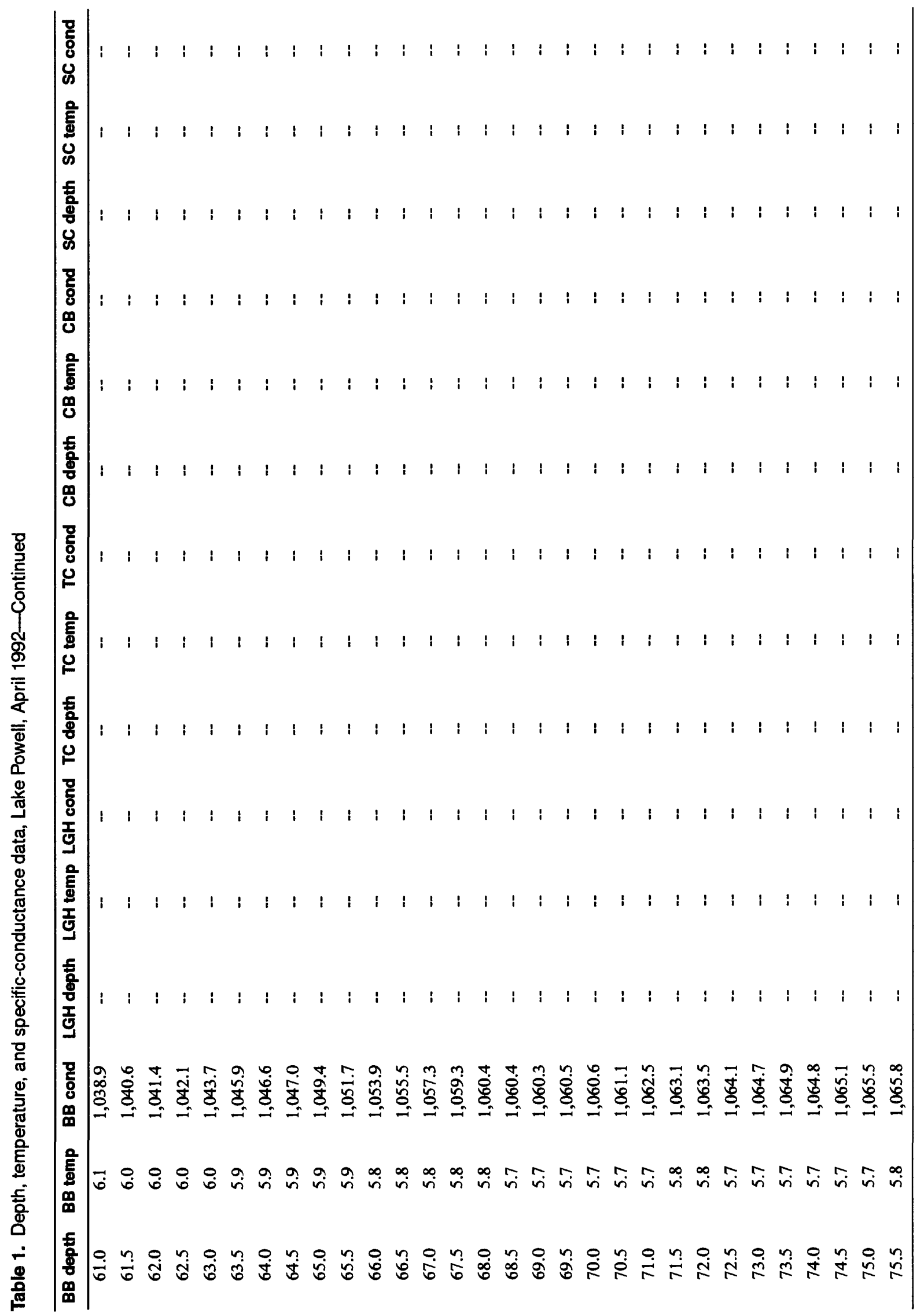


च 量 产 总

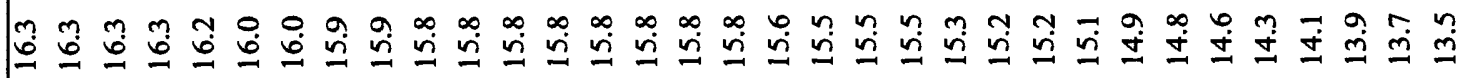
臭

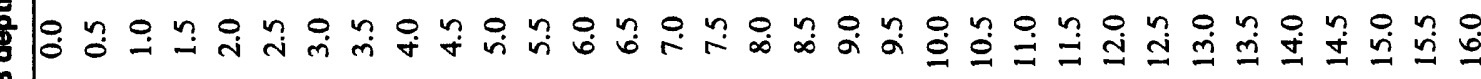
品

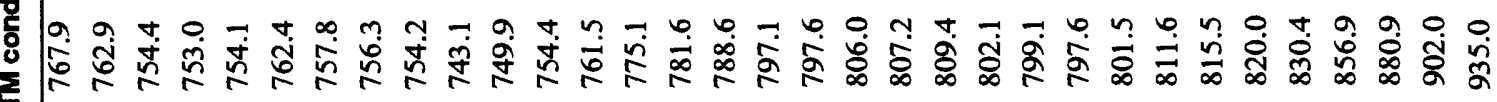
F 我 F

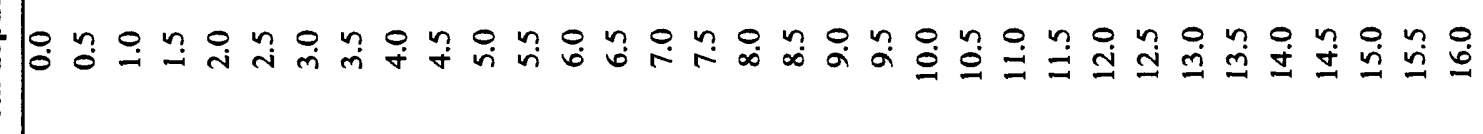




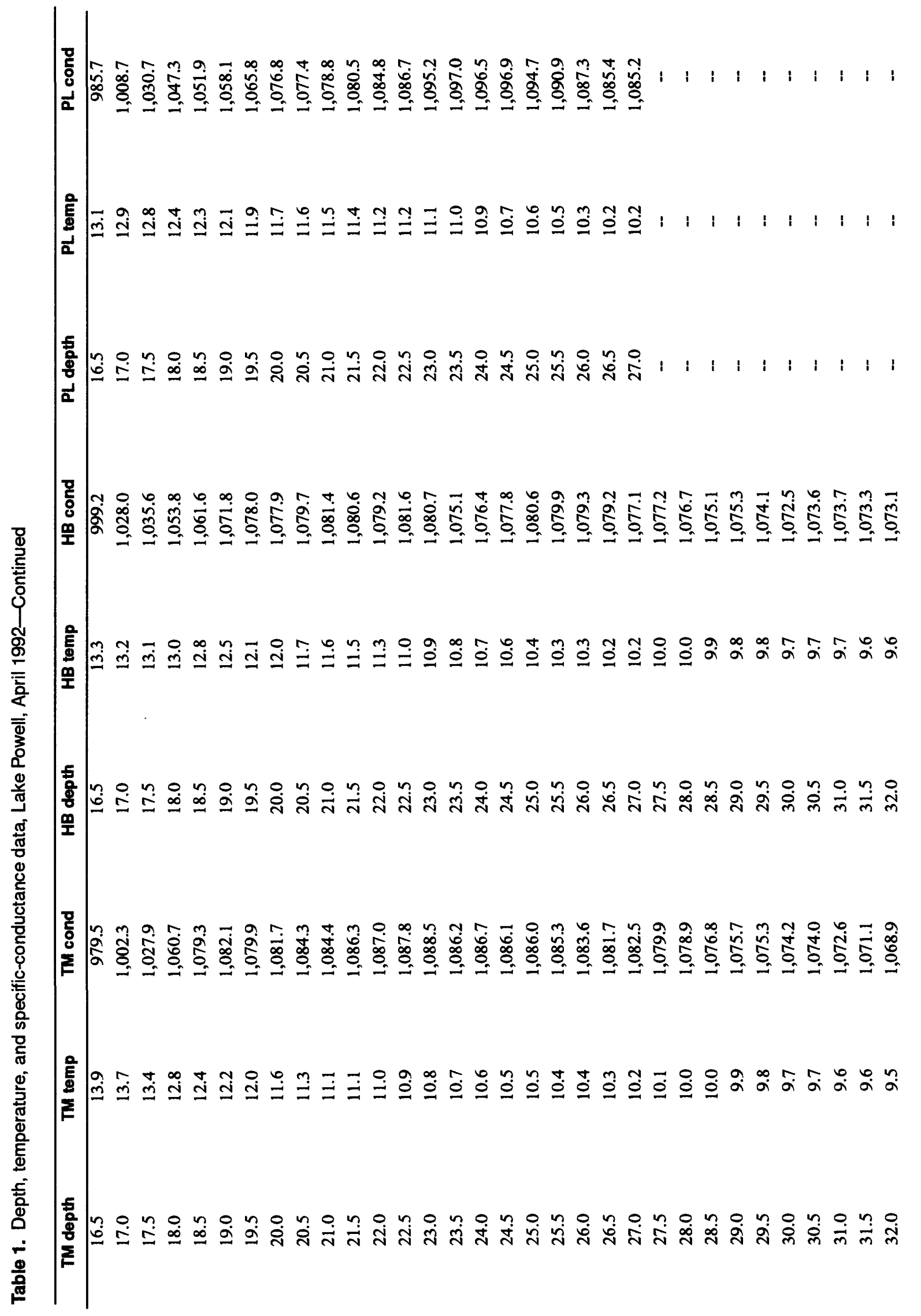




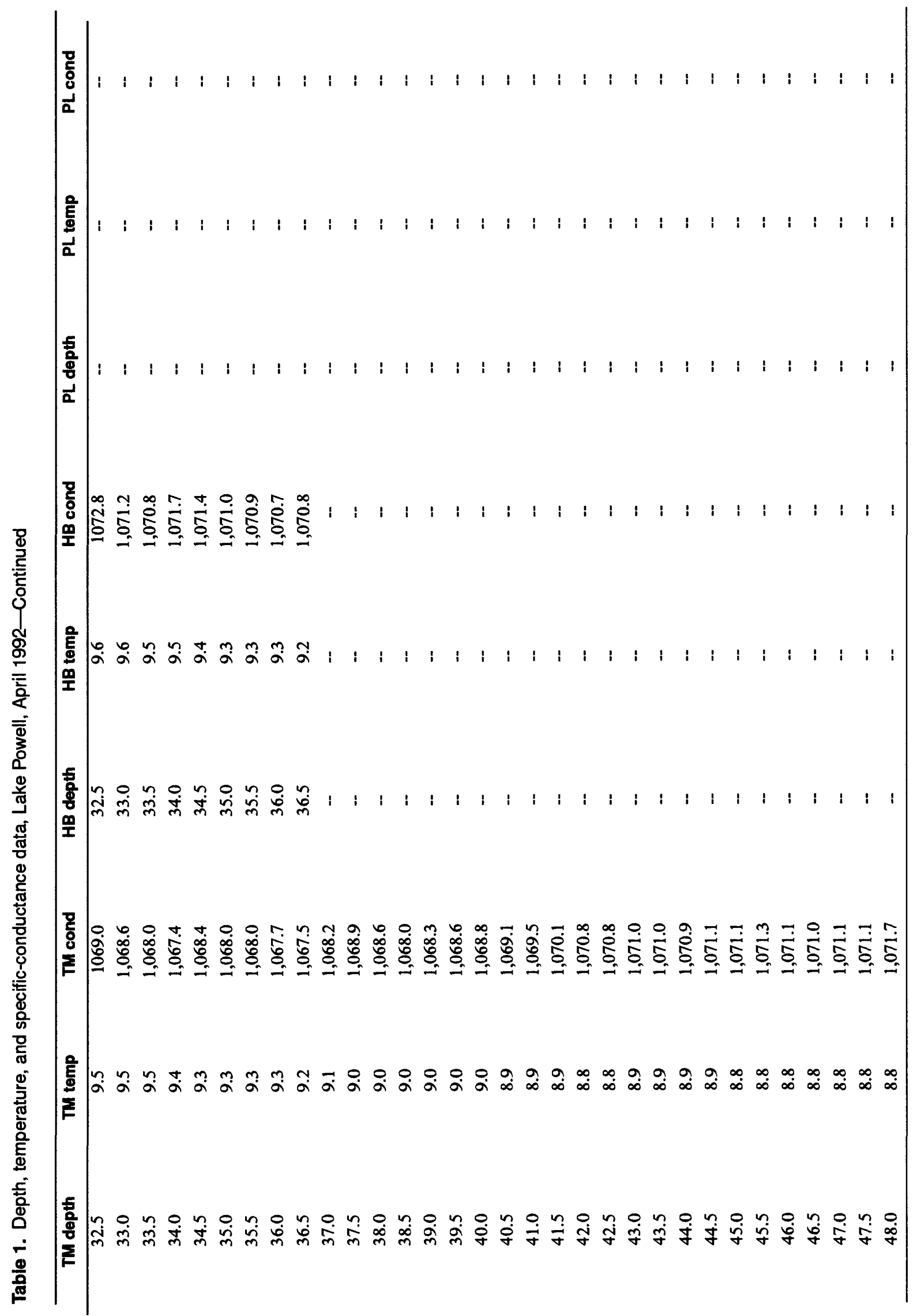




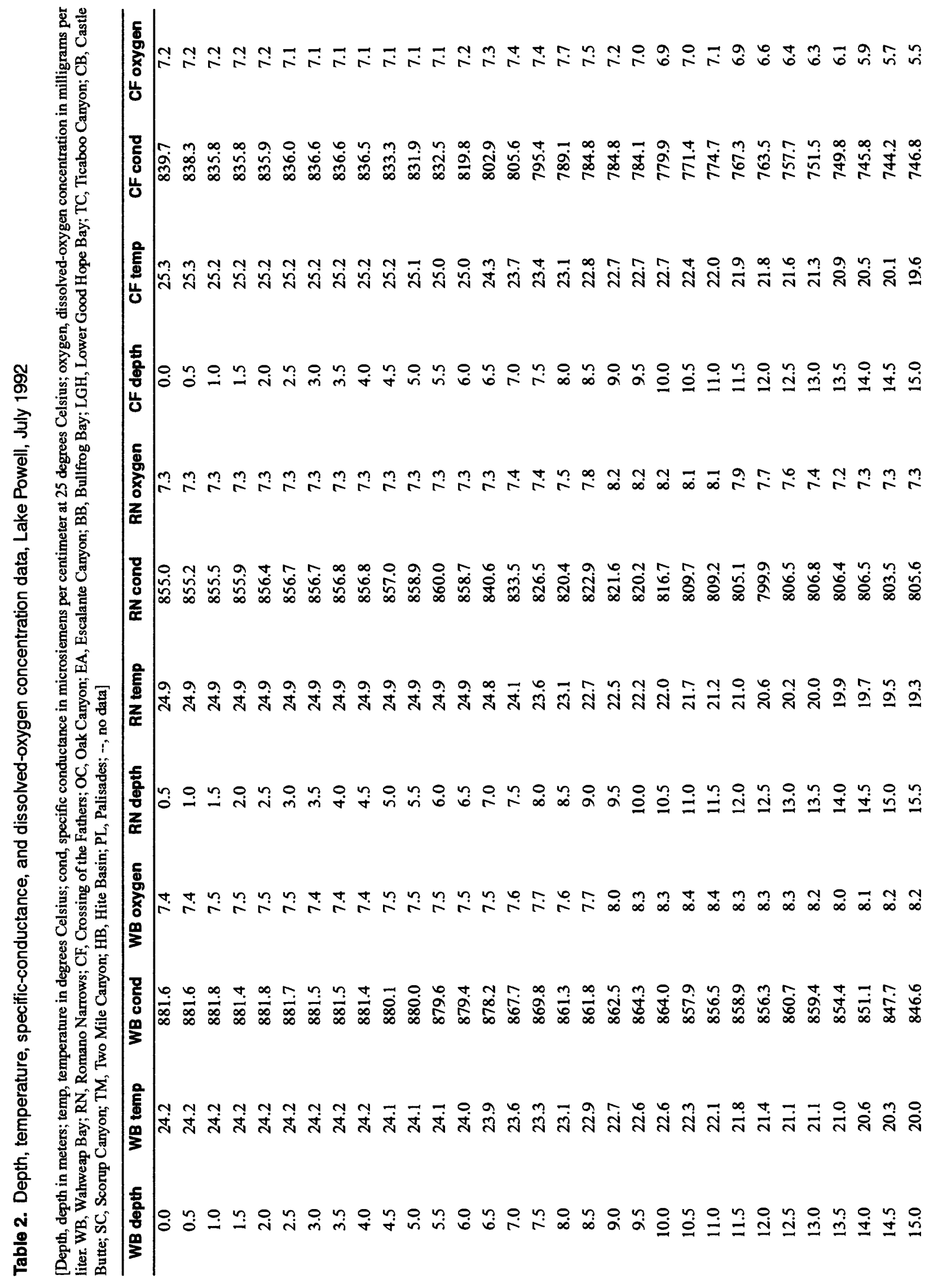




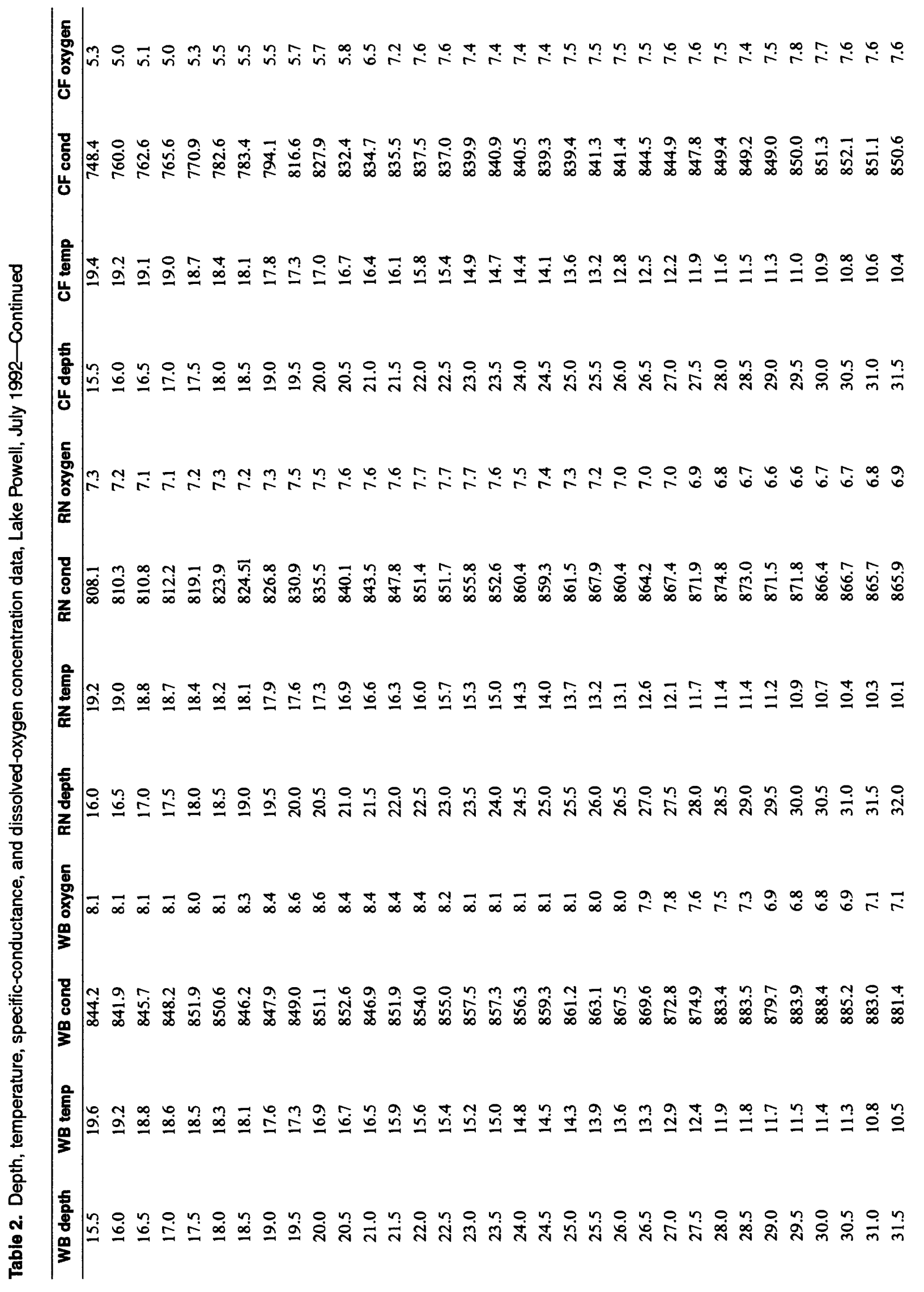




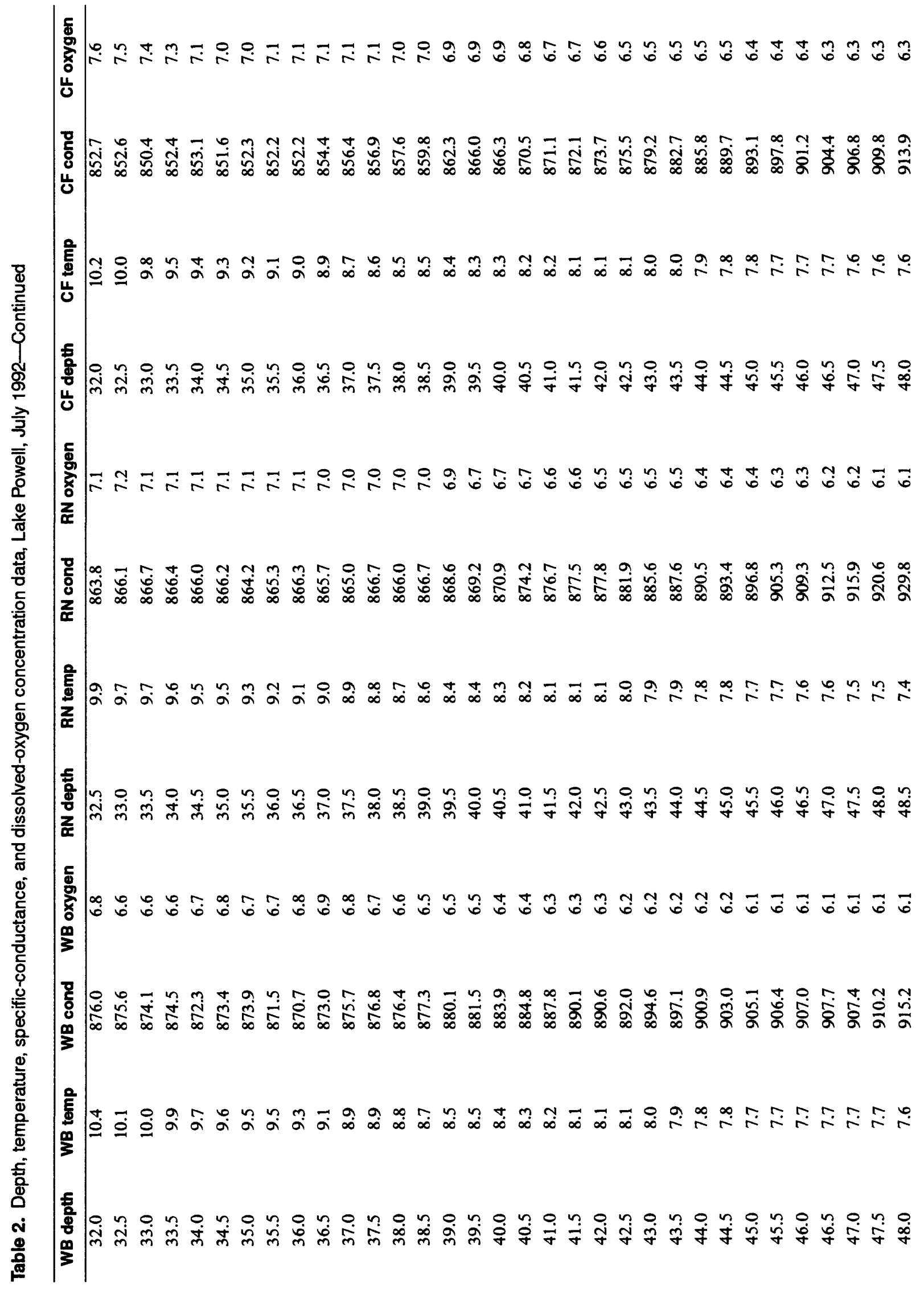




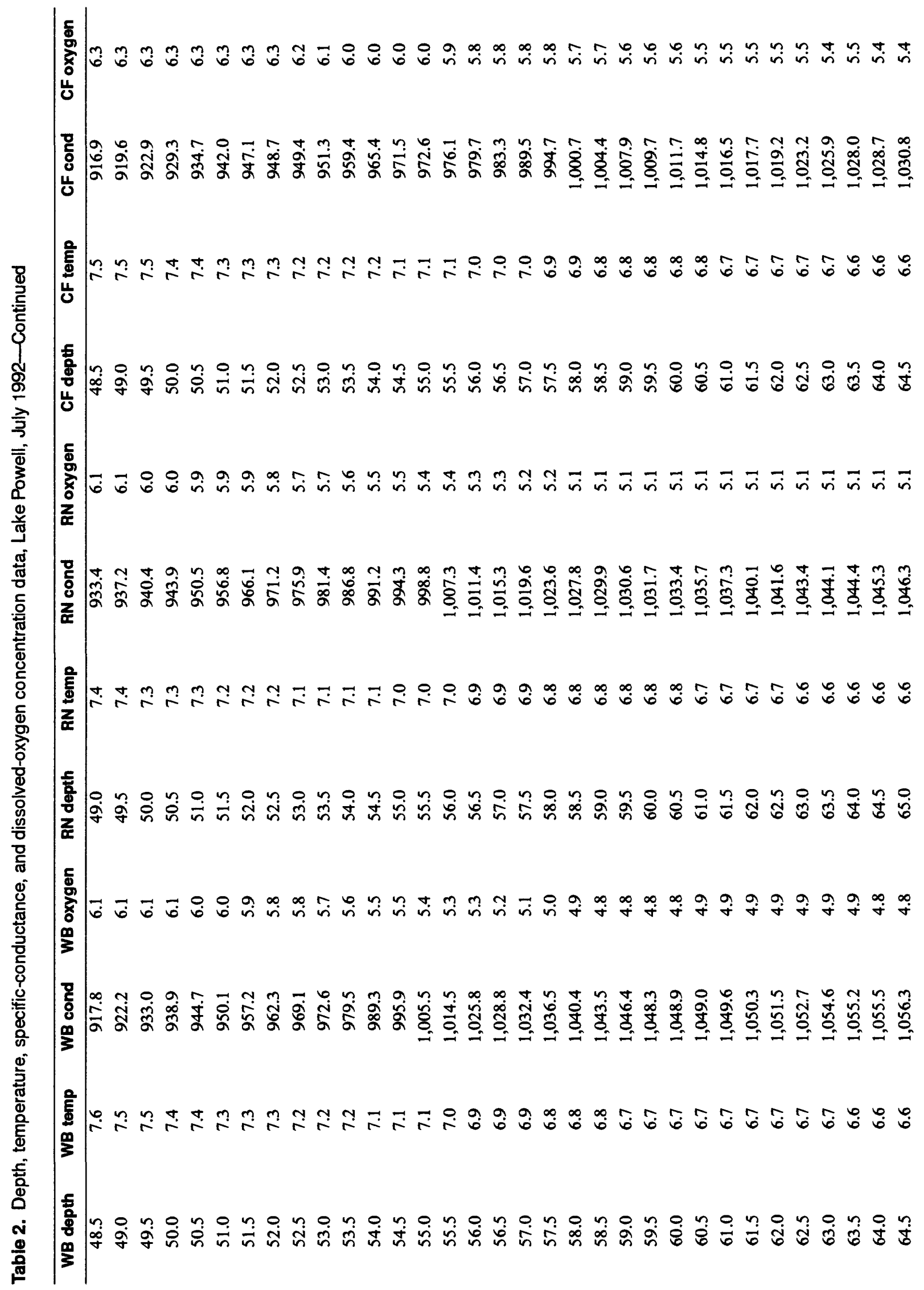




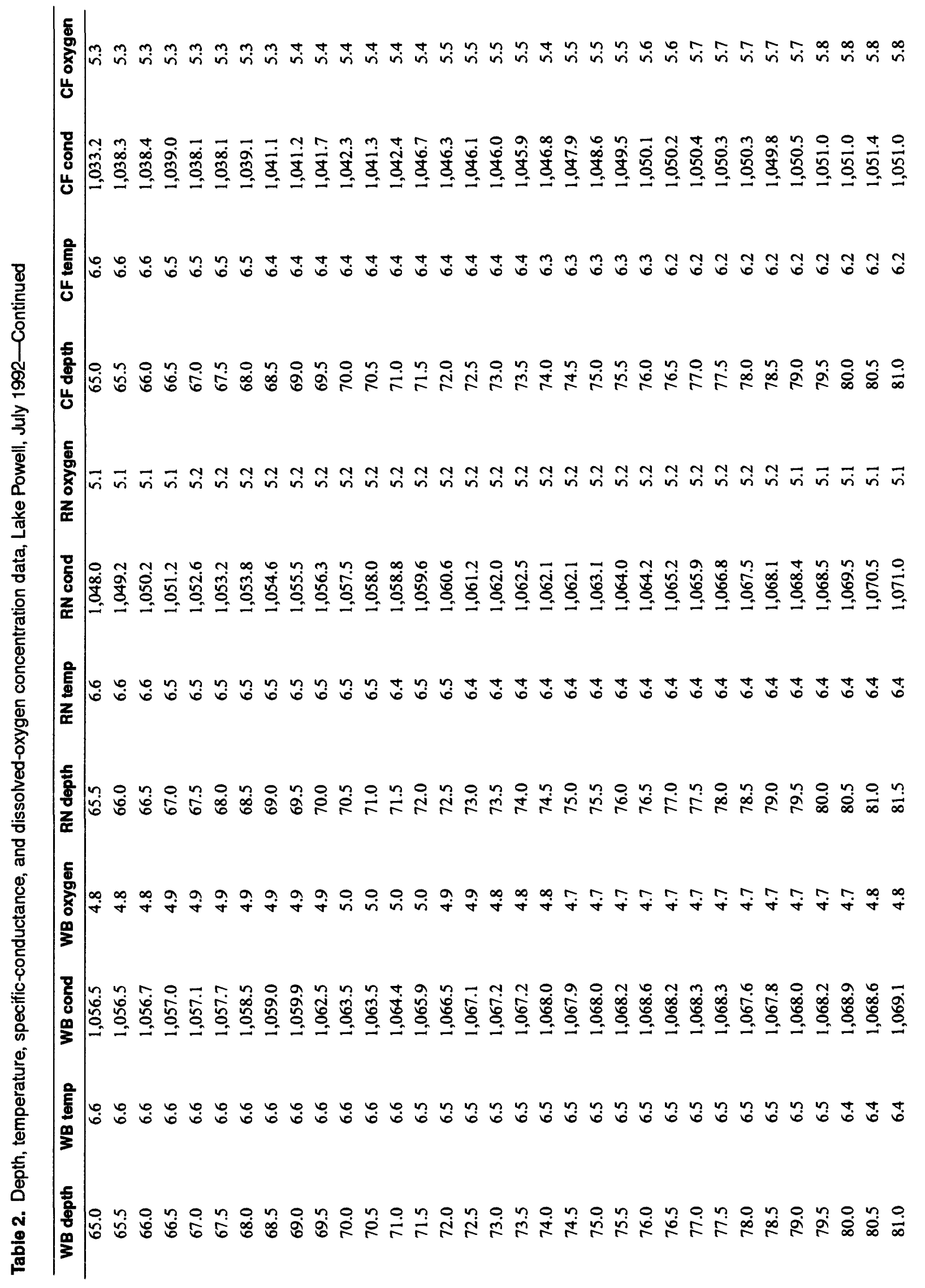




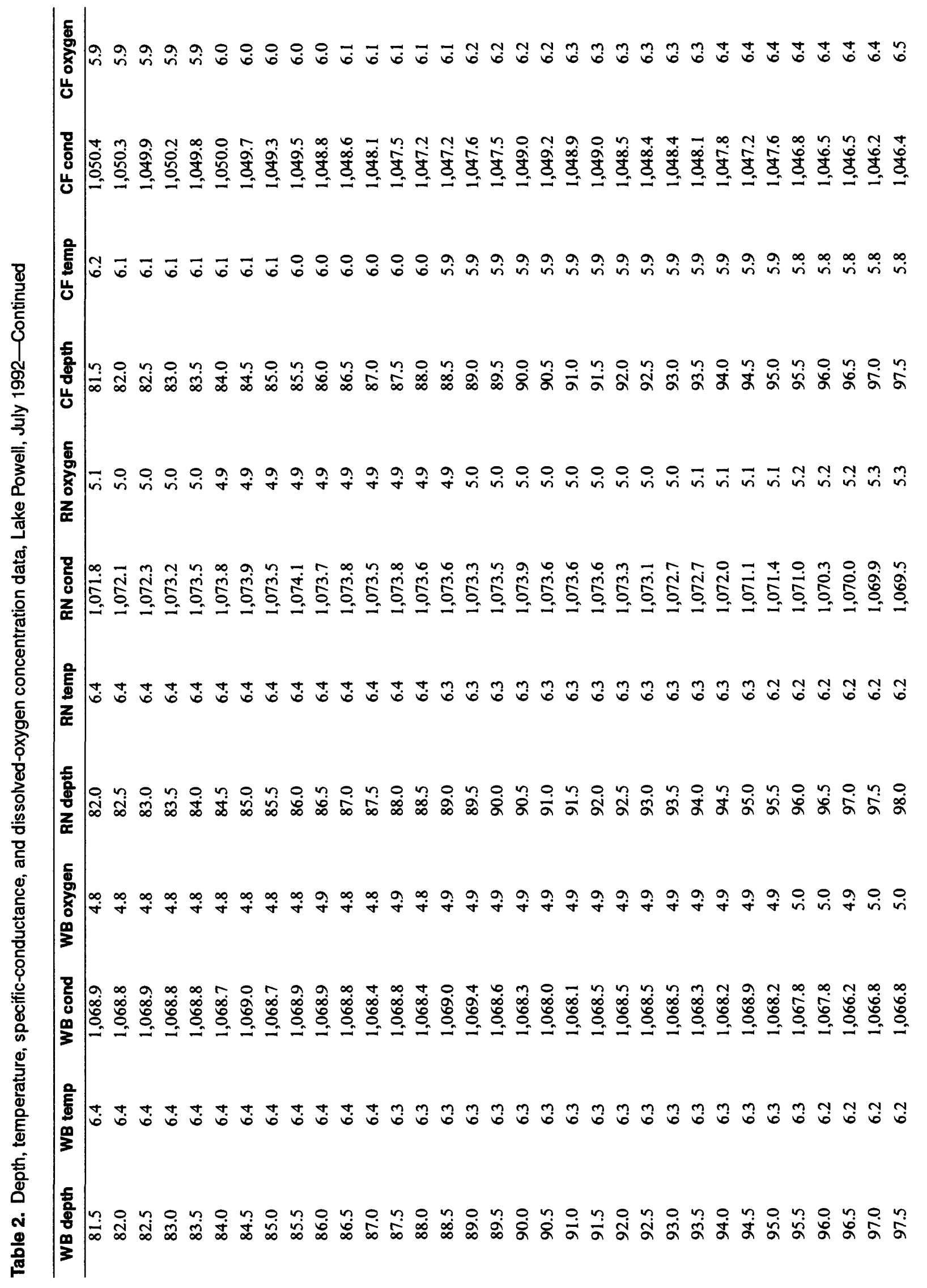




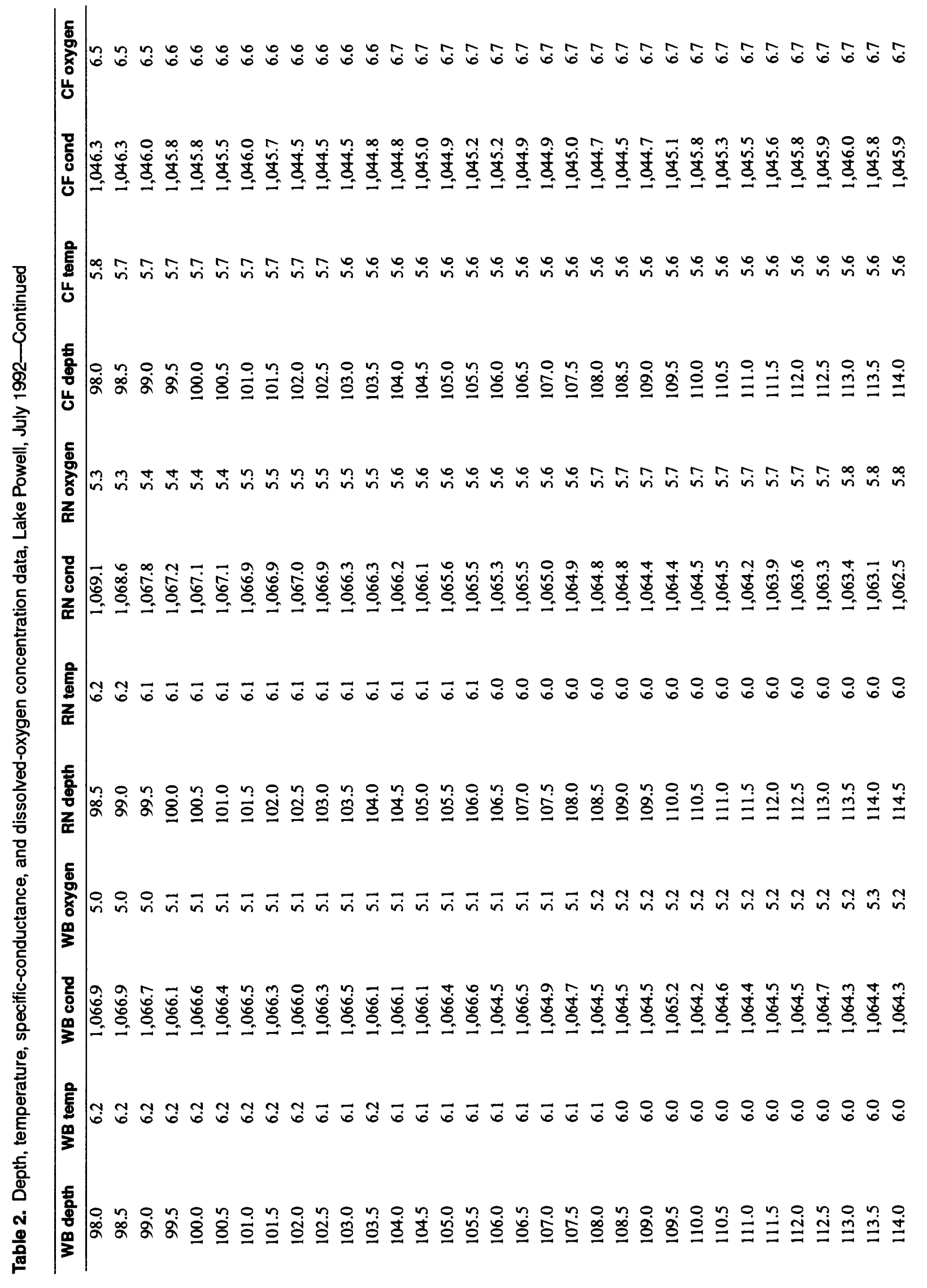




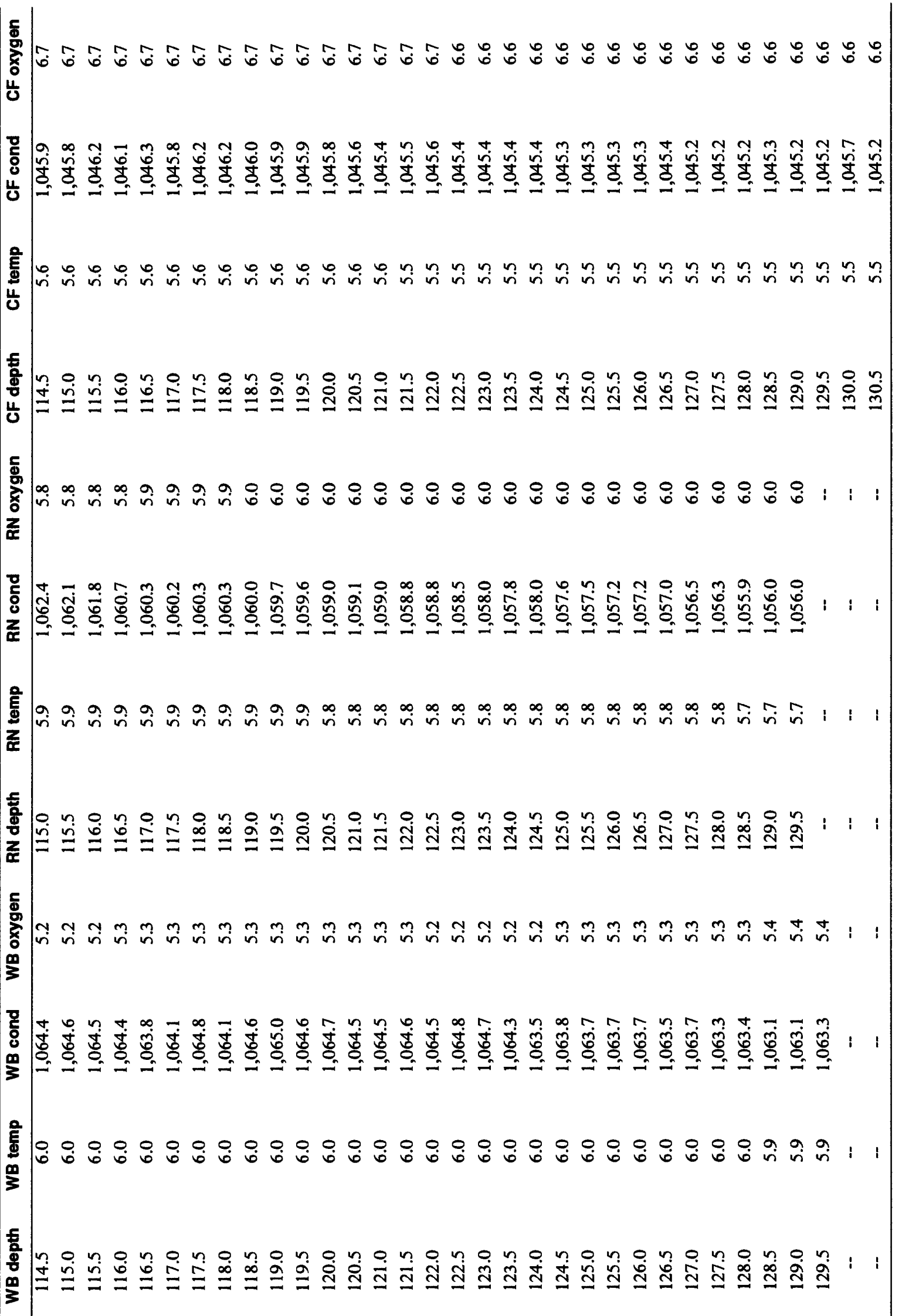




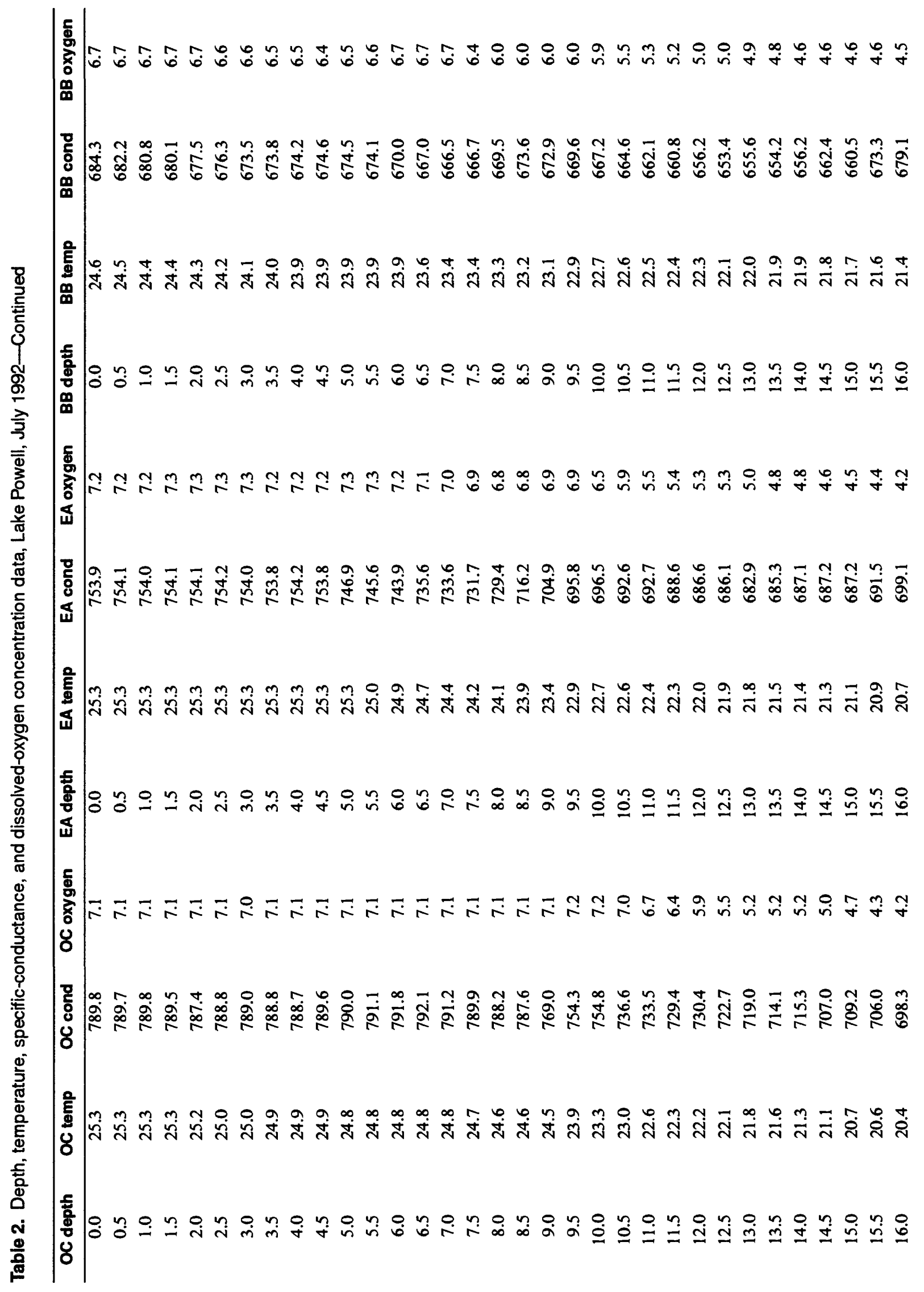




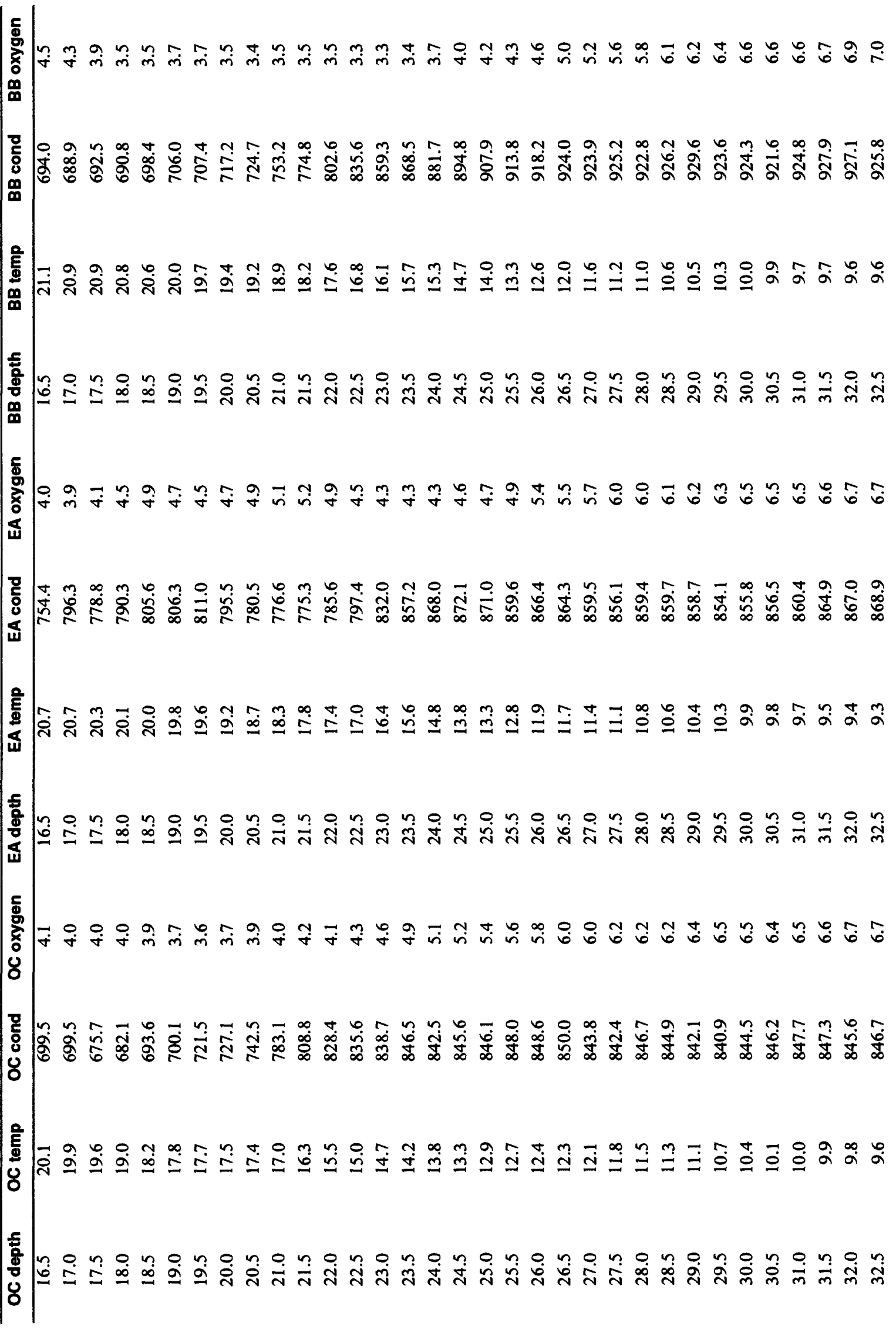




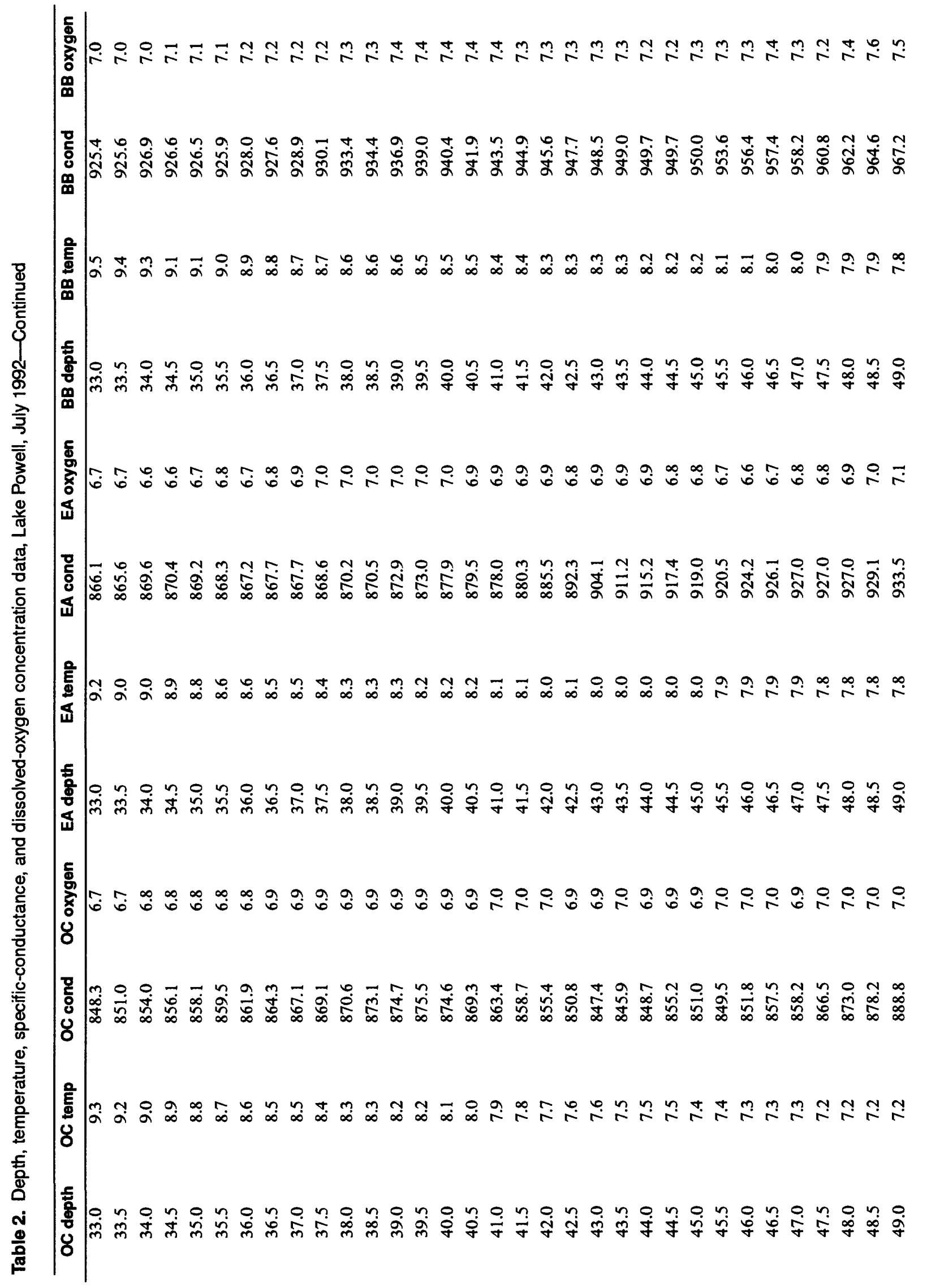




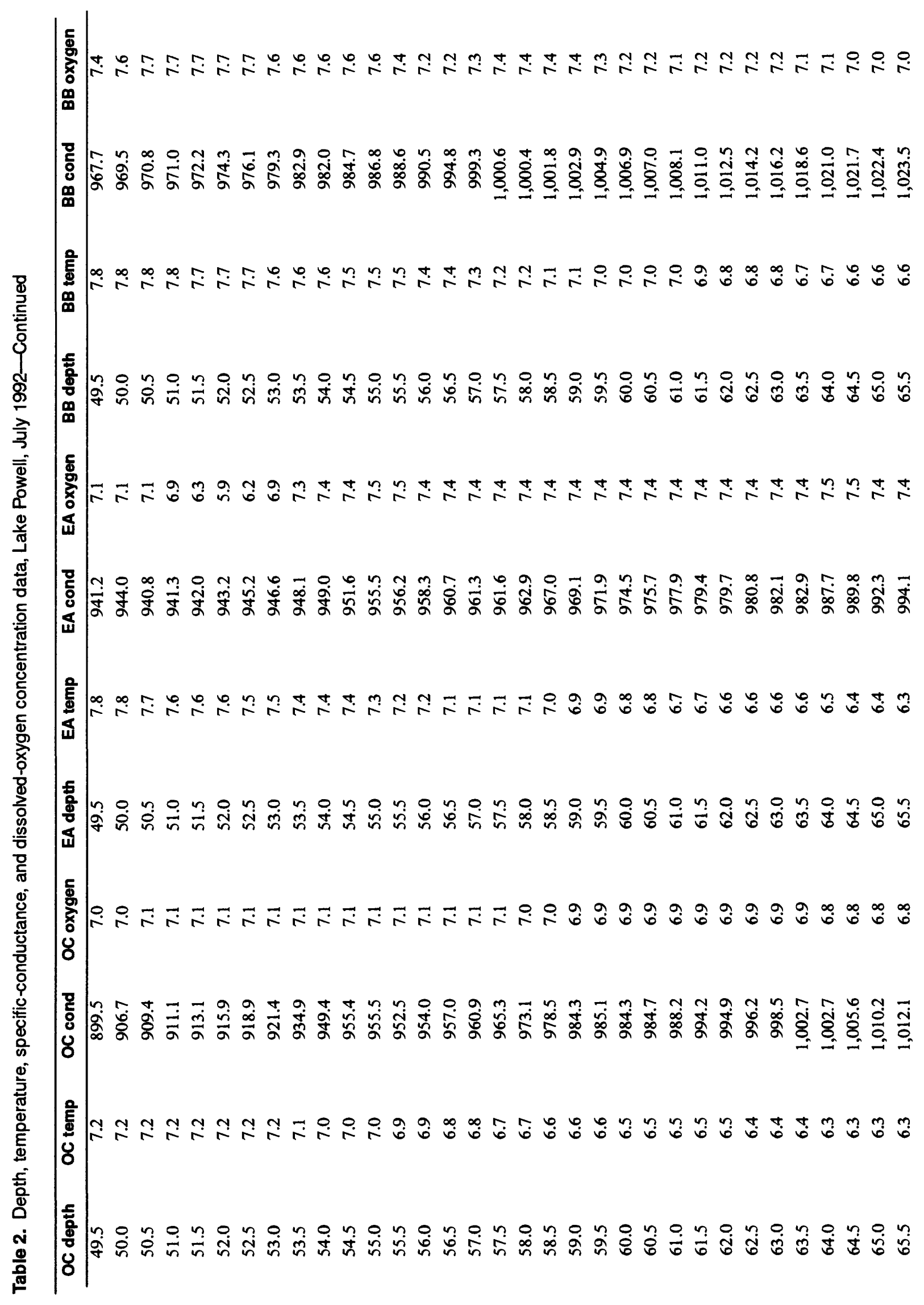




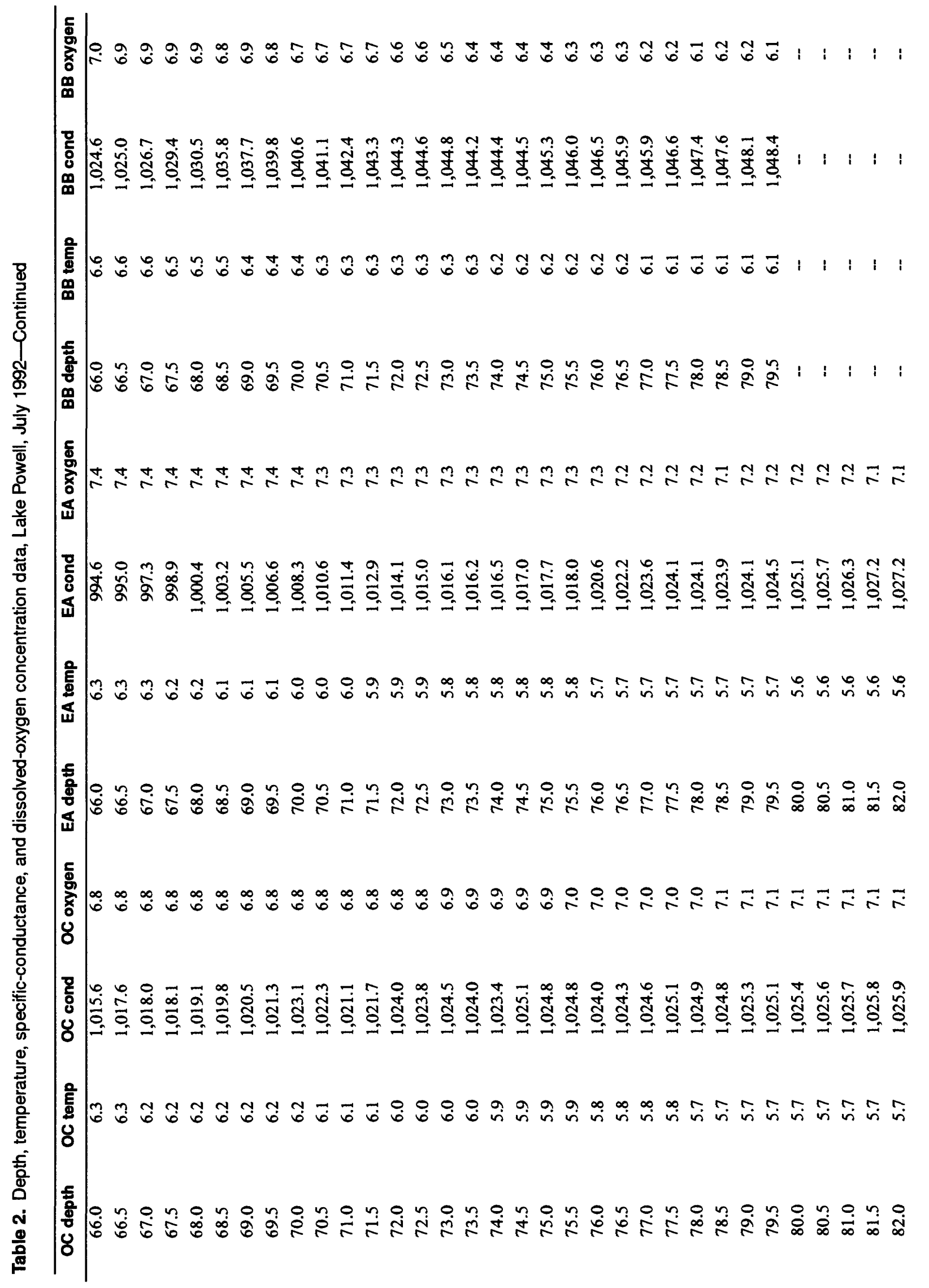




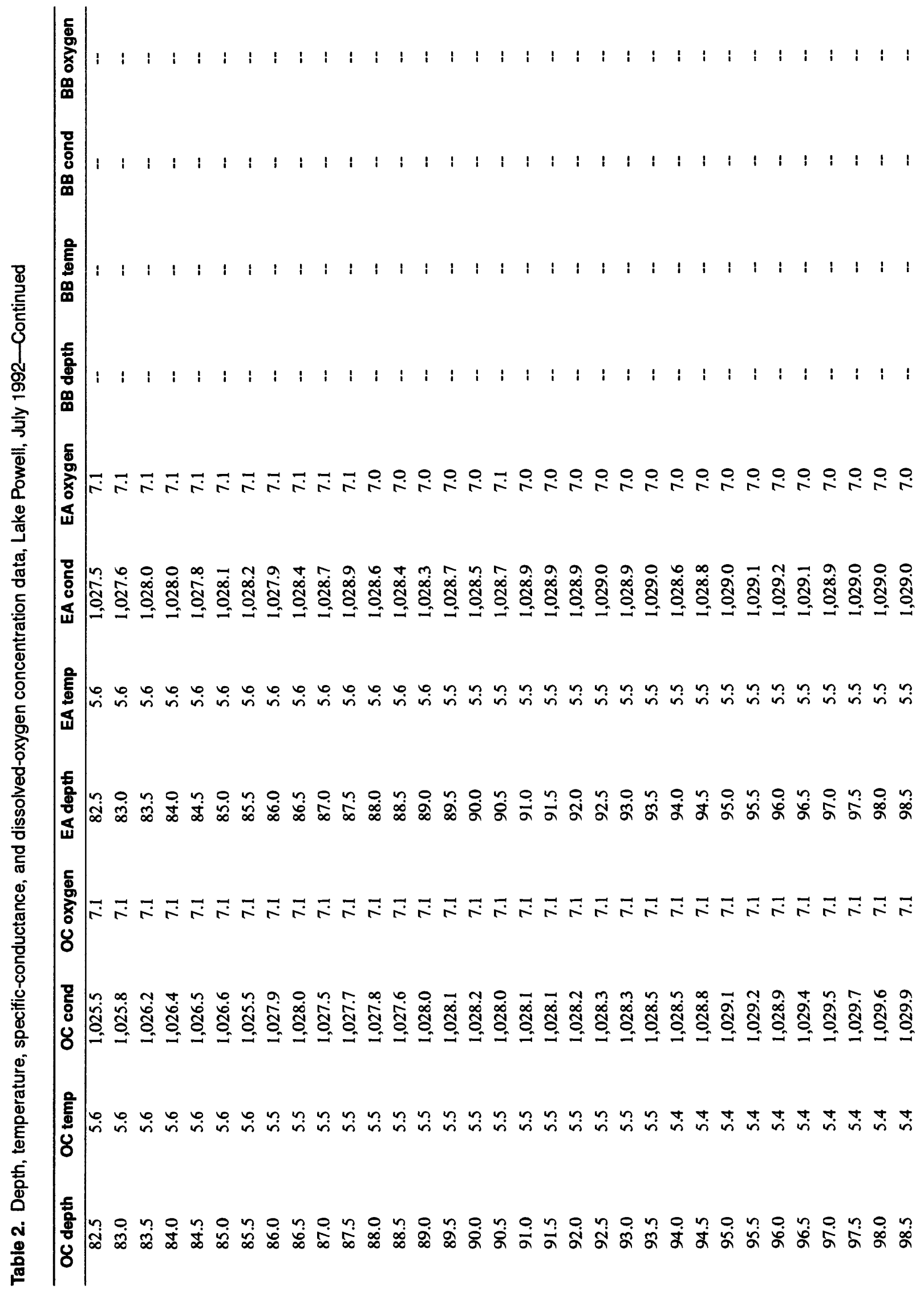




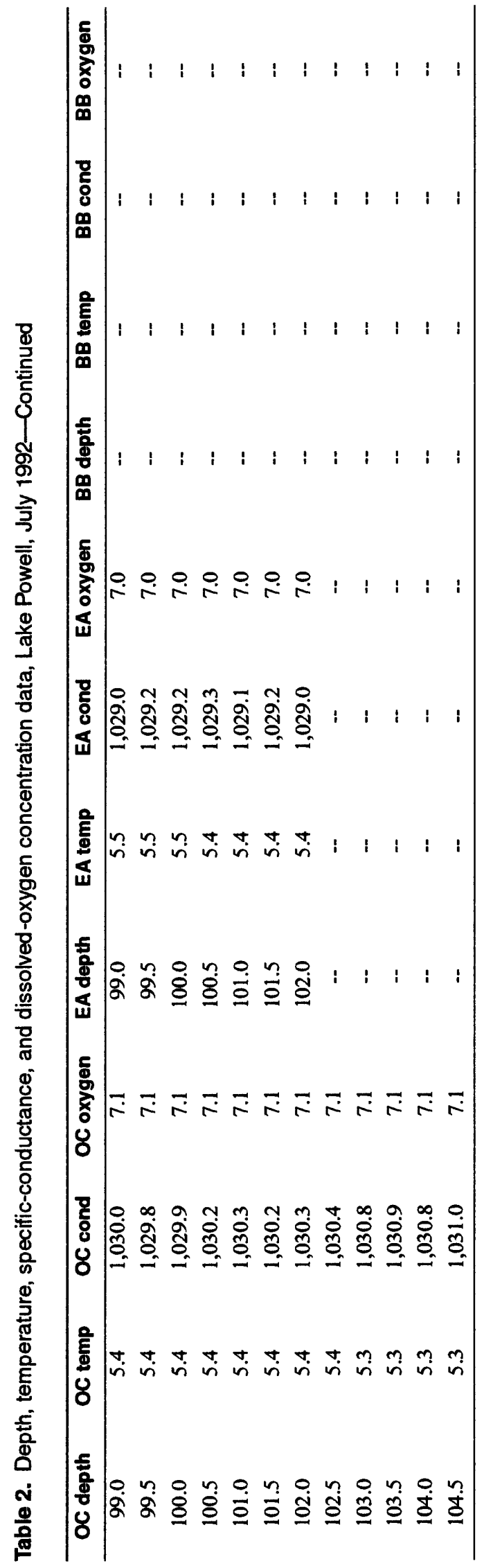




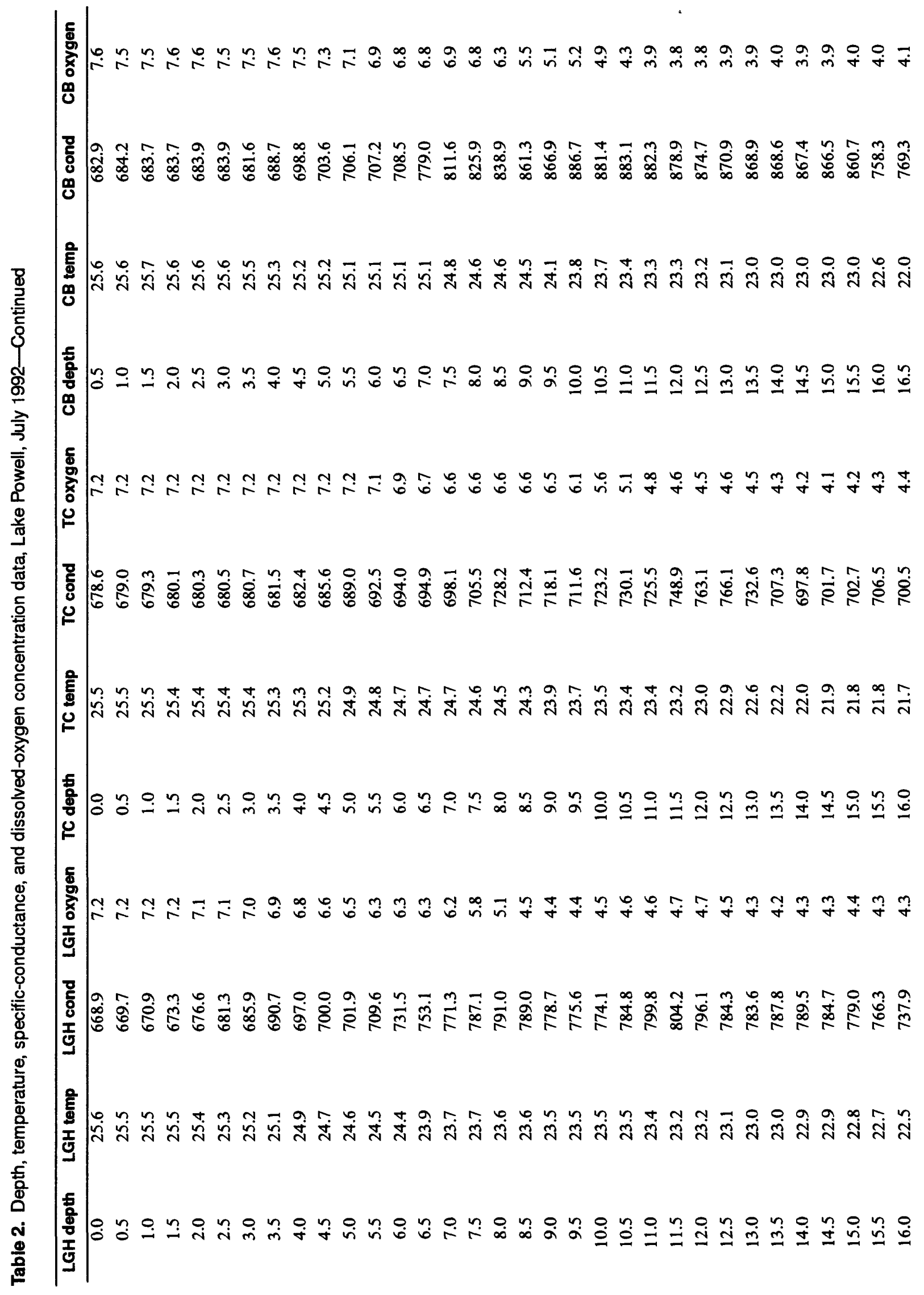




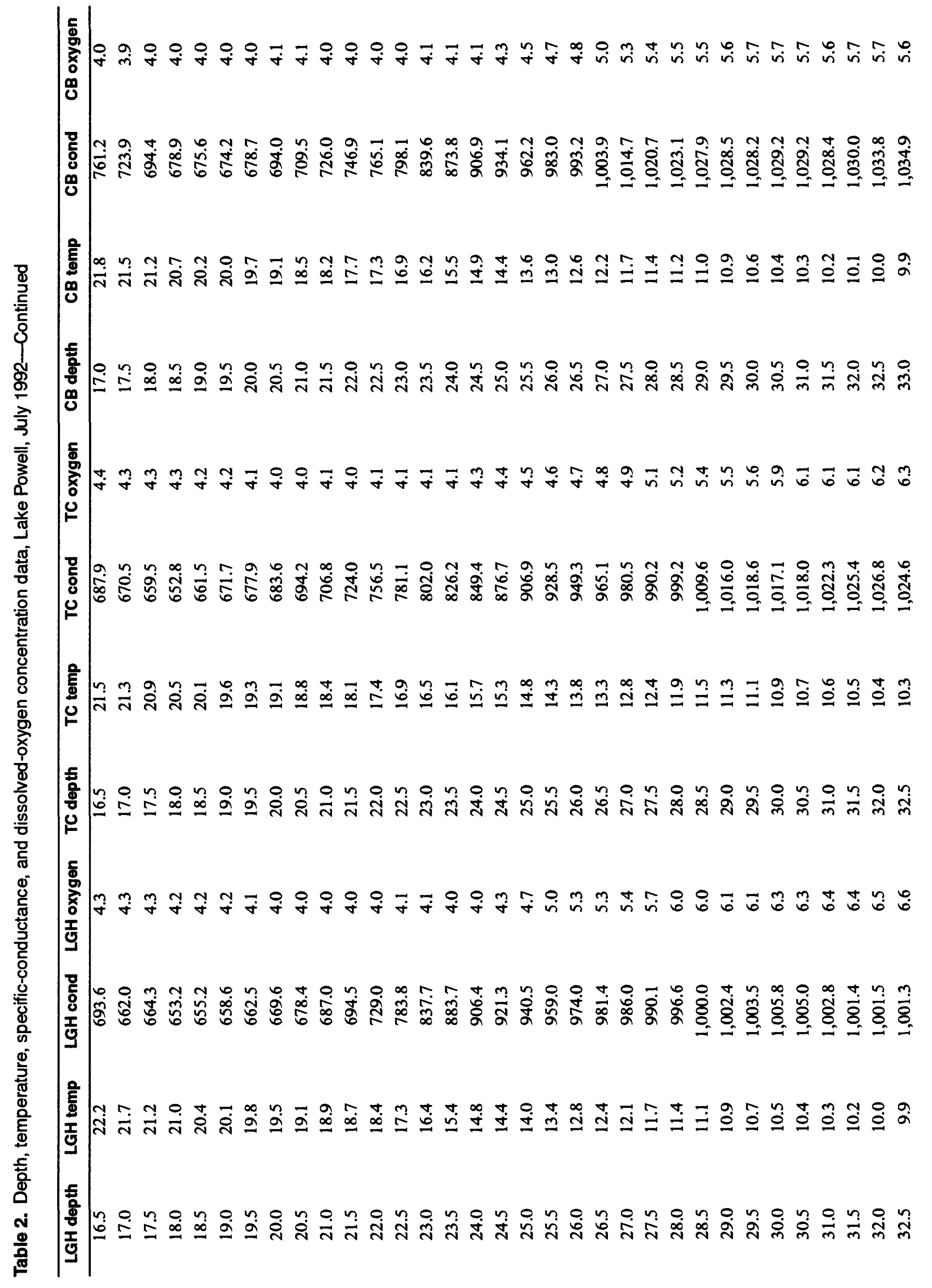




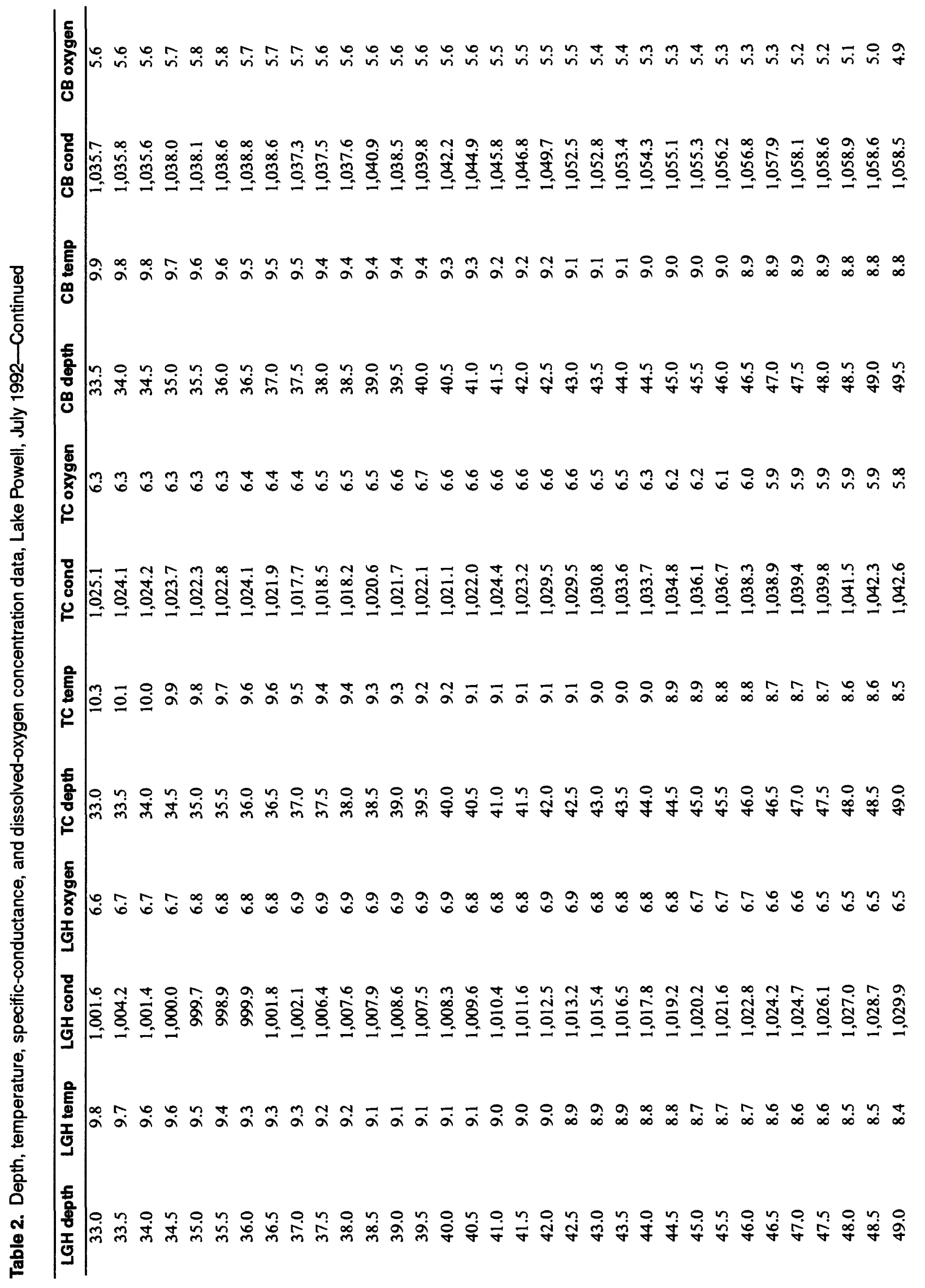




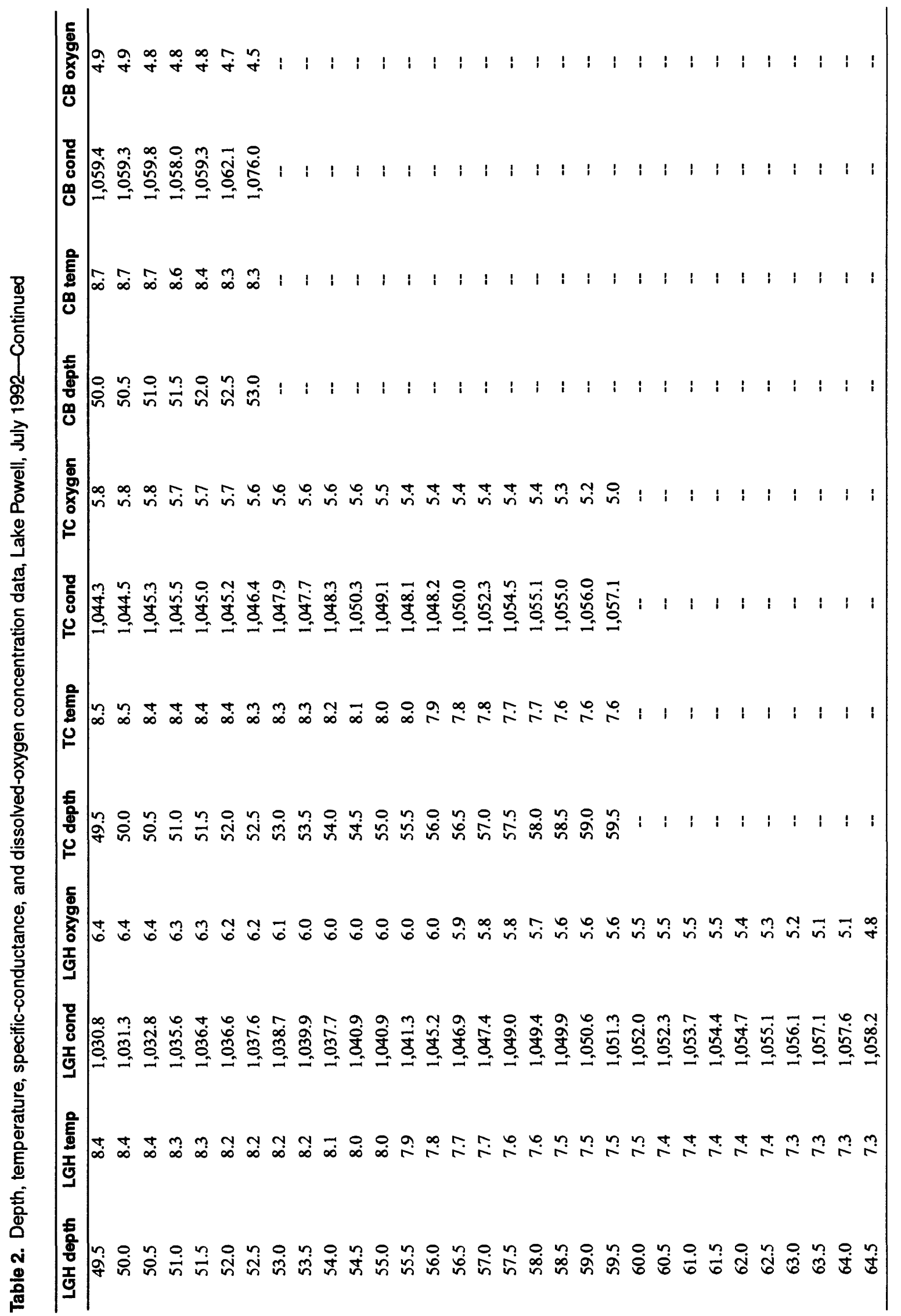




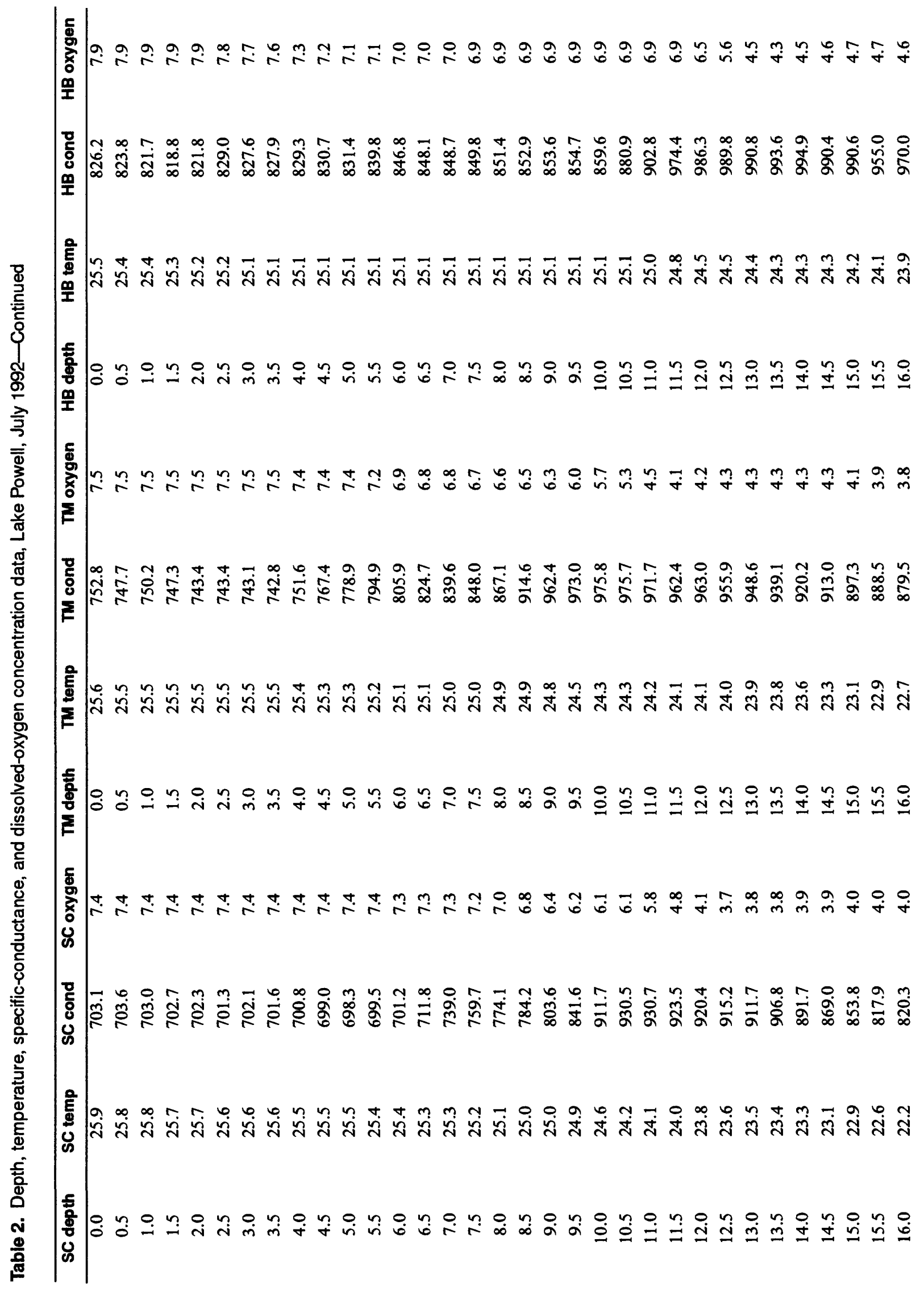




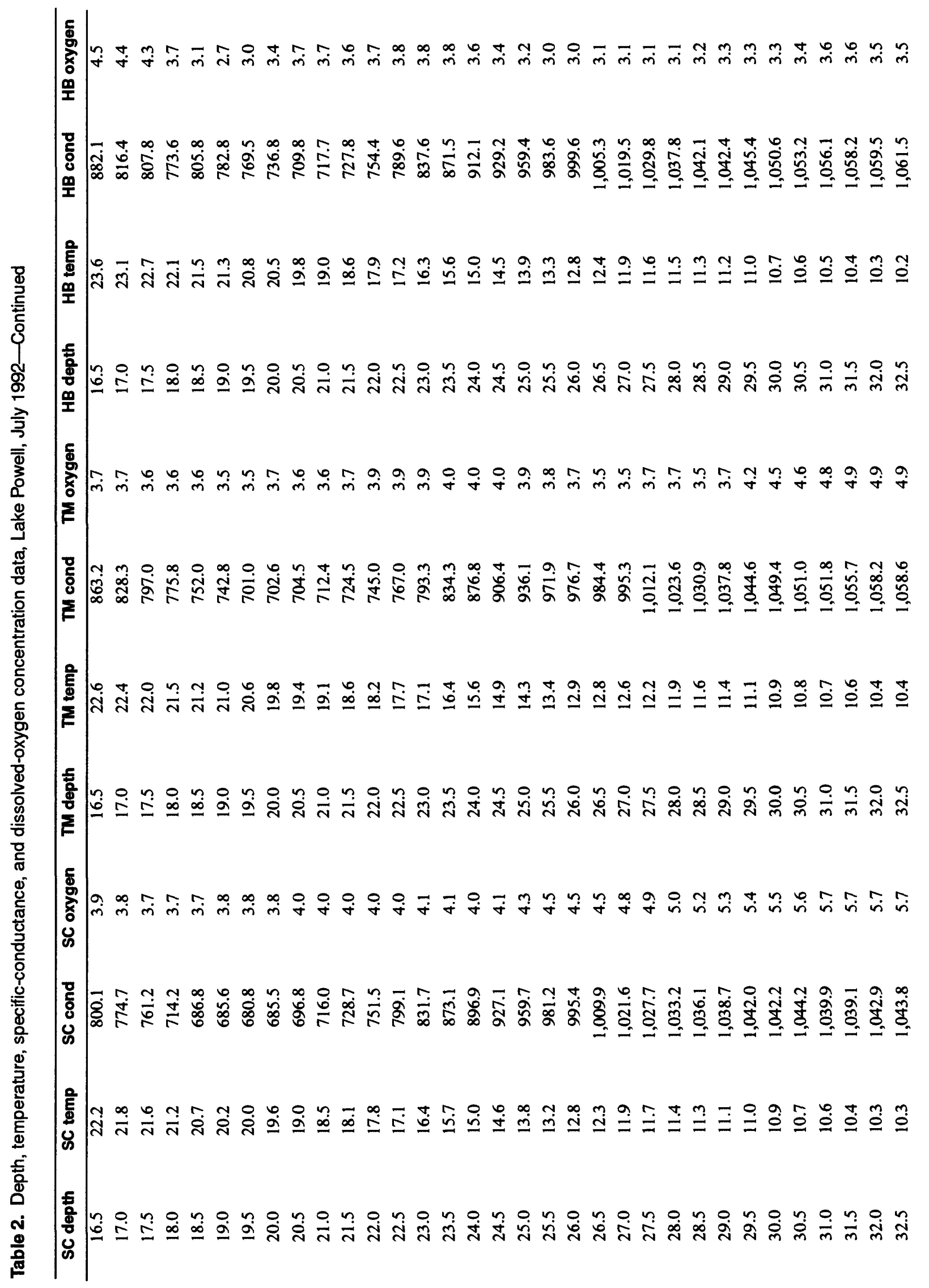




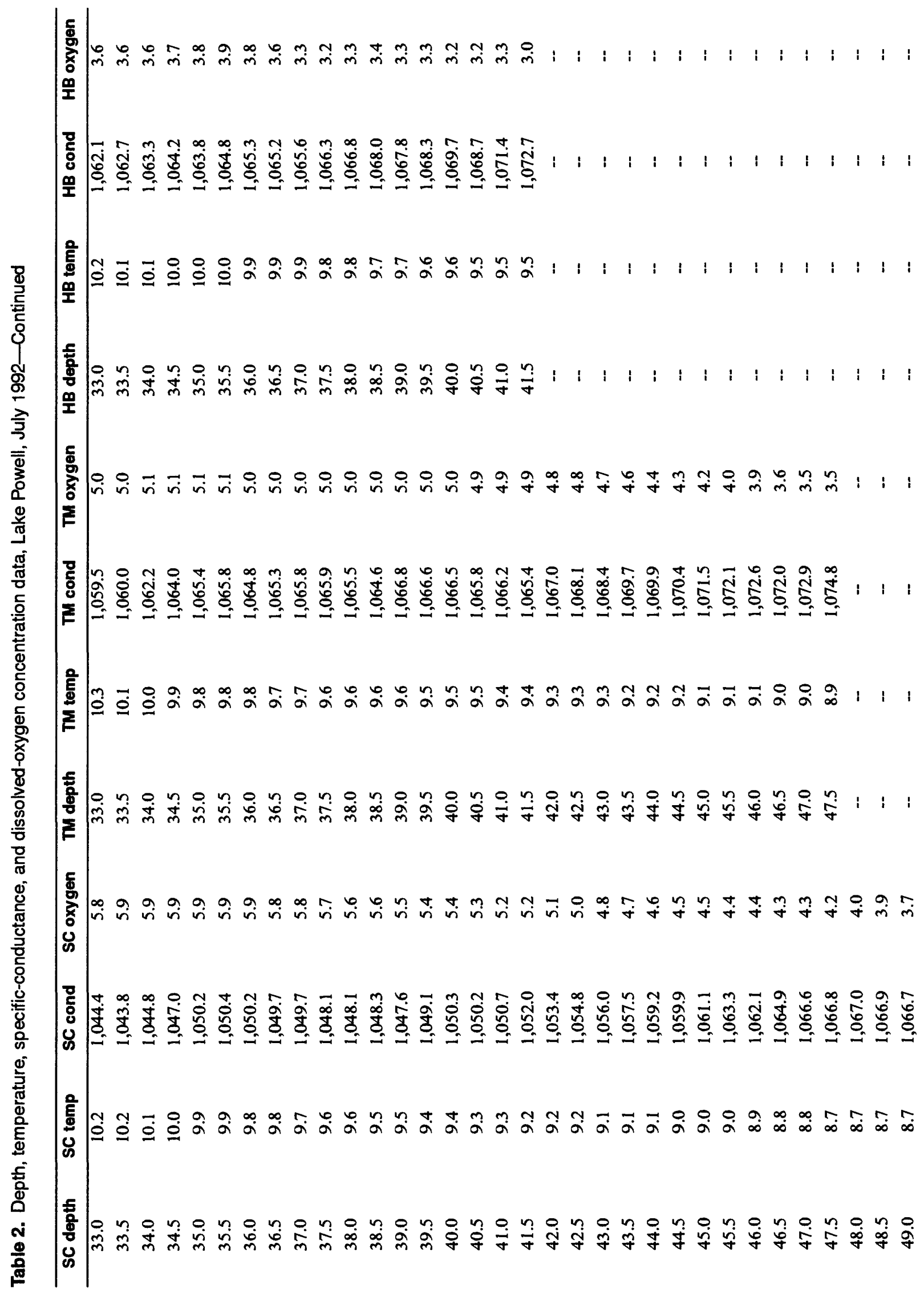




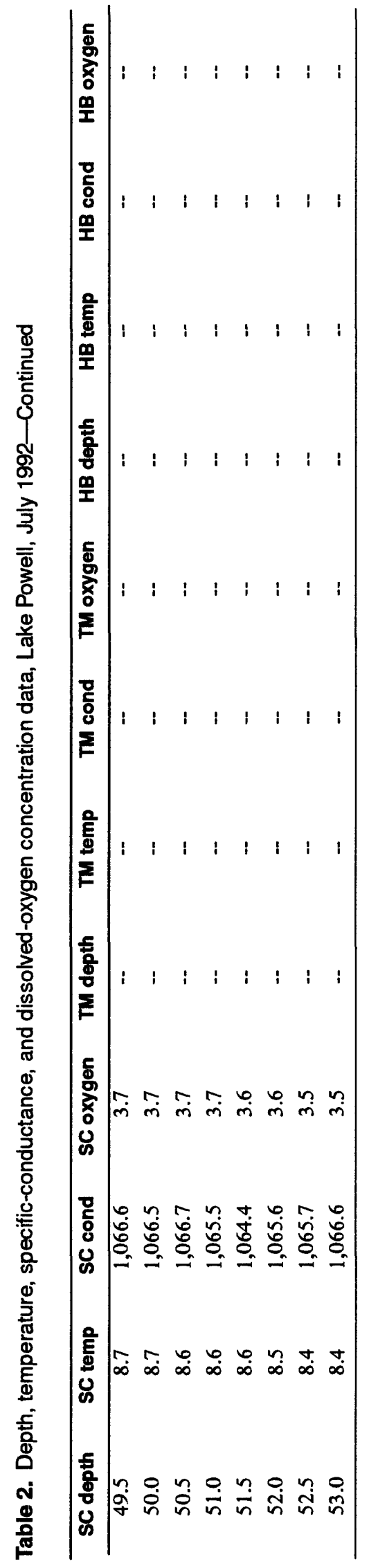




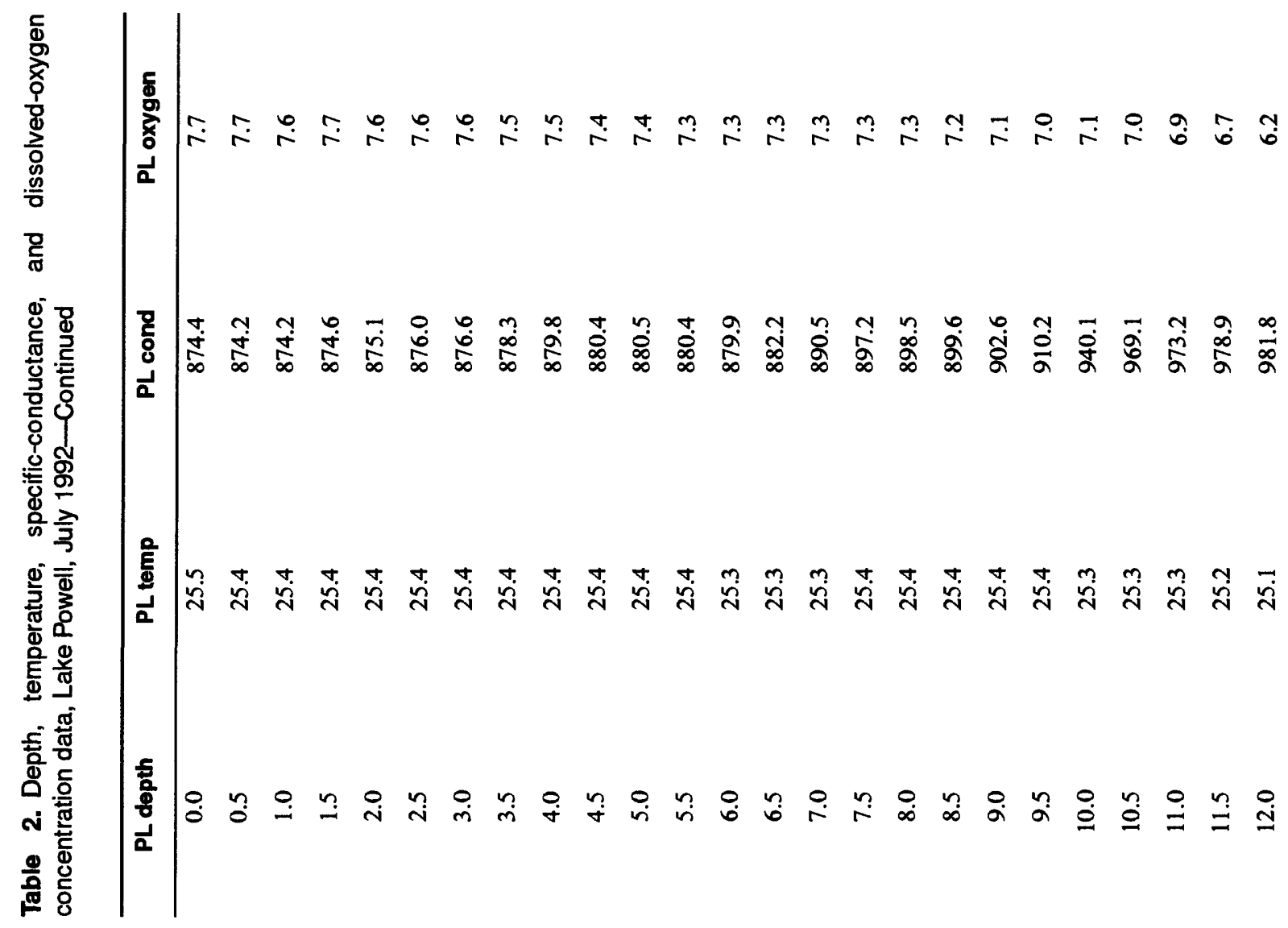




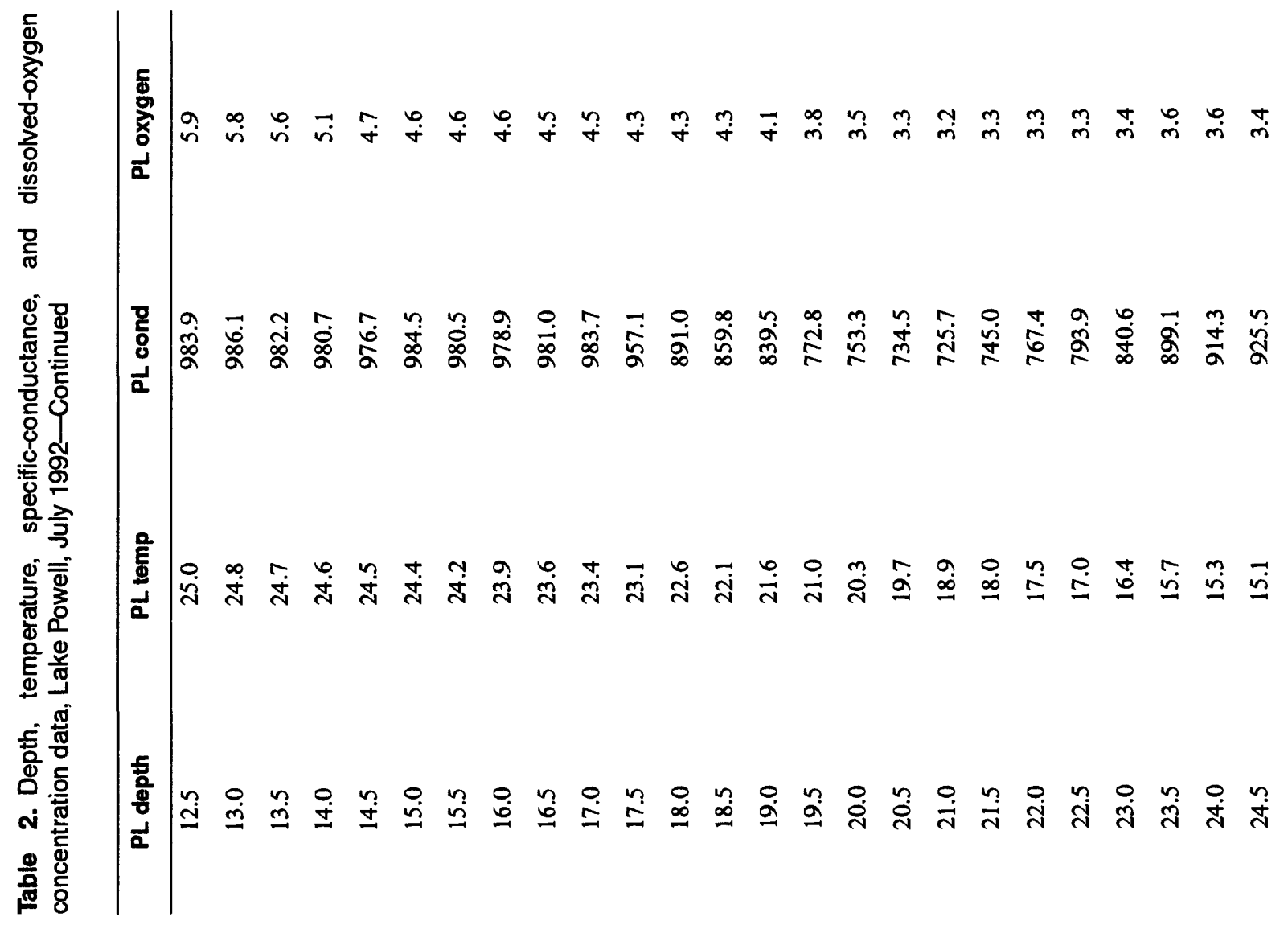




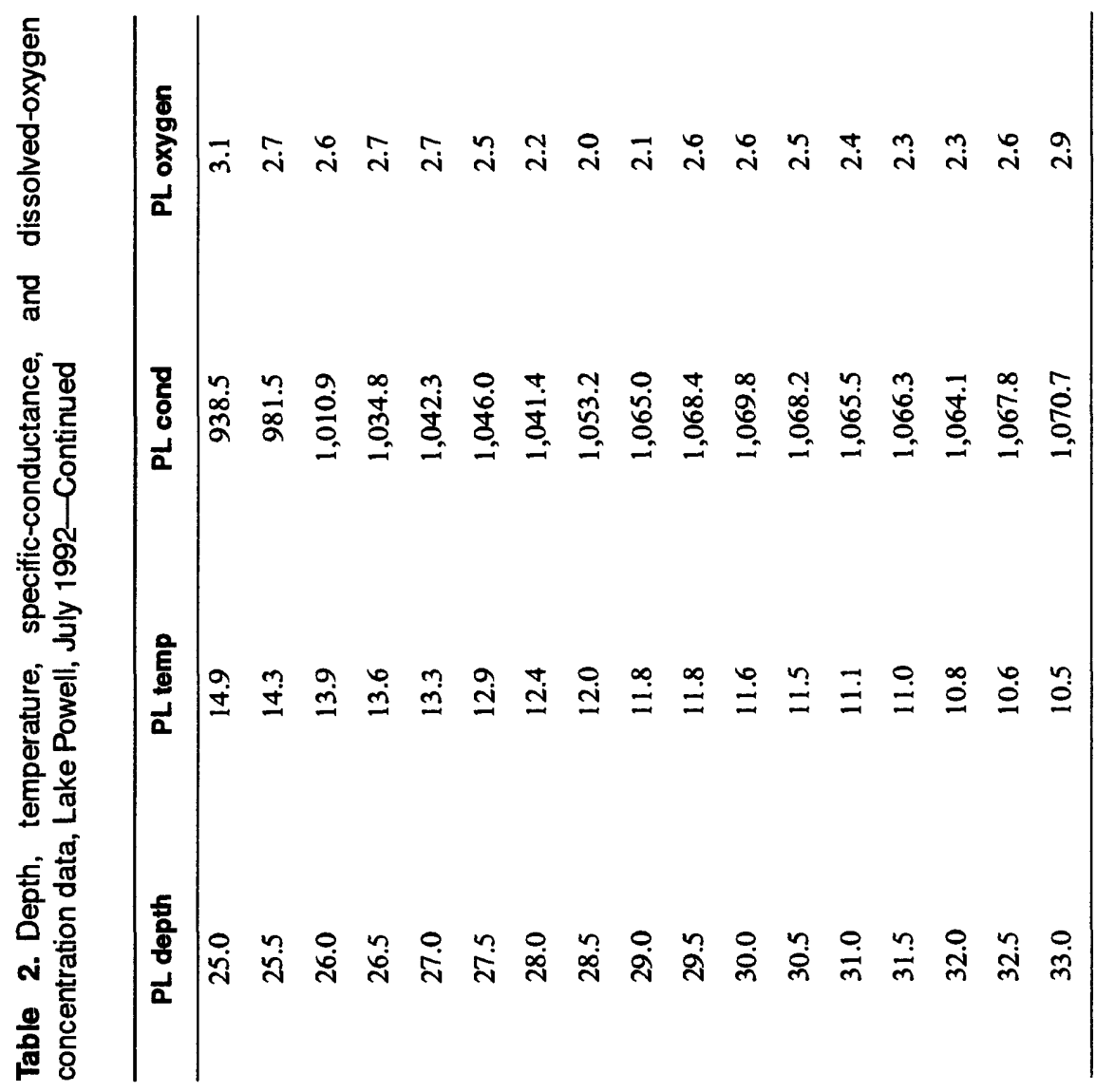




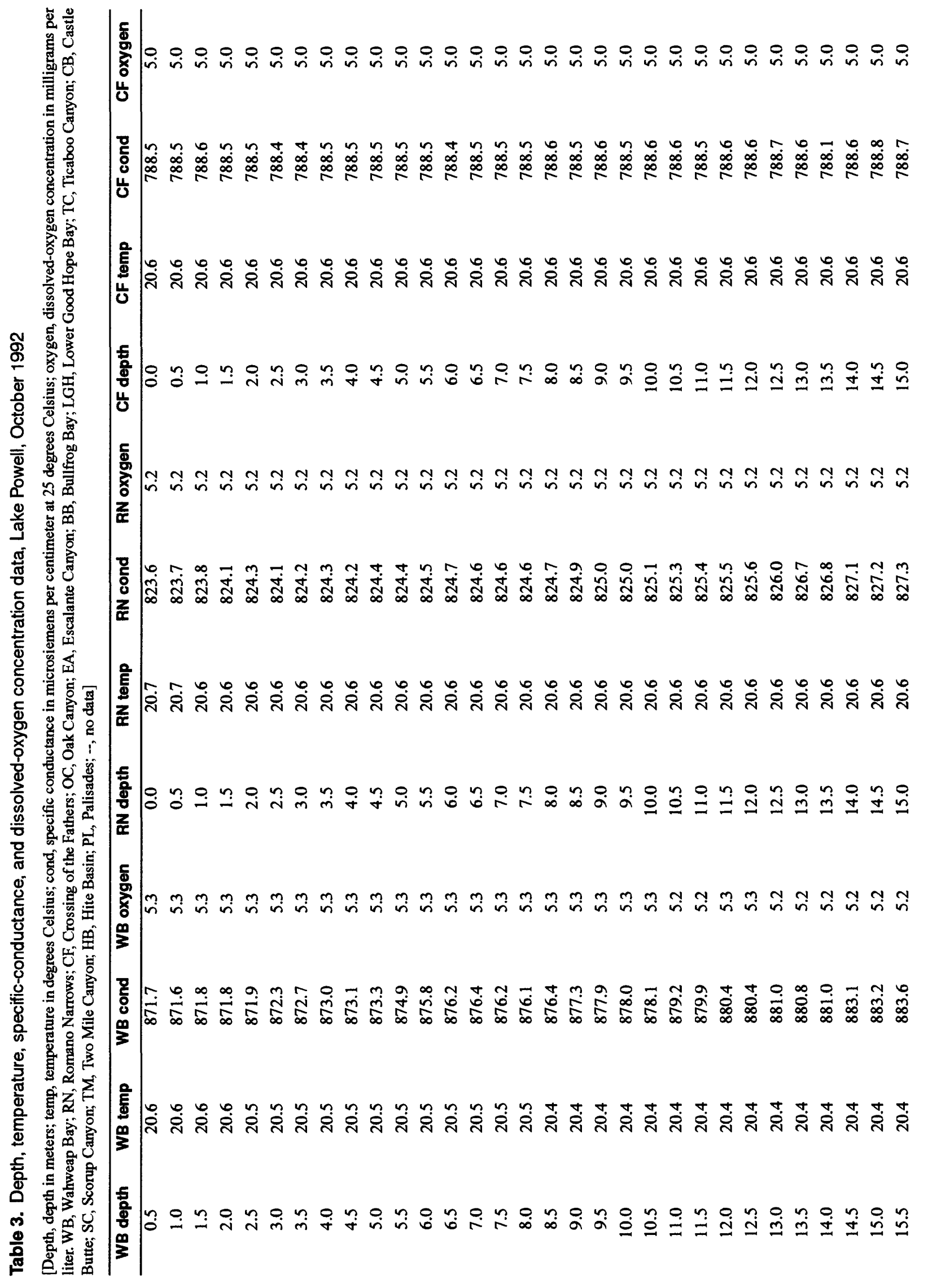




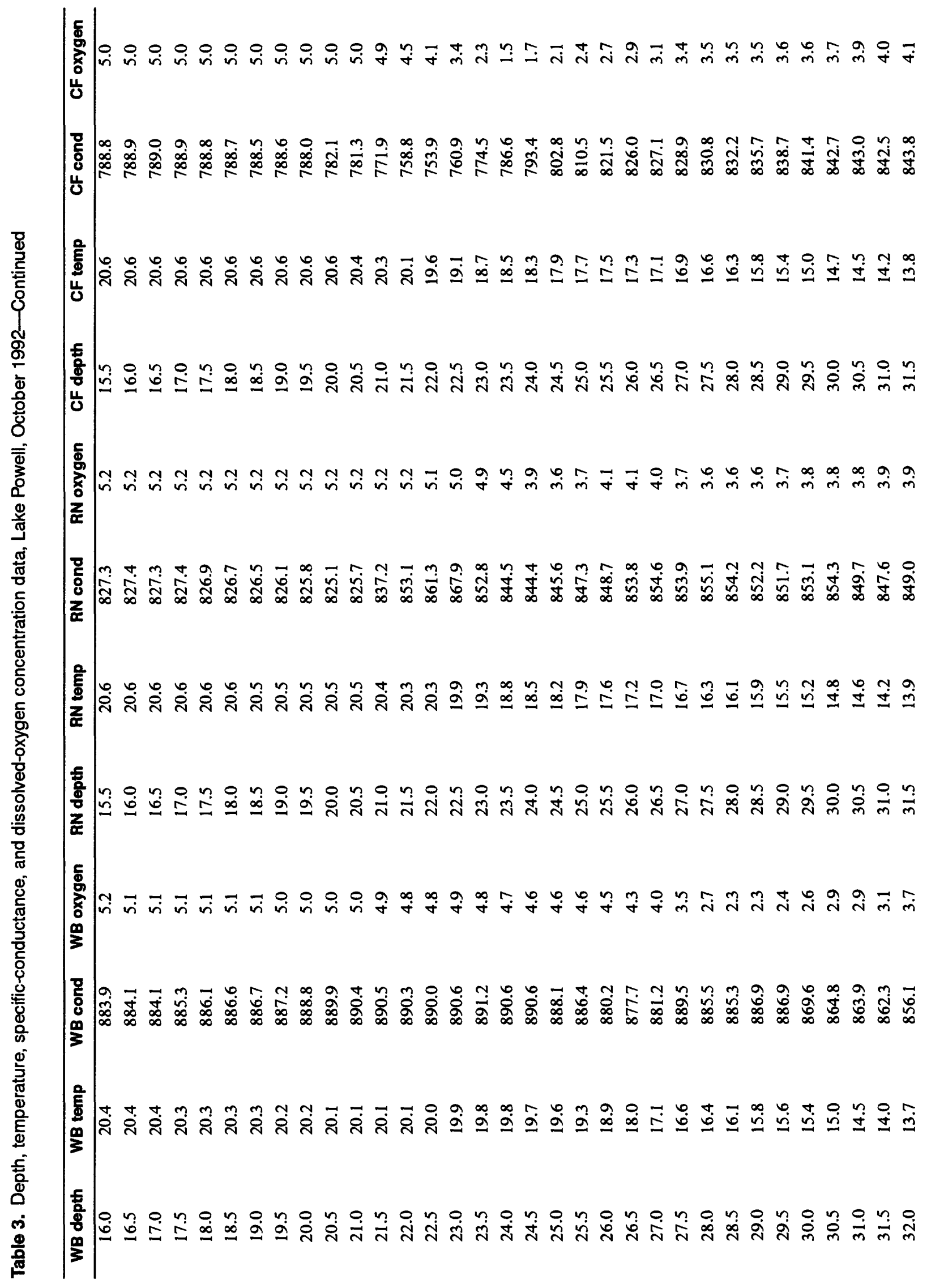




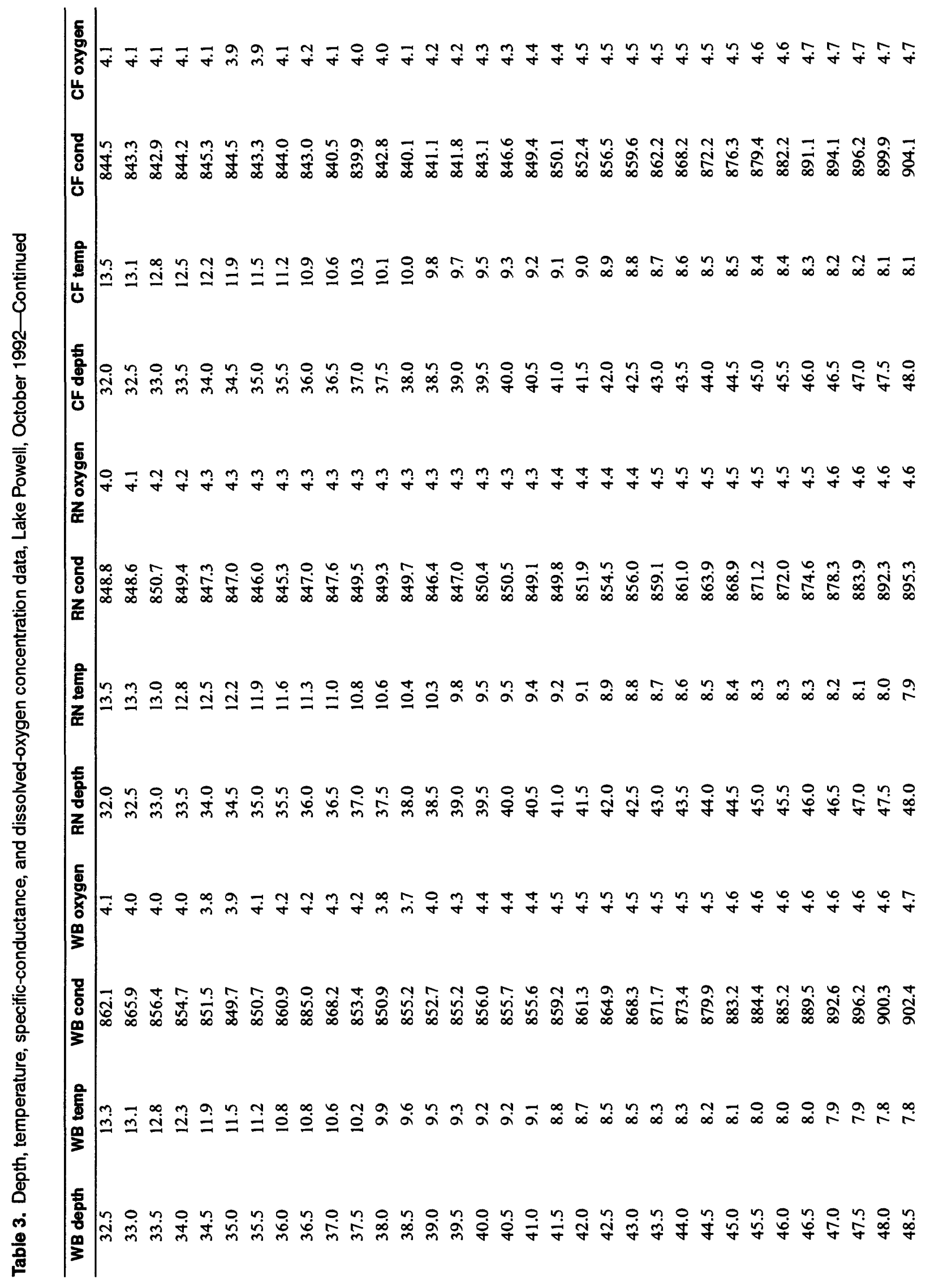




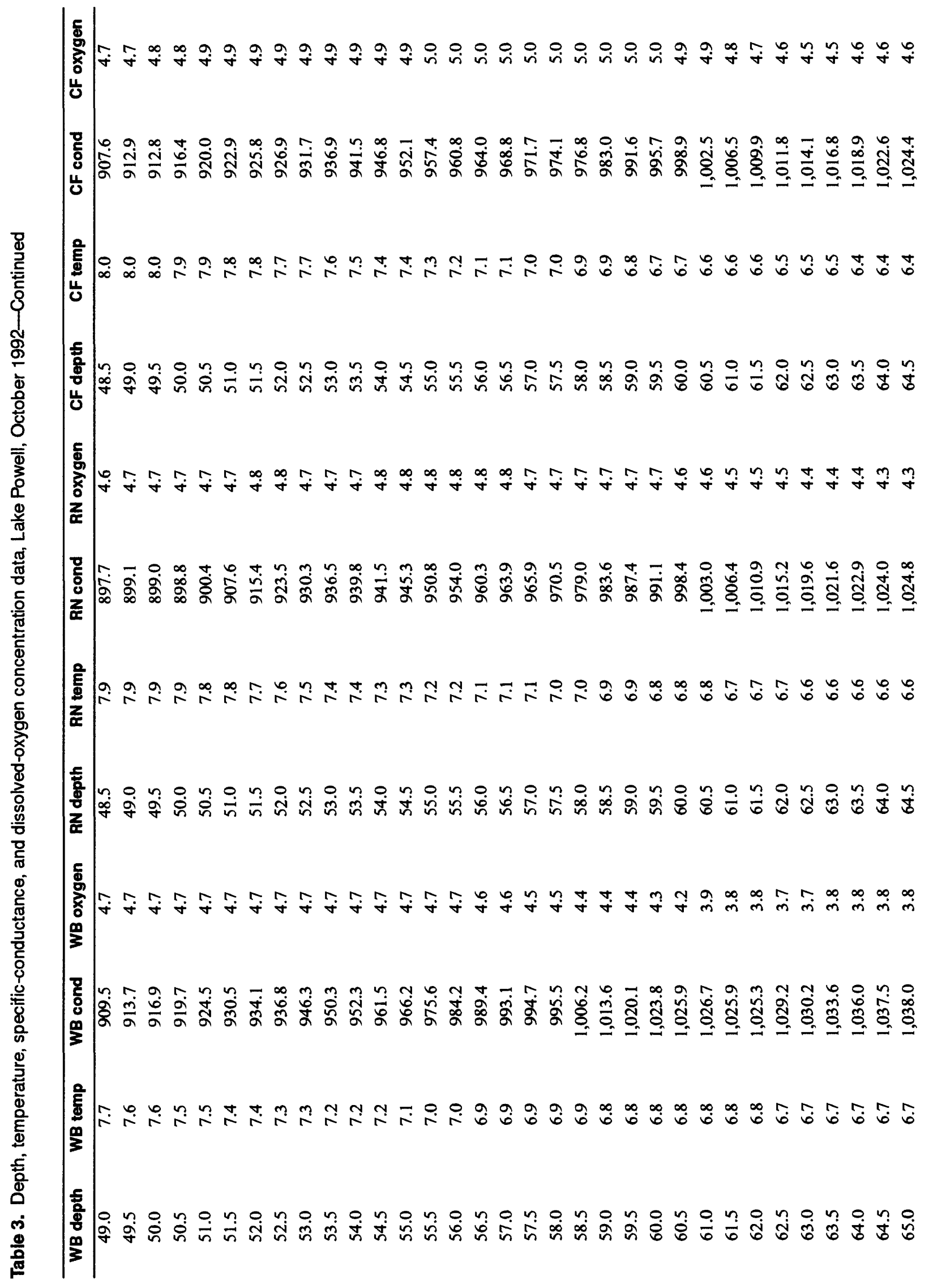




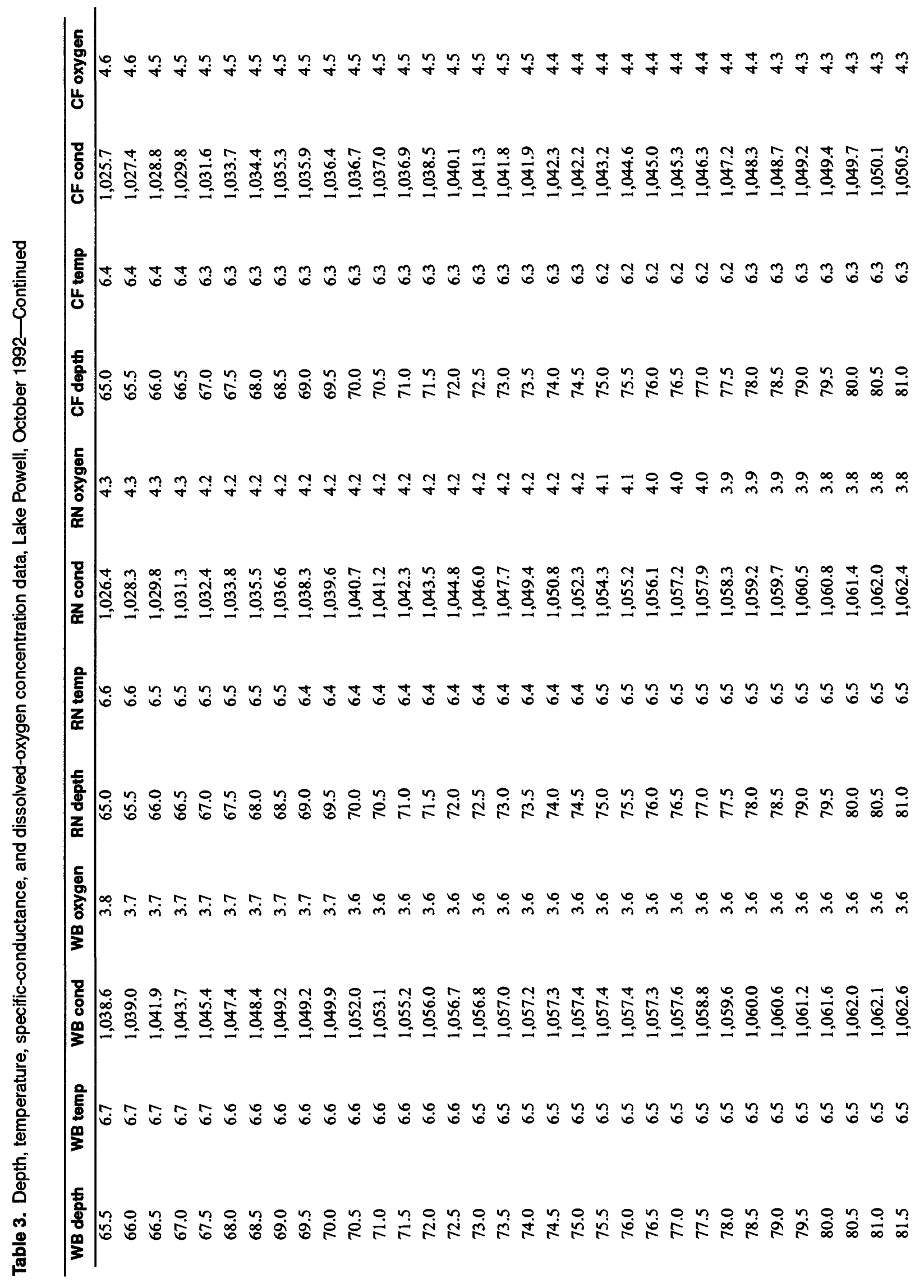




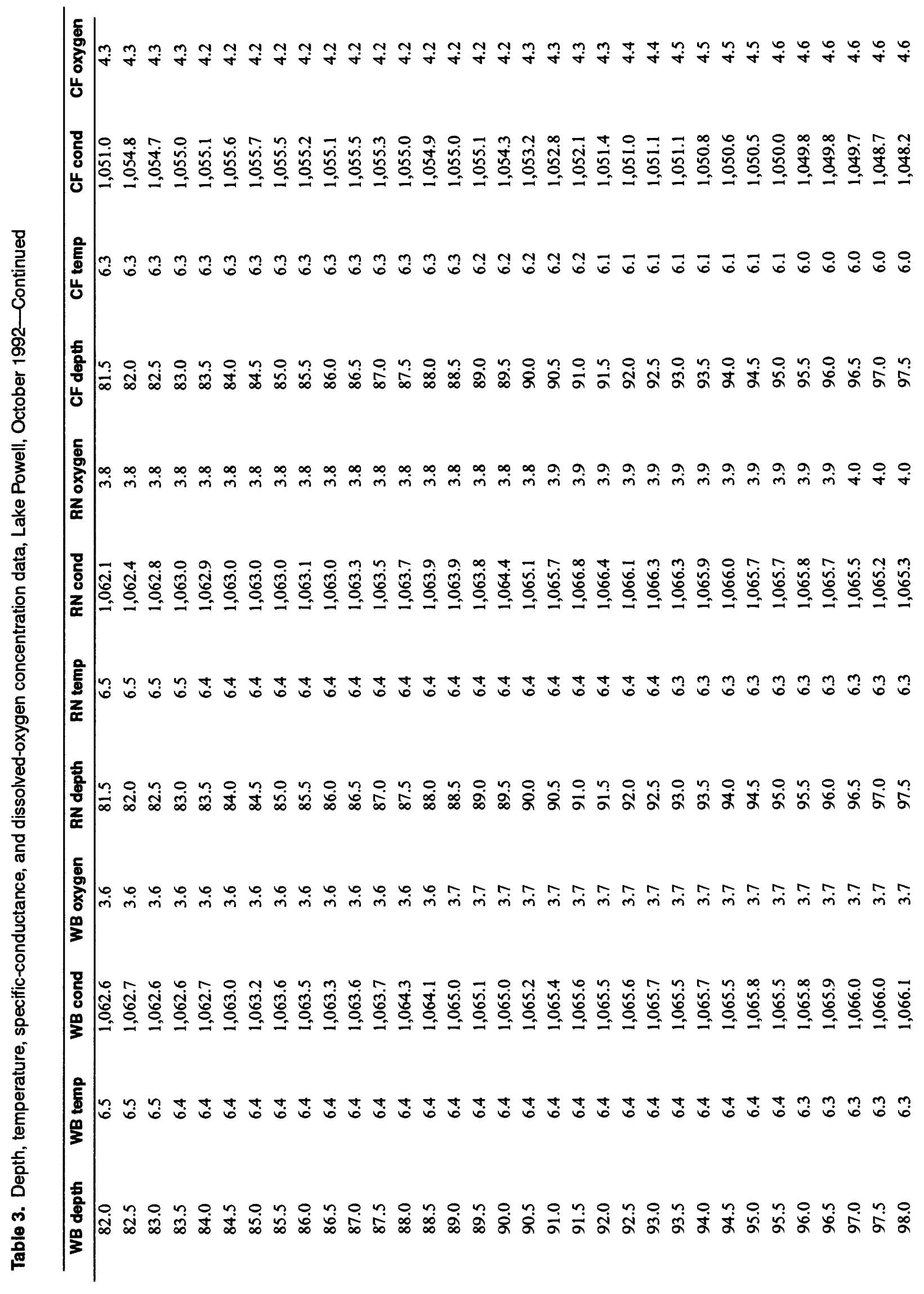

54 Depth Profiles of Temperature, Speclfic Conductance, and Oxygen Concentration in Lake Poweil, Az-Utah, 1992-95 


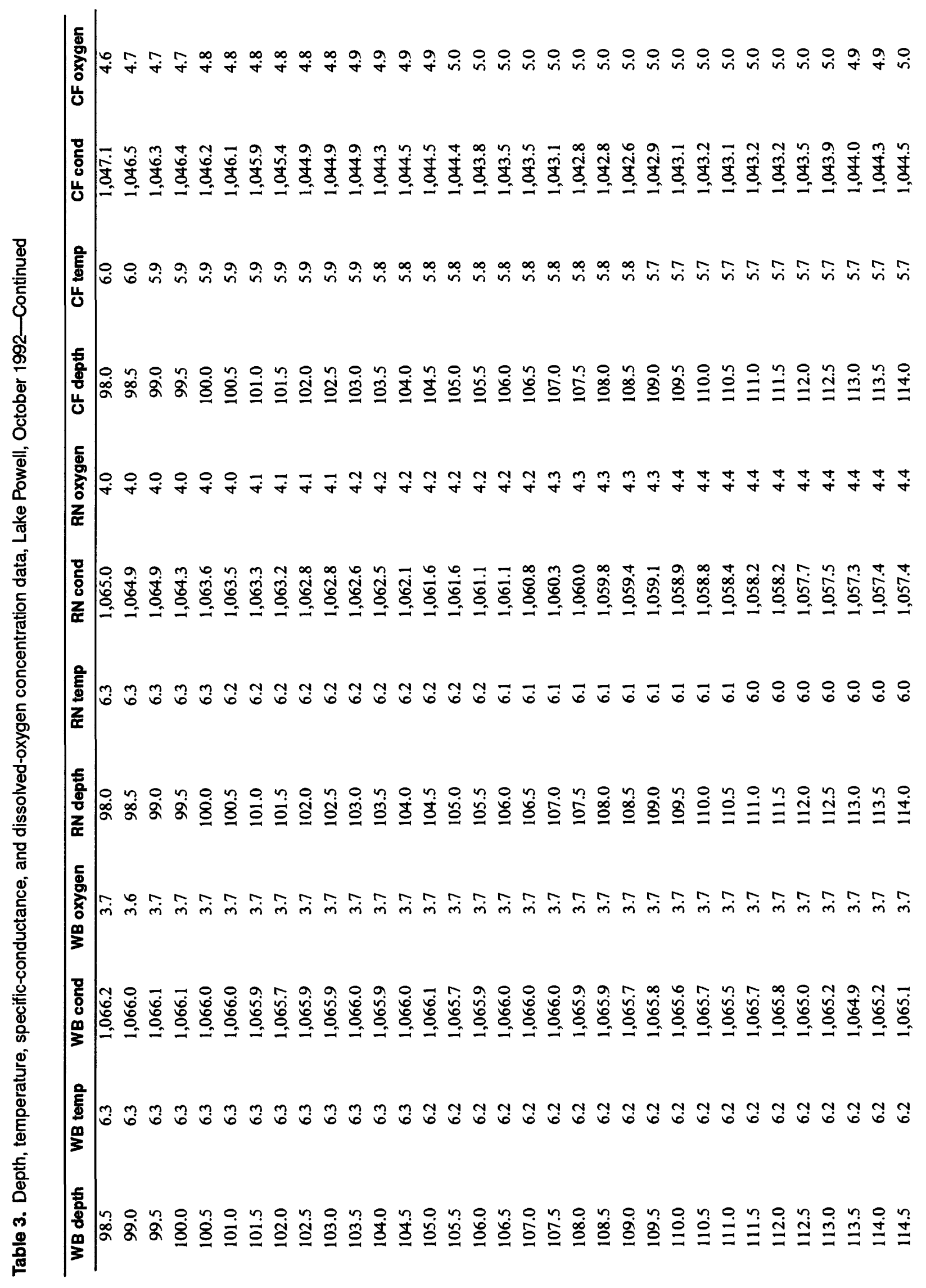




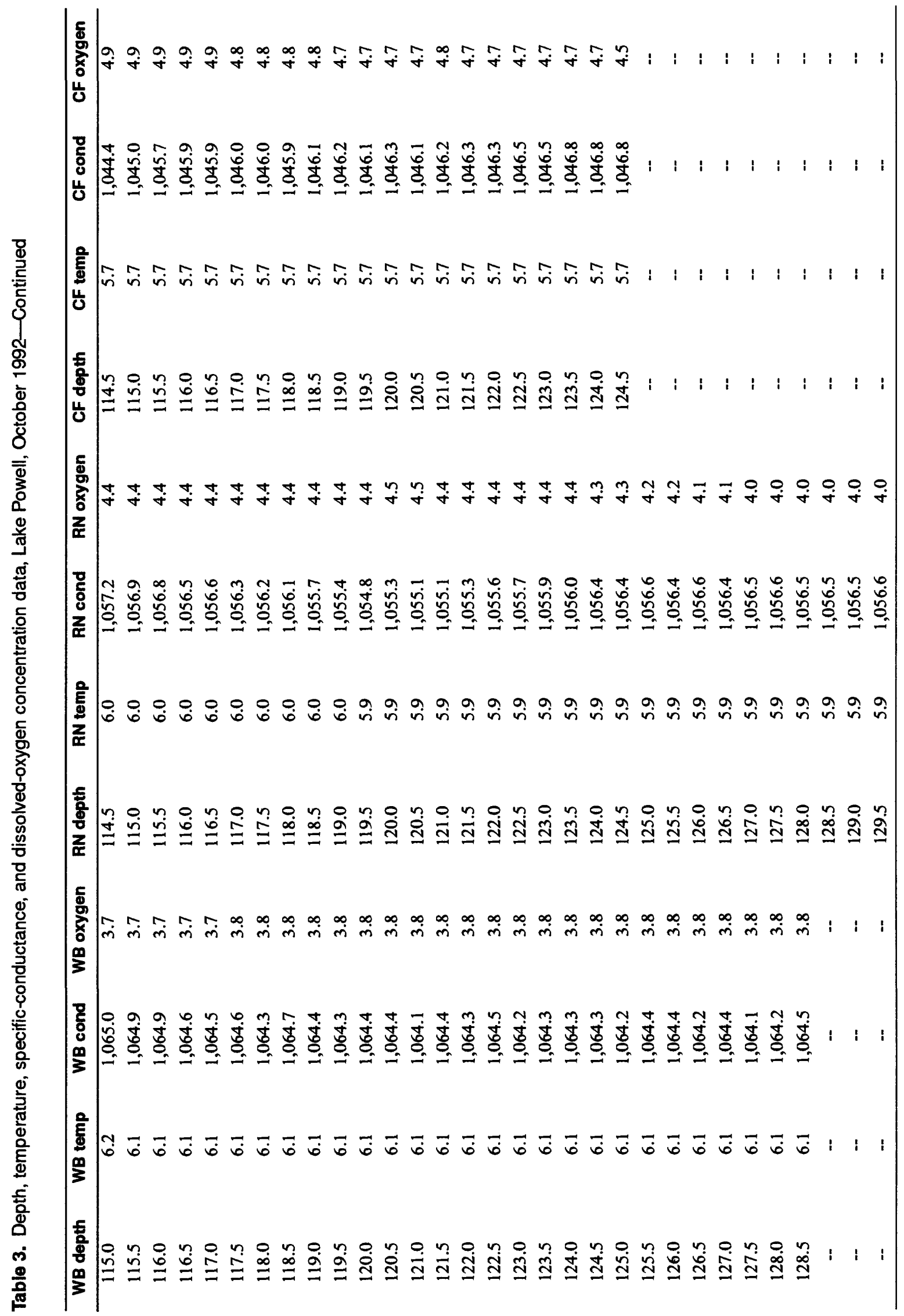




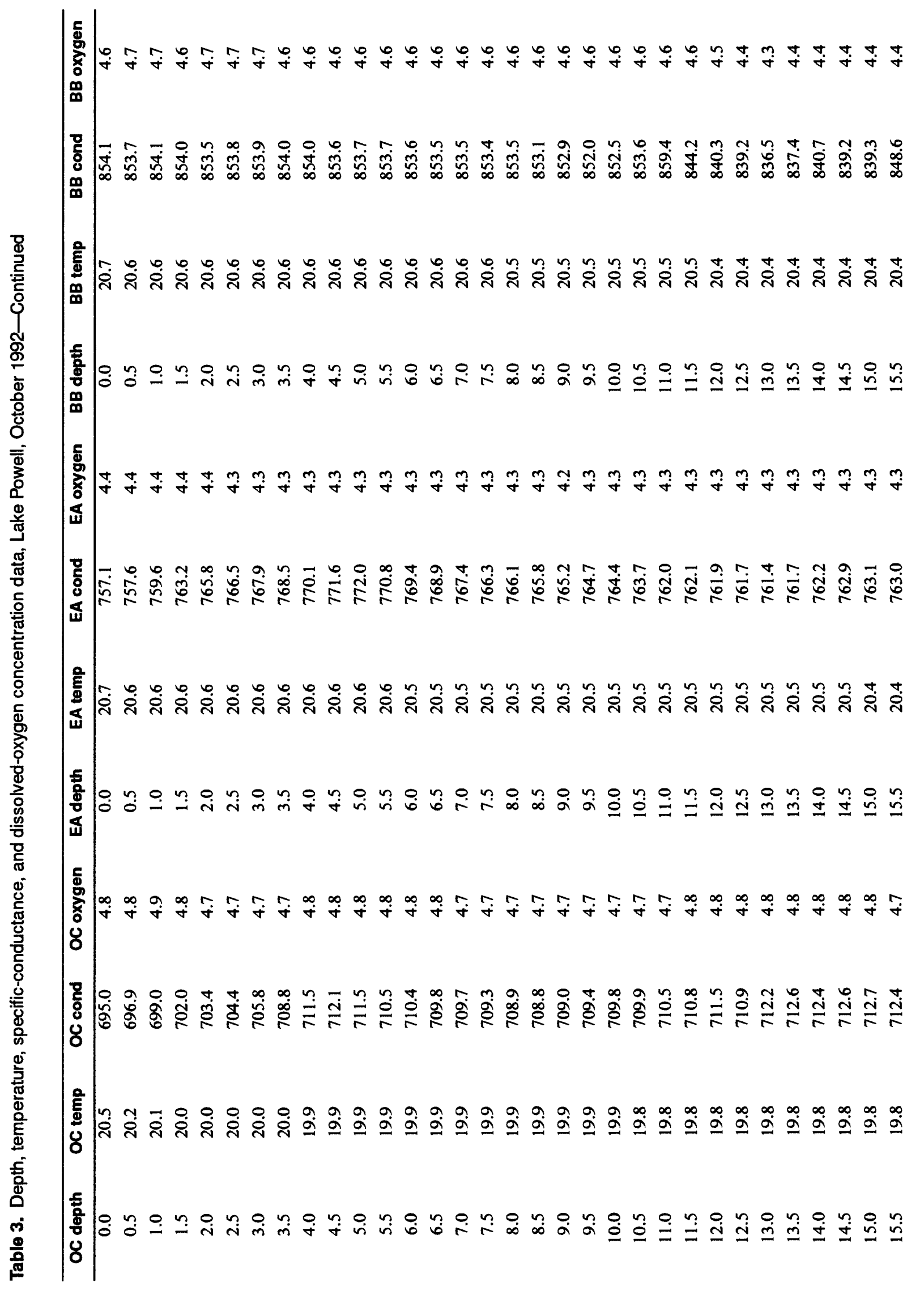




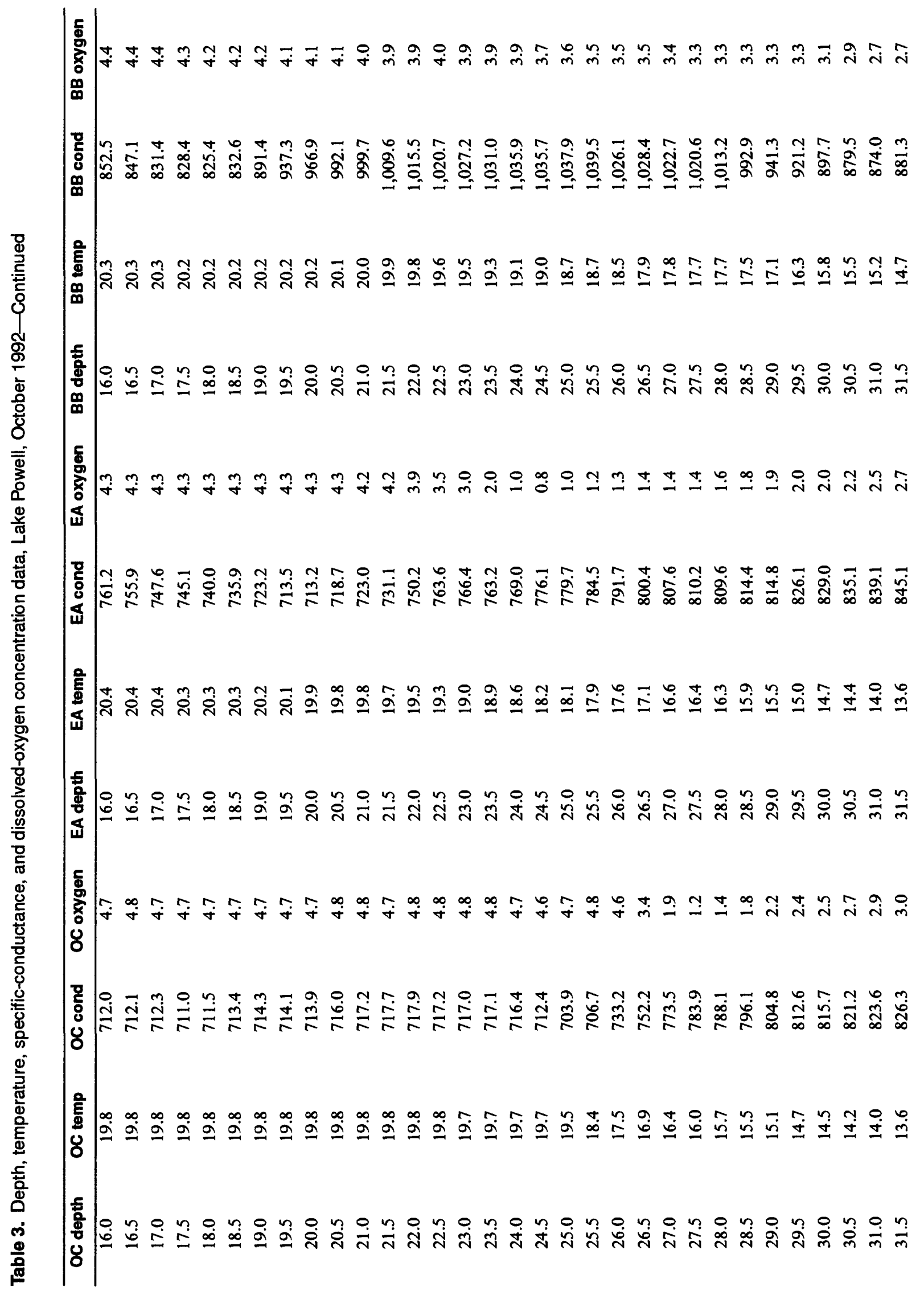




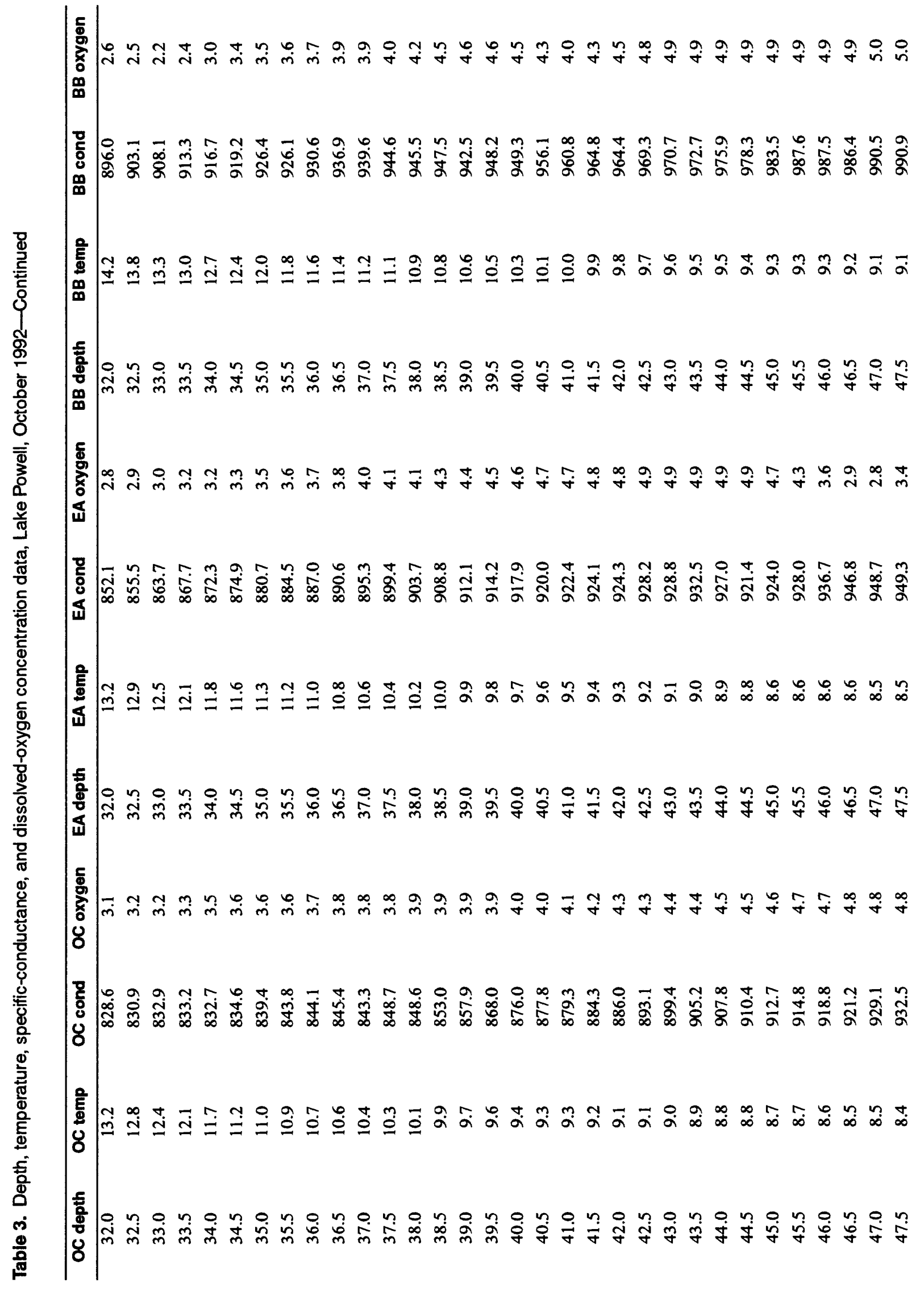




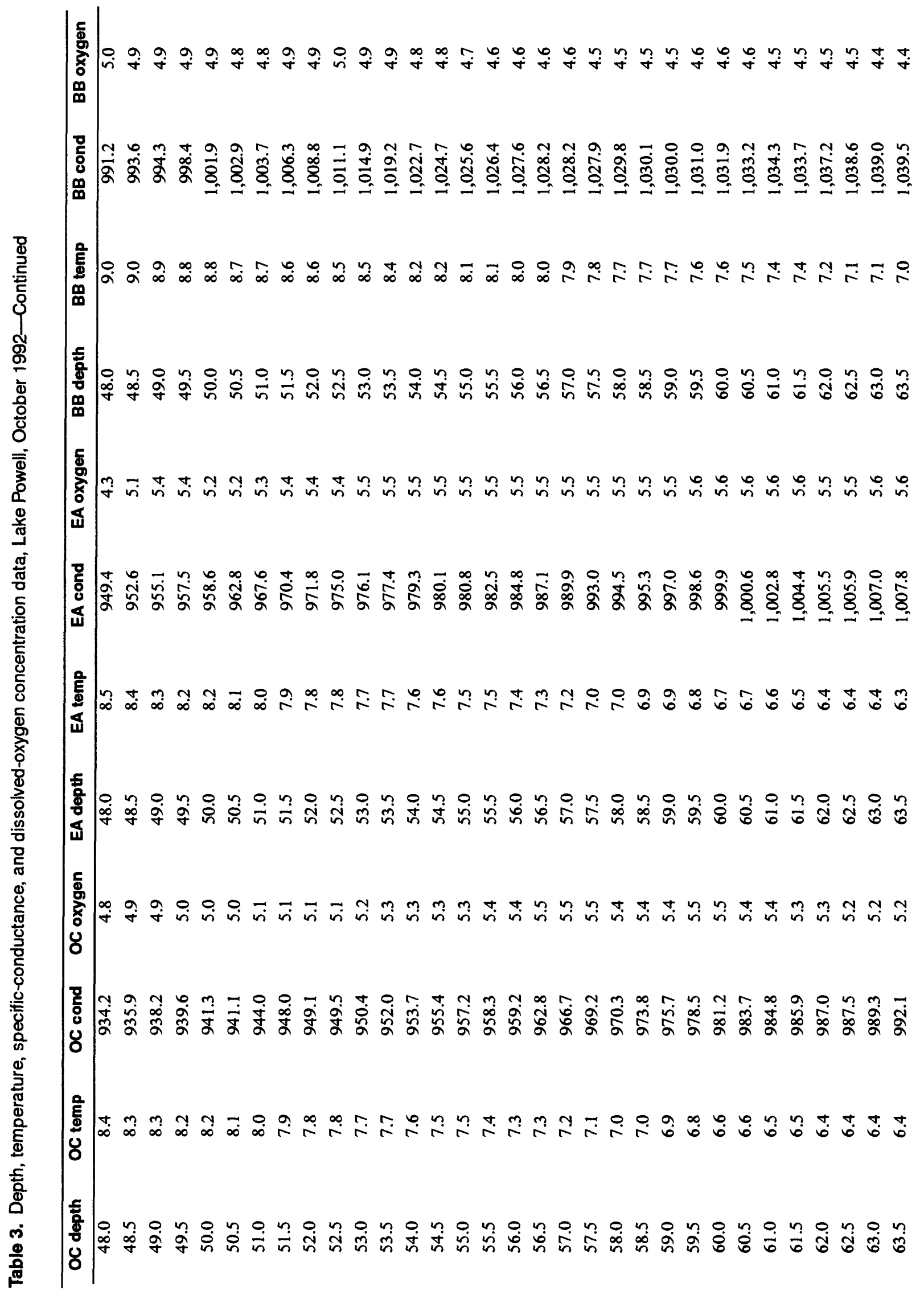




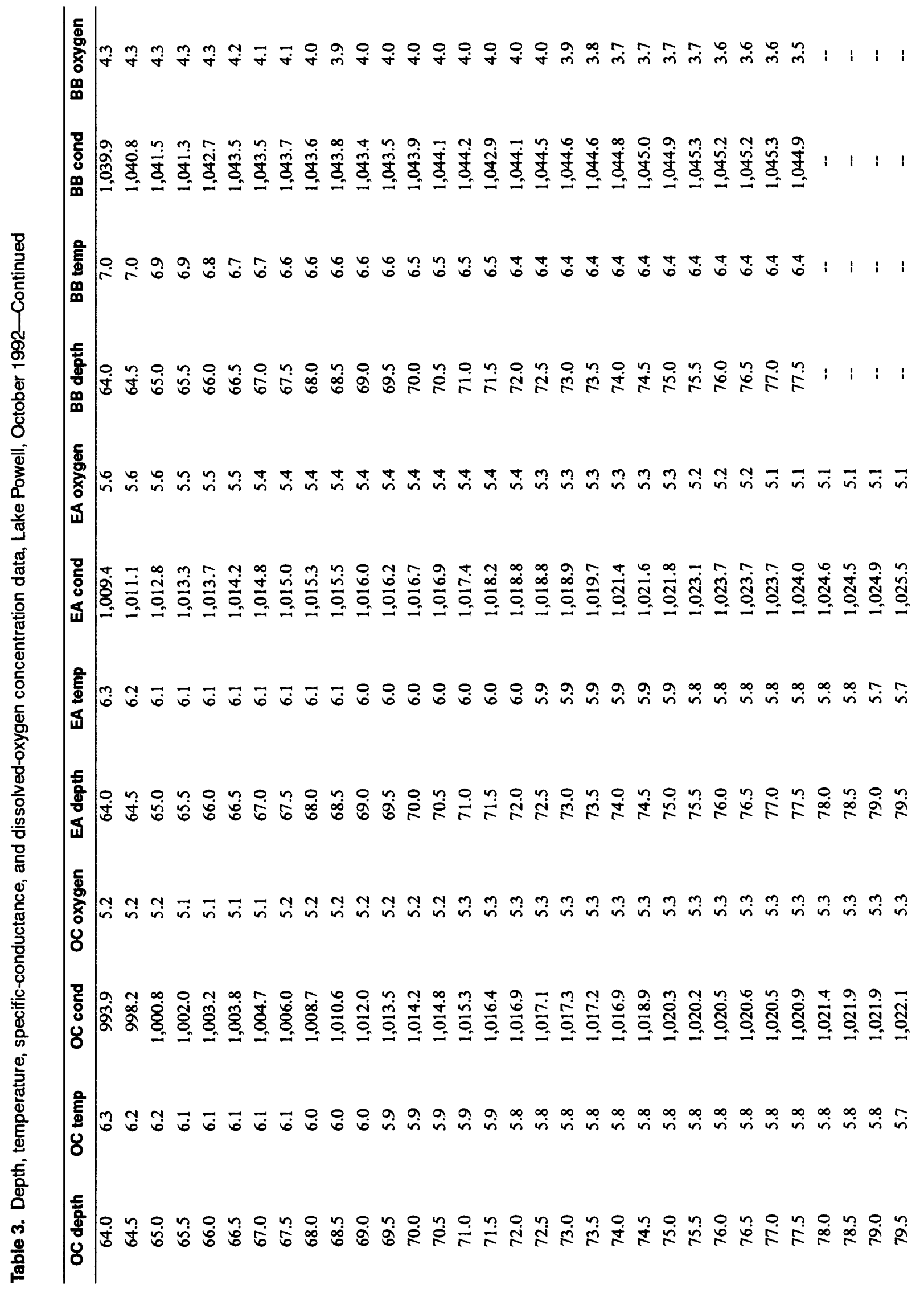




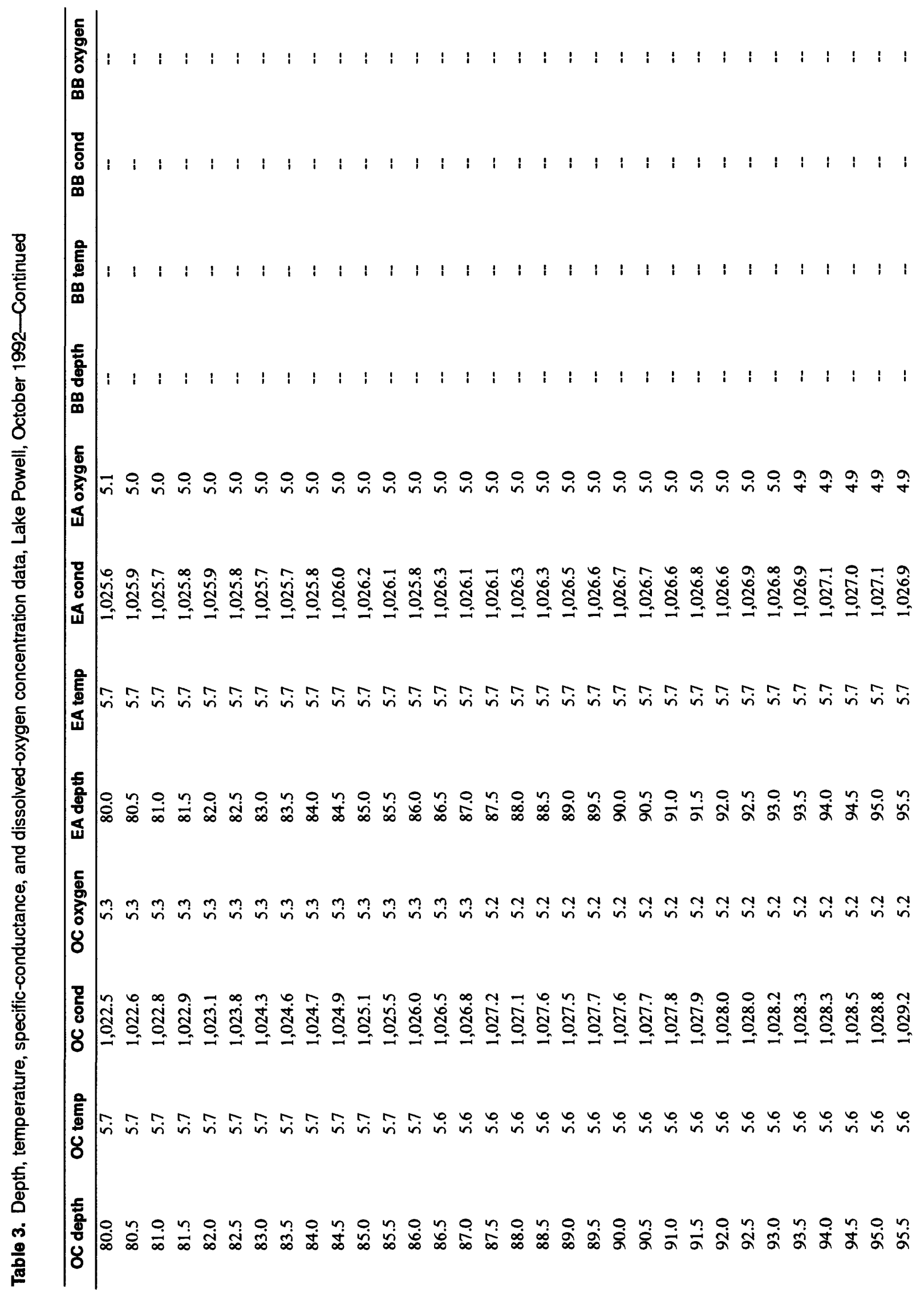




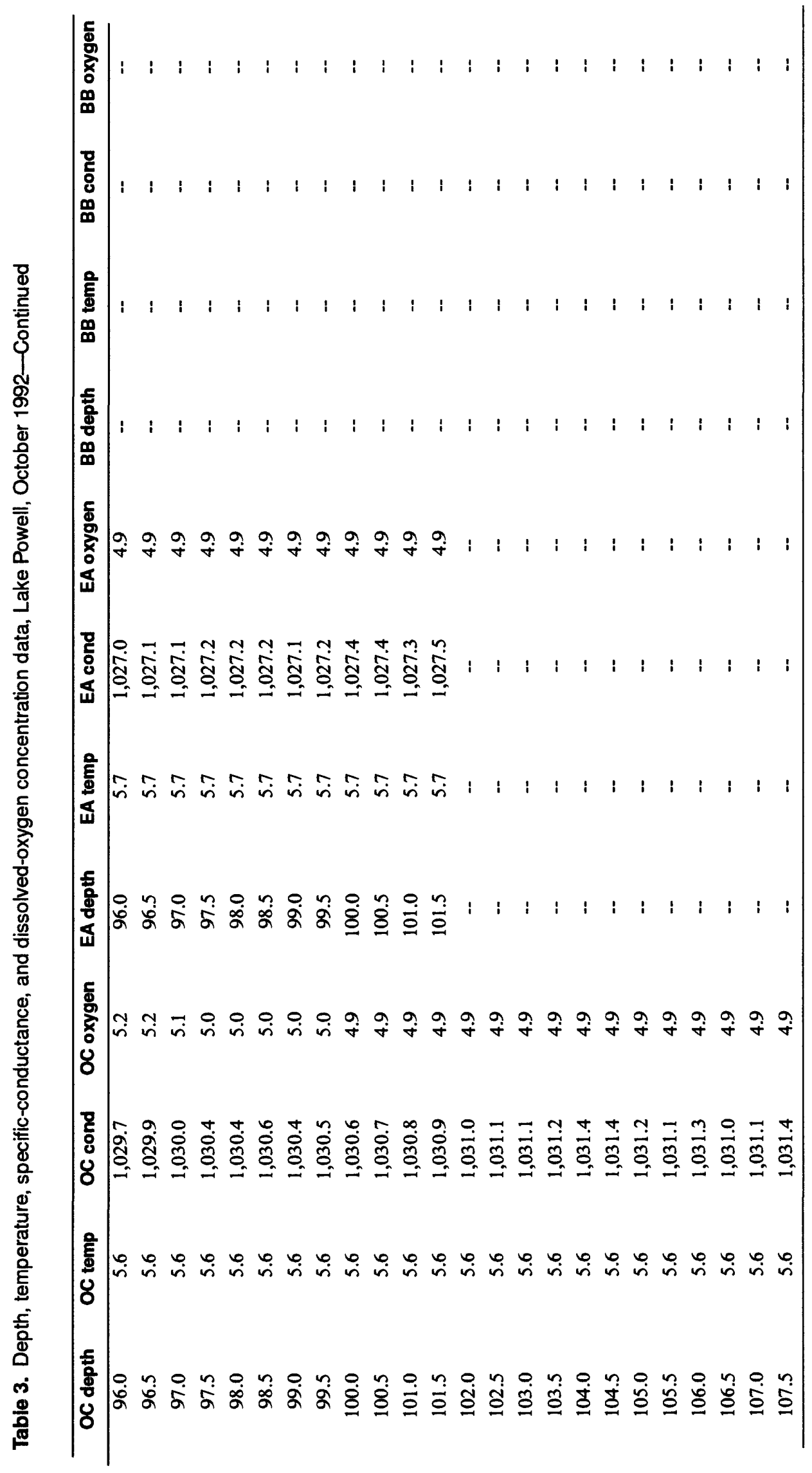




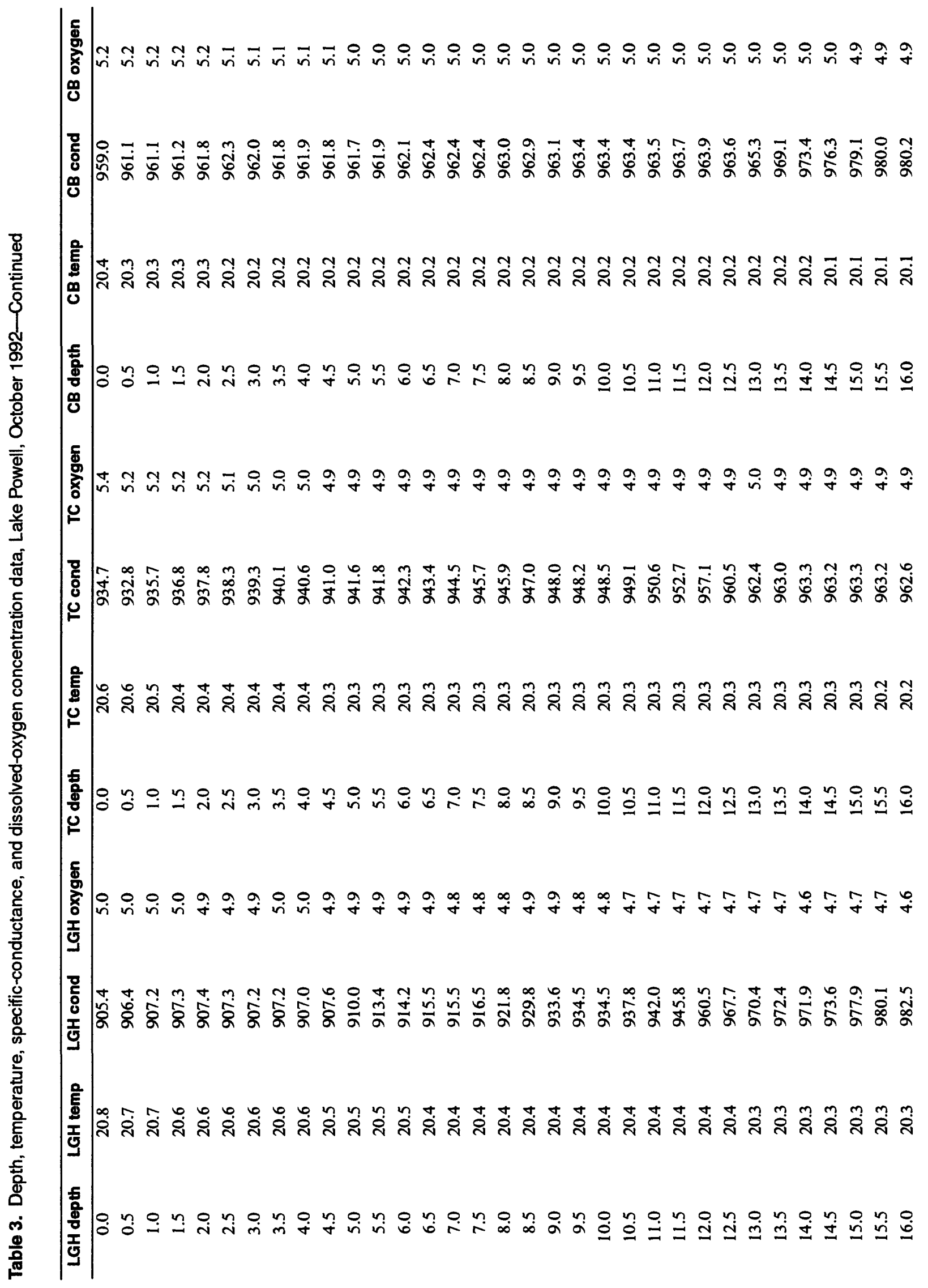




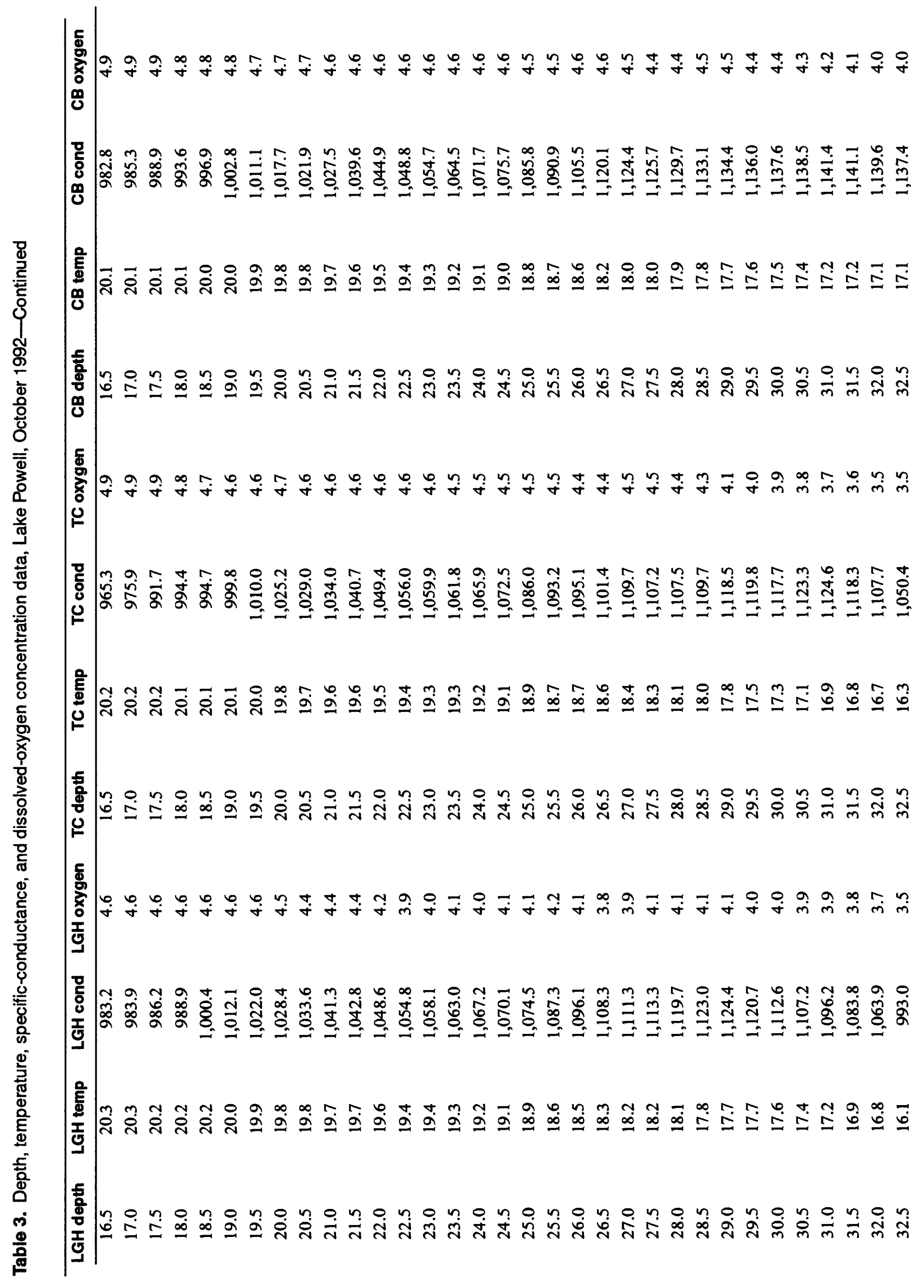




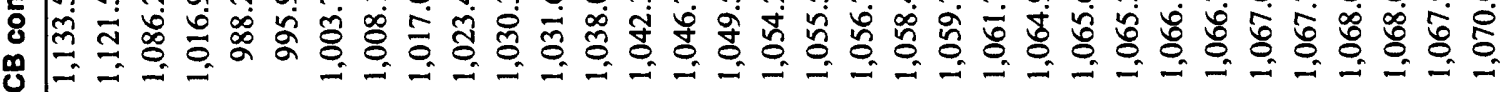

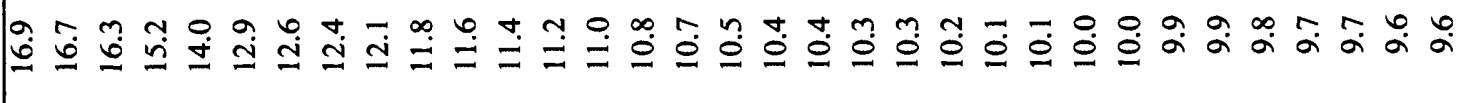

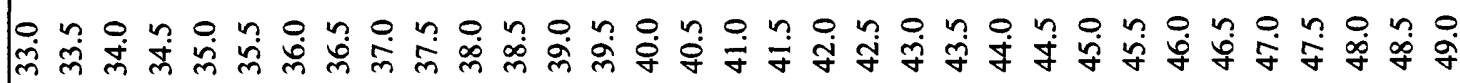

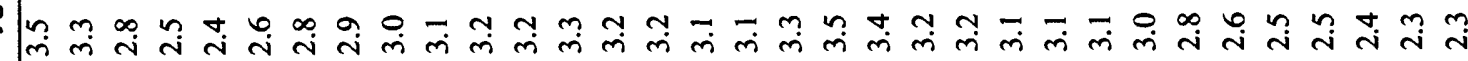

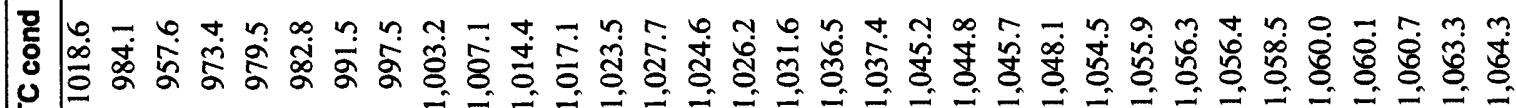

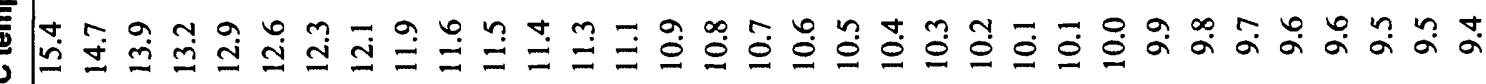

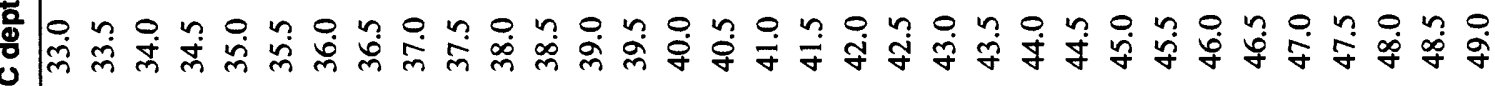

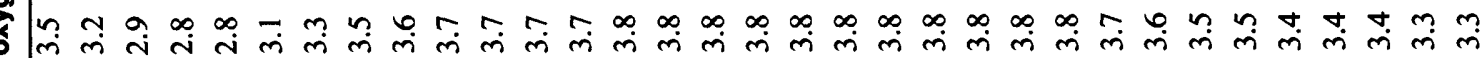

ซ

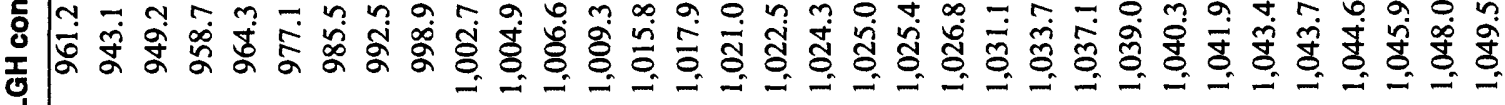

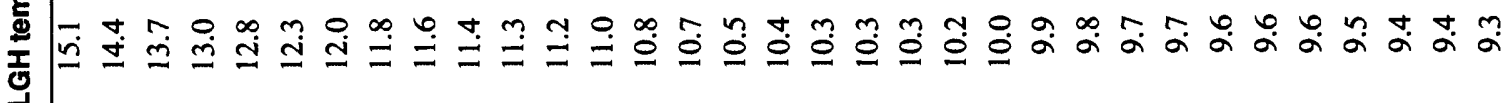




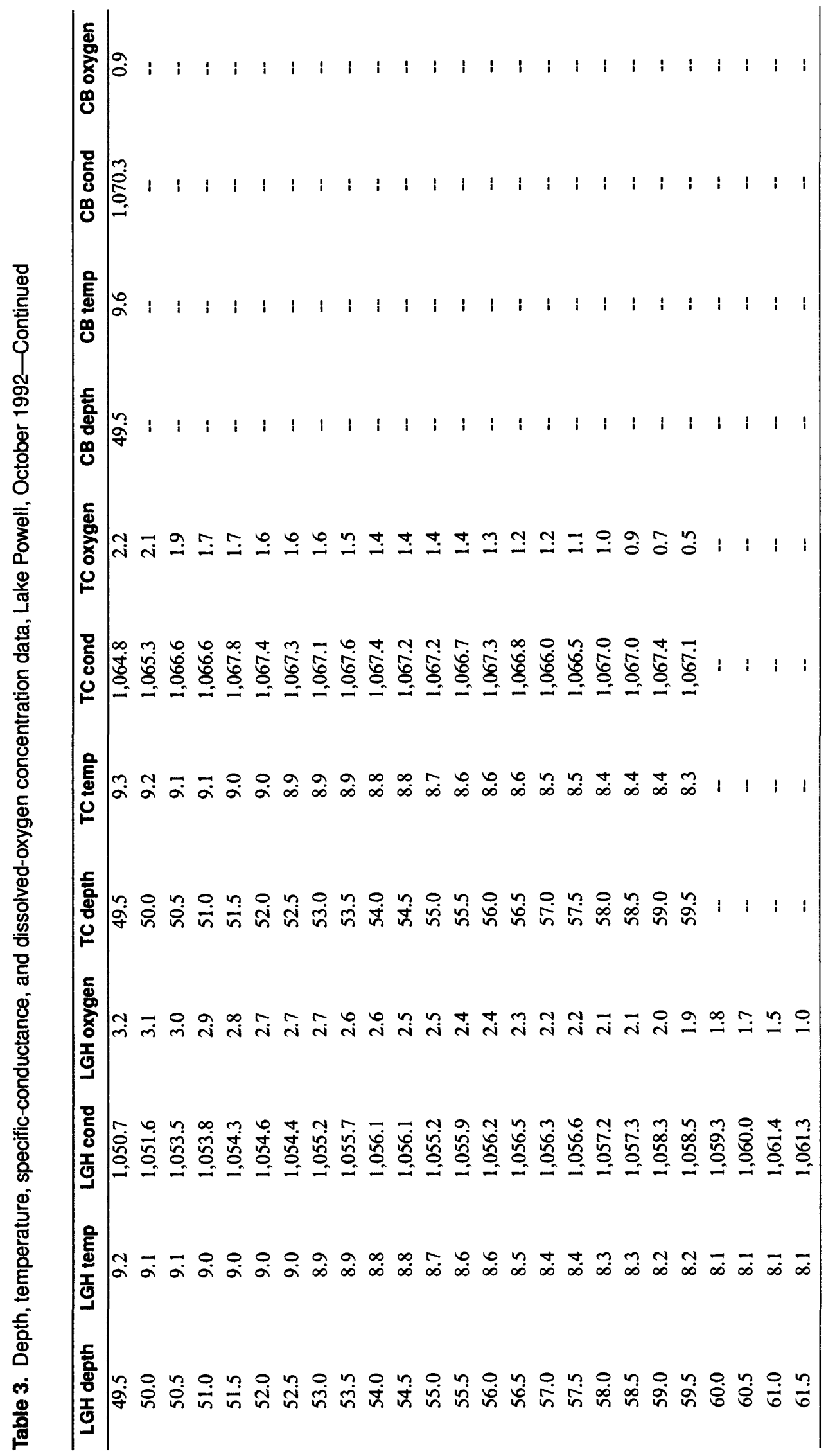




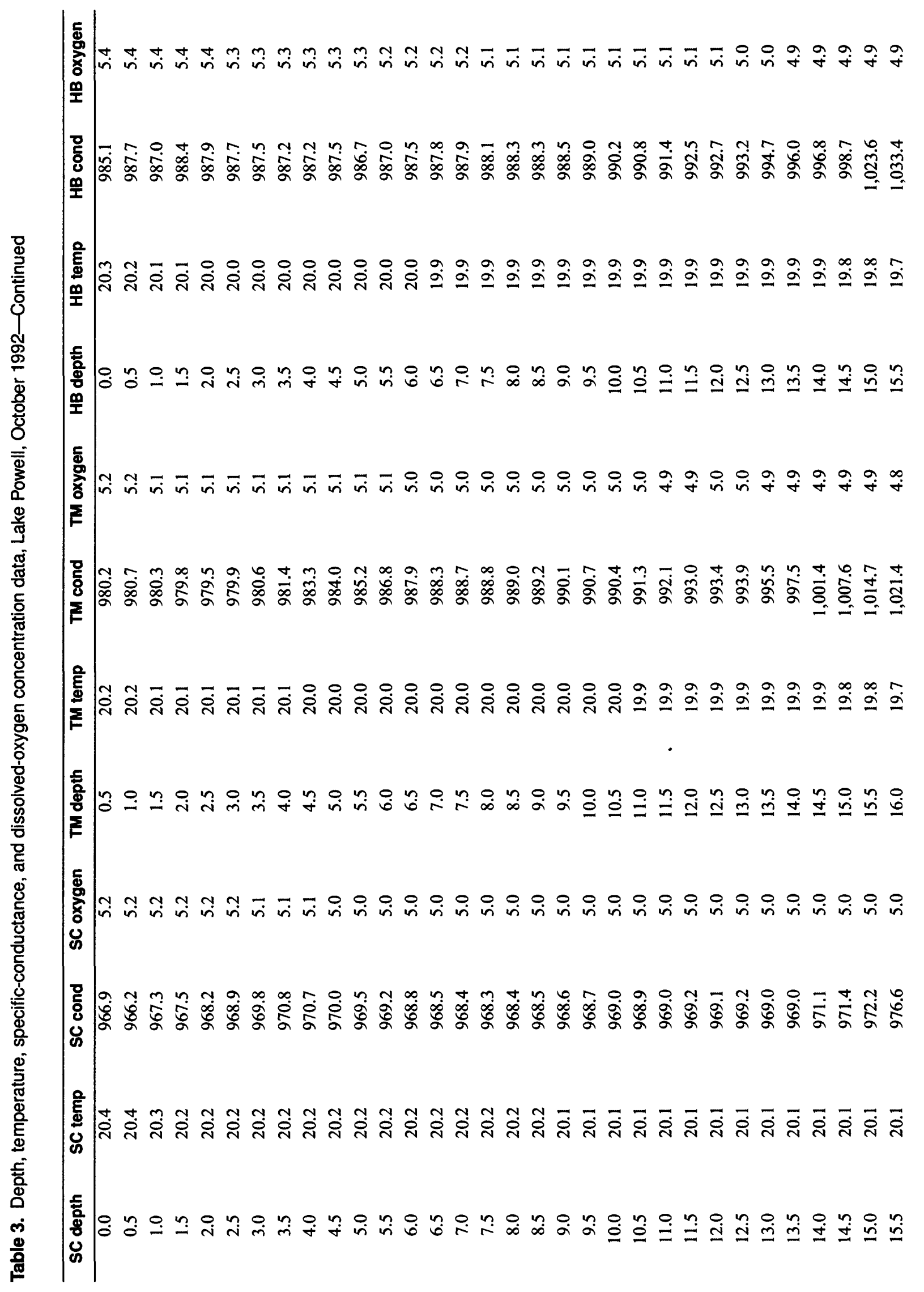




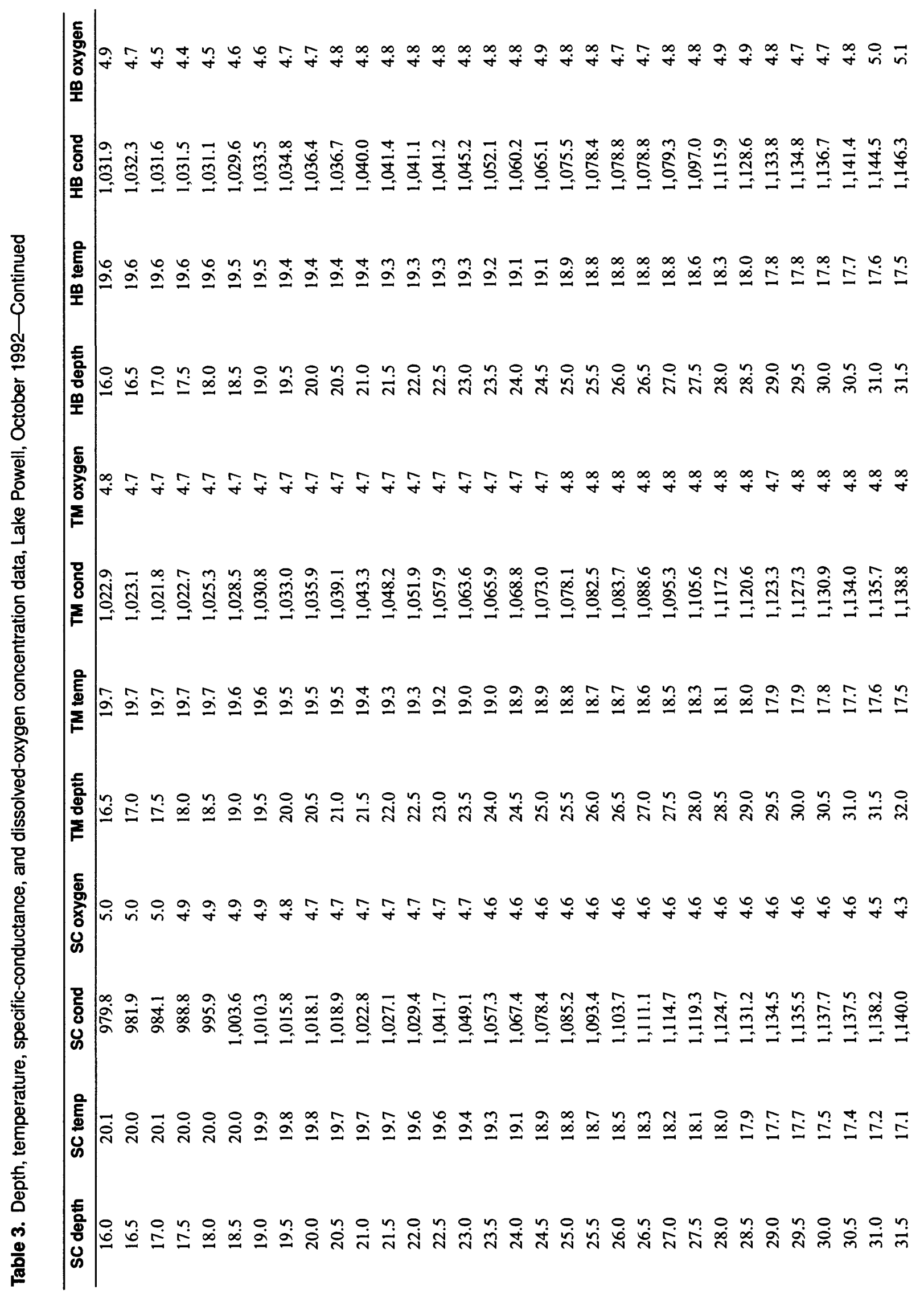




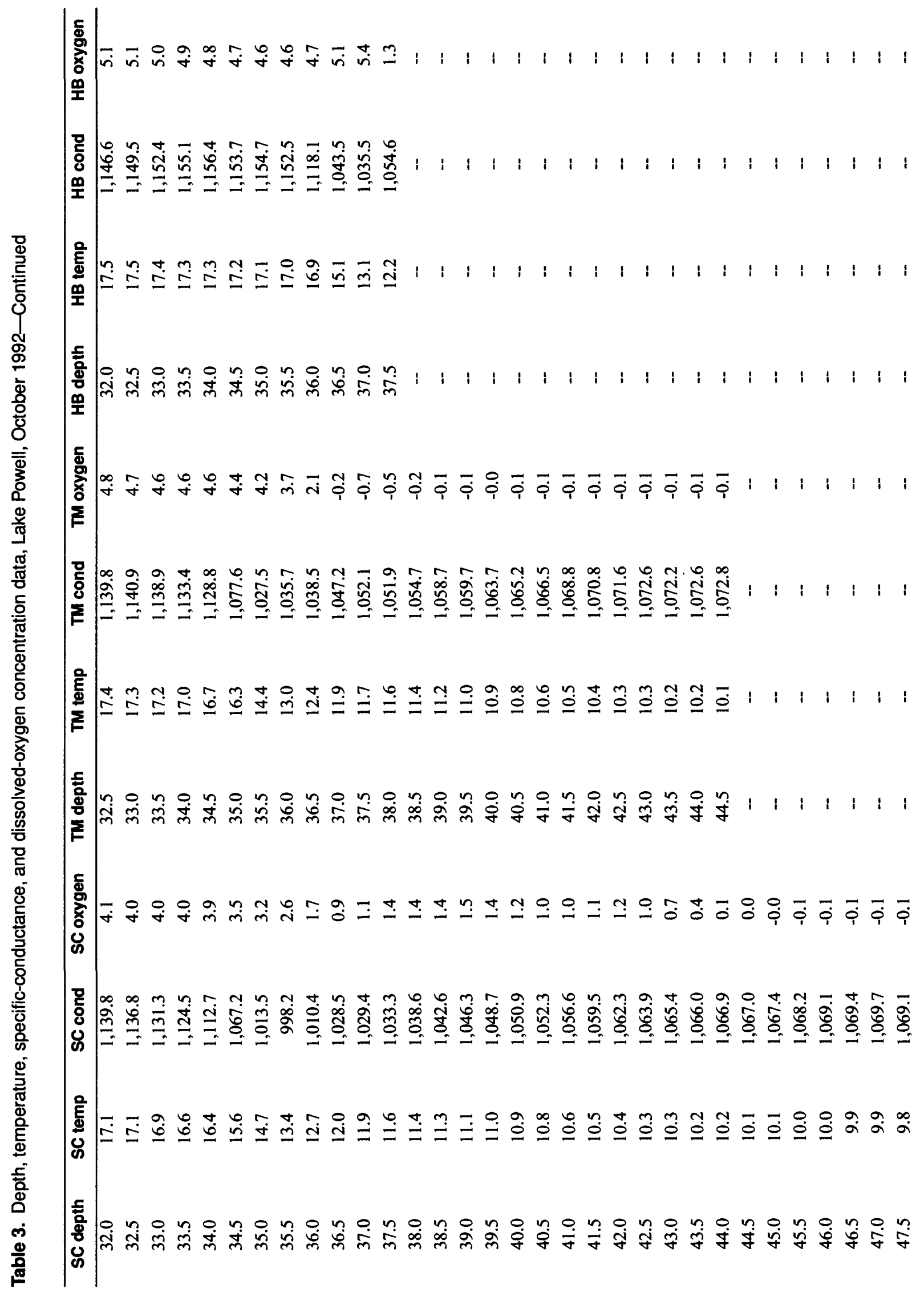

70 Depth Profiles of Temperature, Specific Conductance, and Oxygen Concentration In Lake Poweil, Az-Utah, 1992-95 


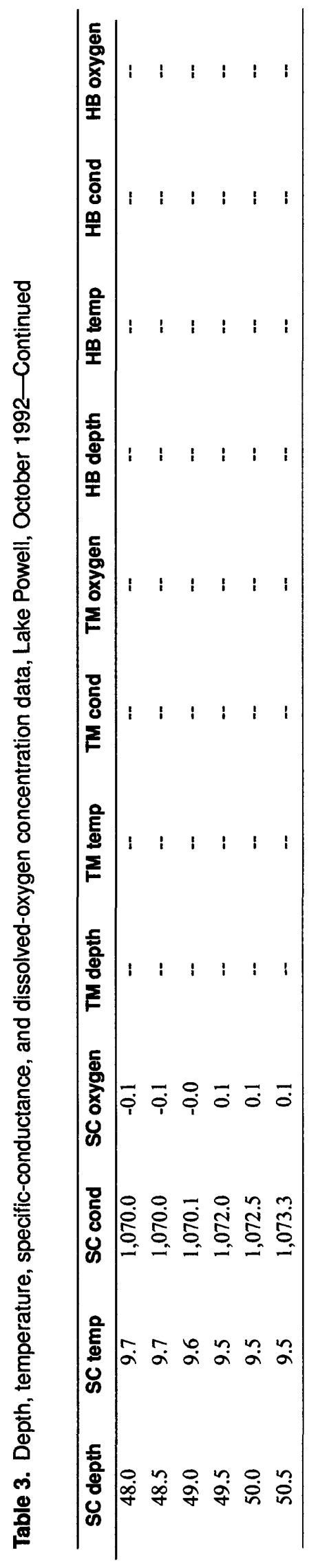




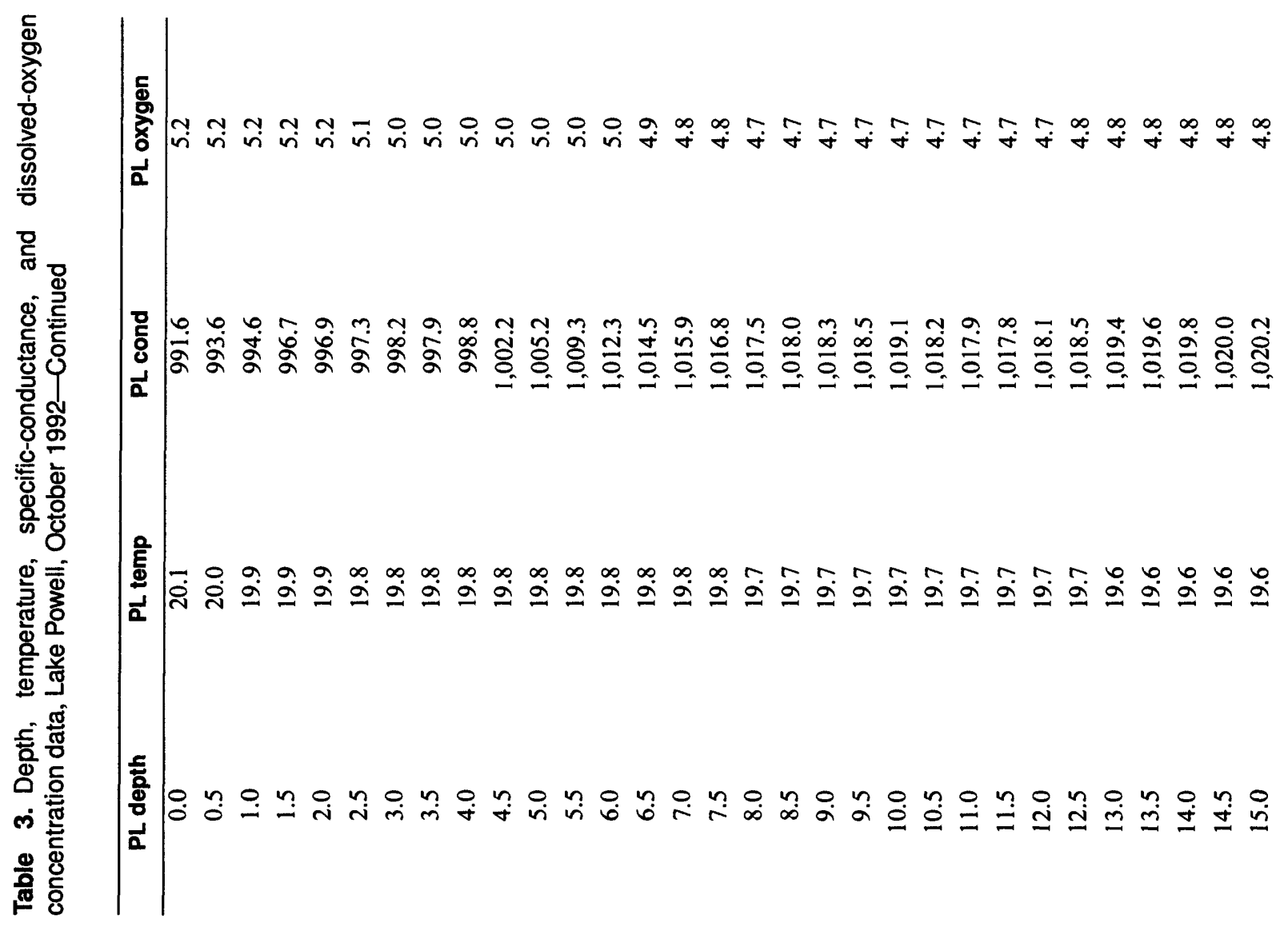




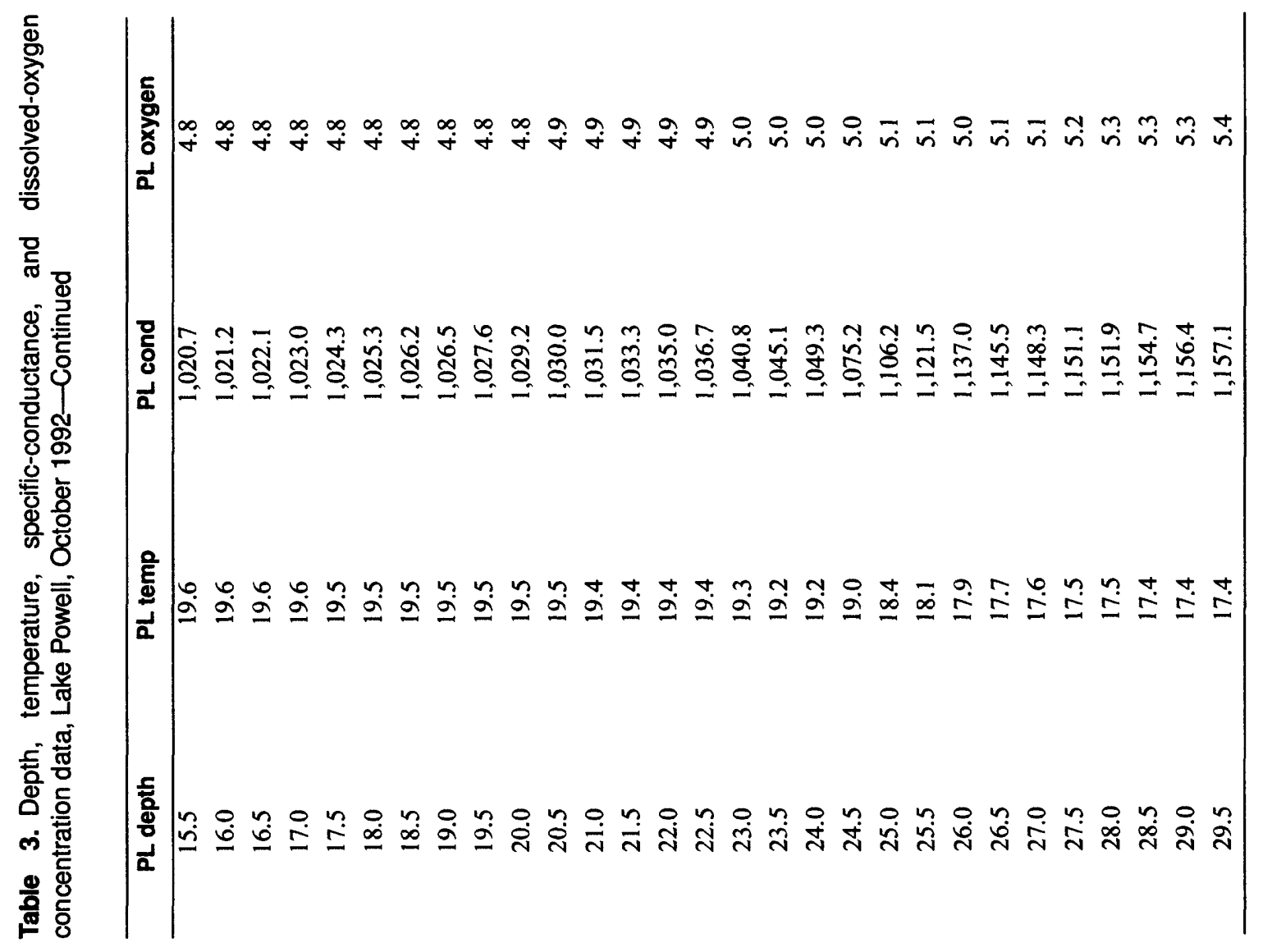




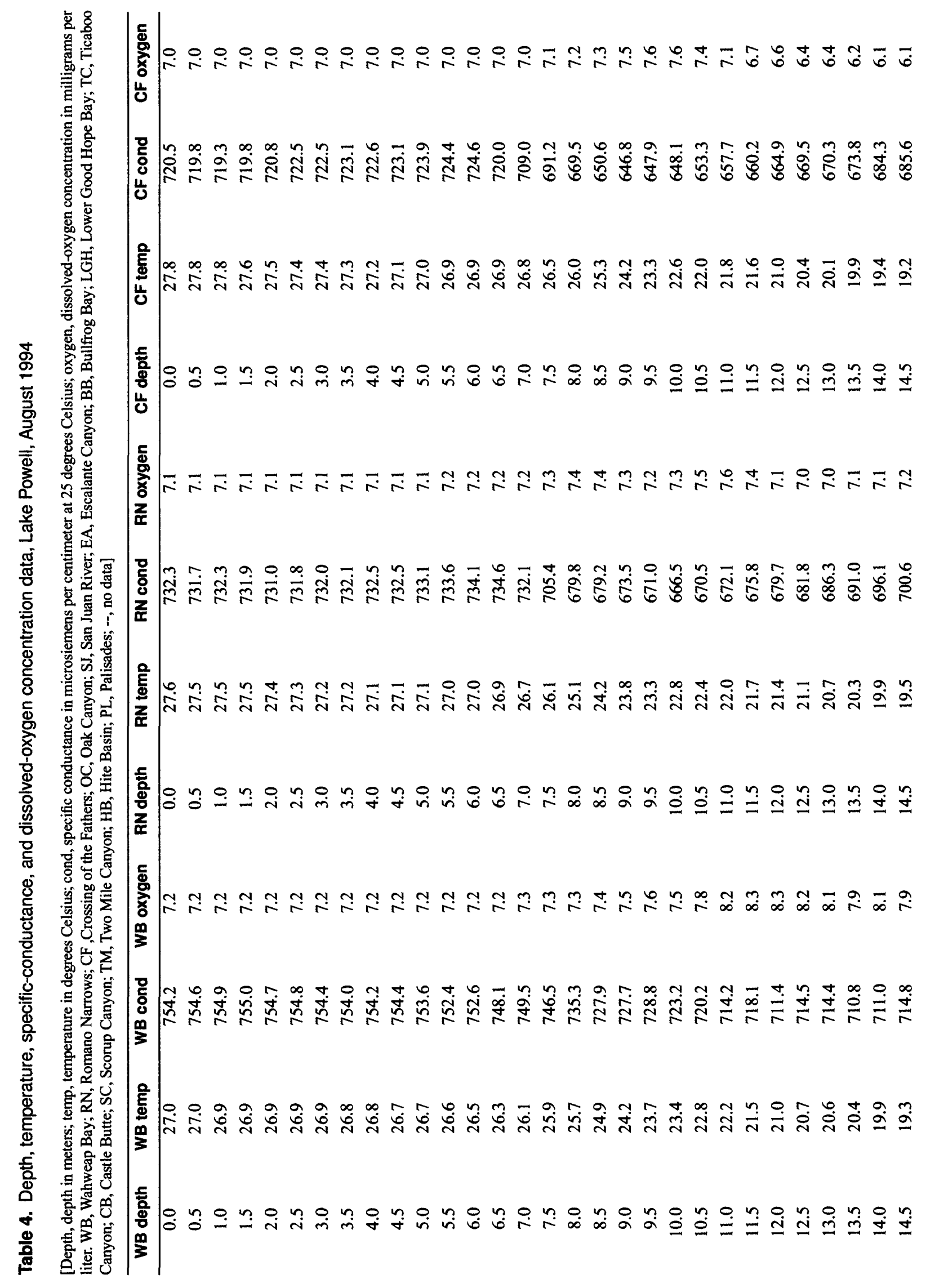




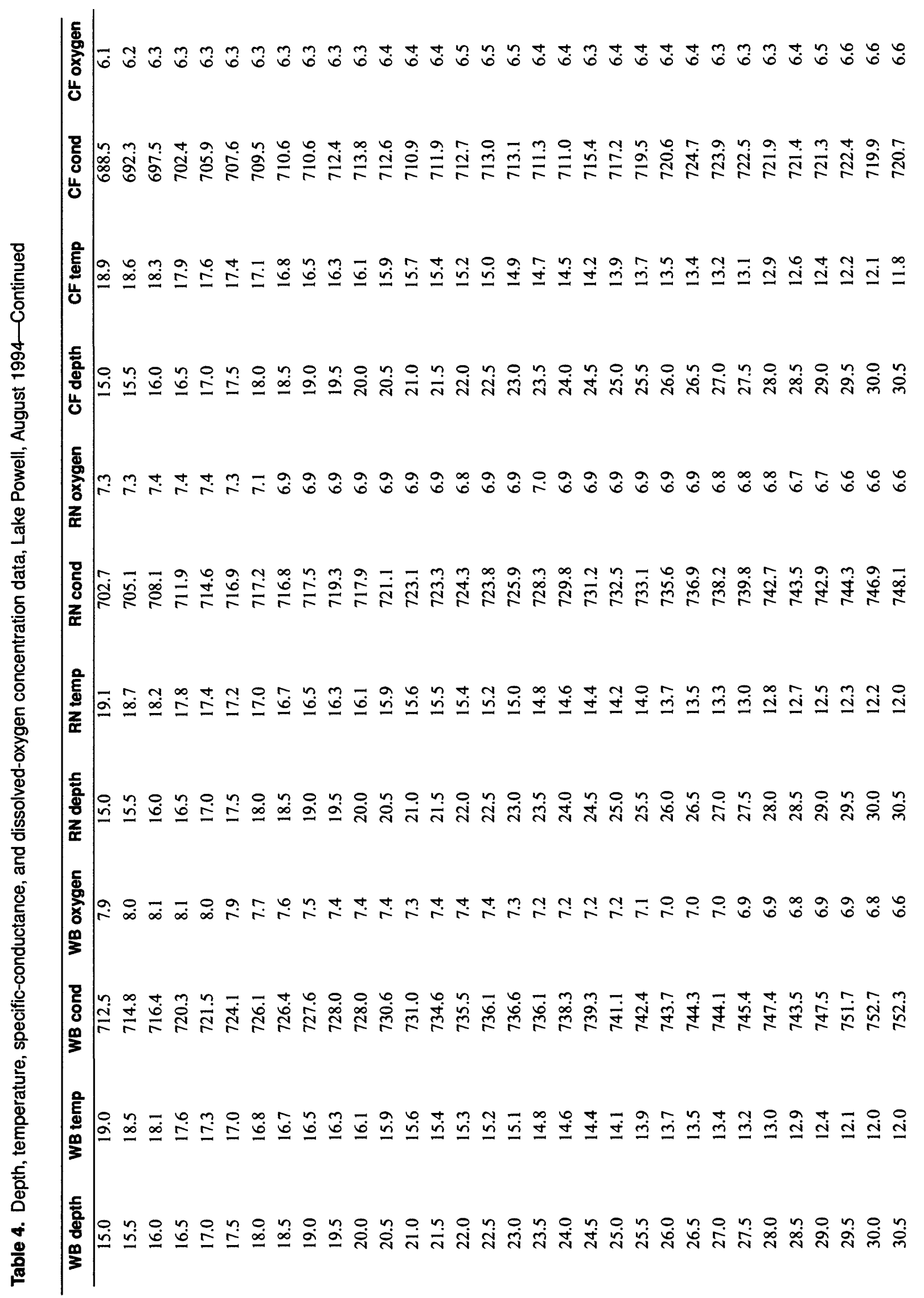




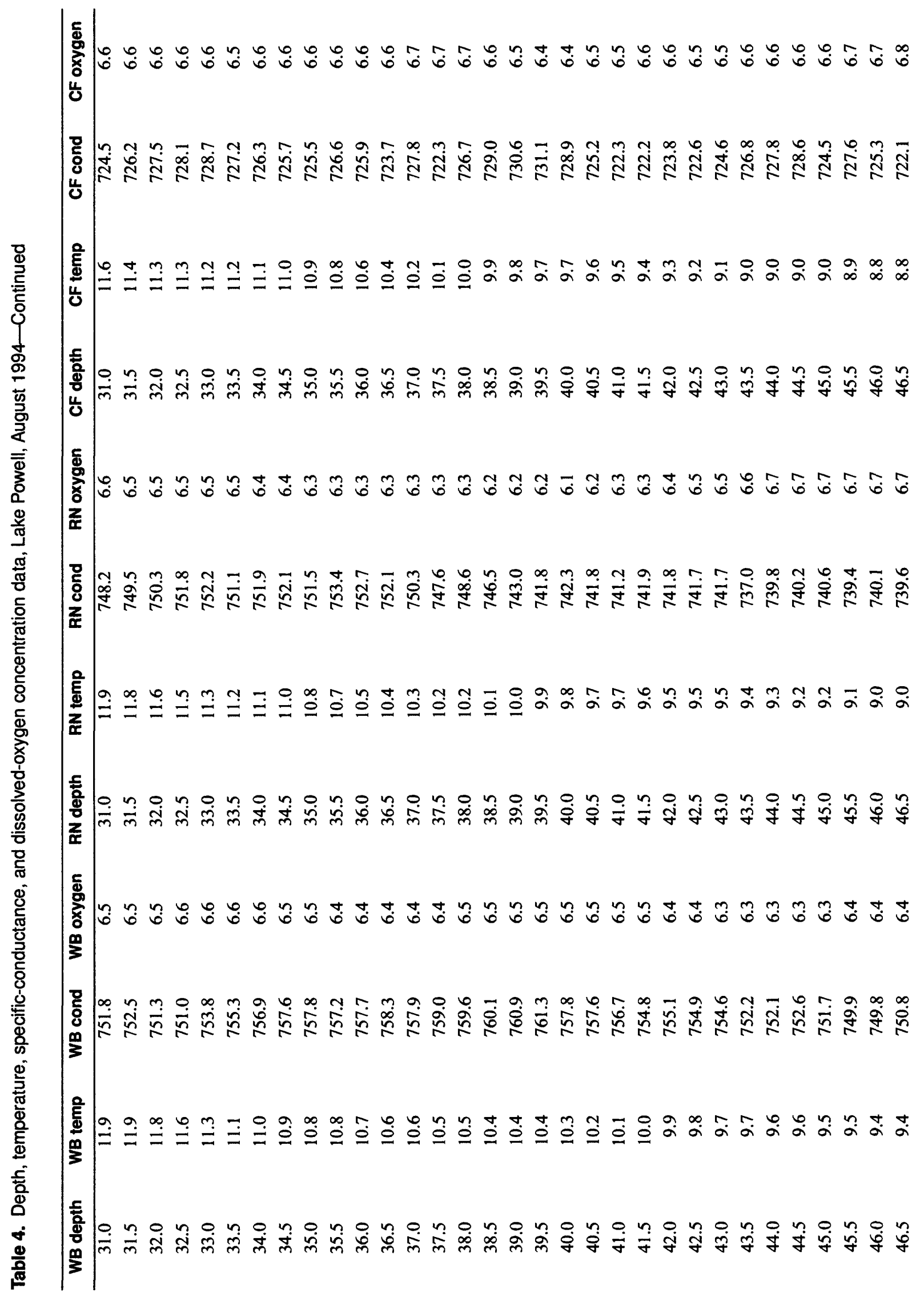




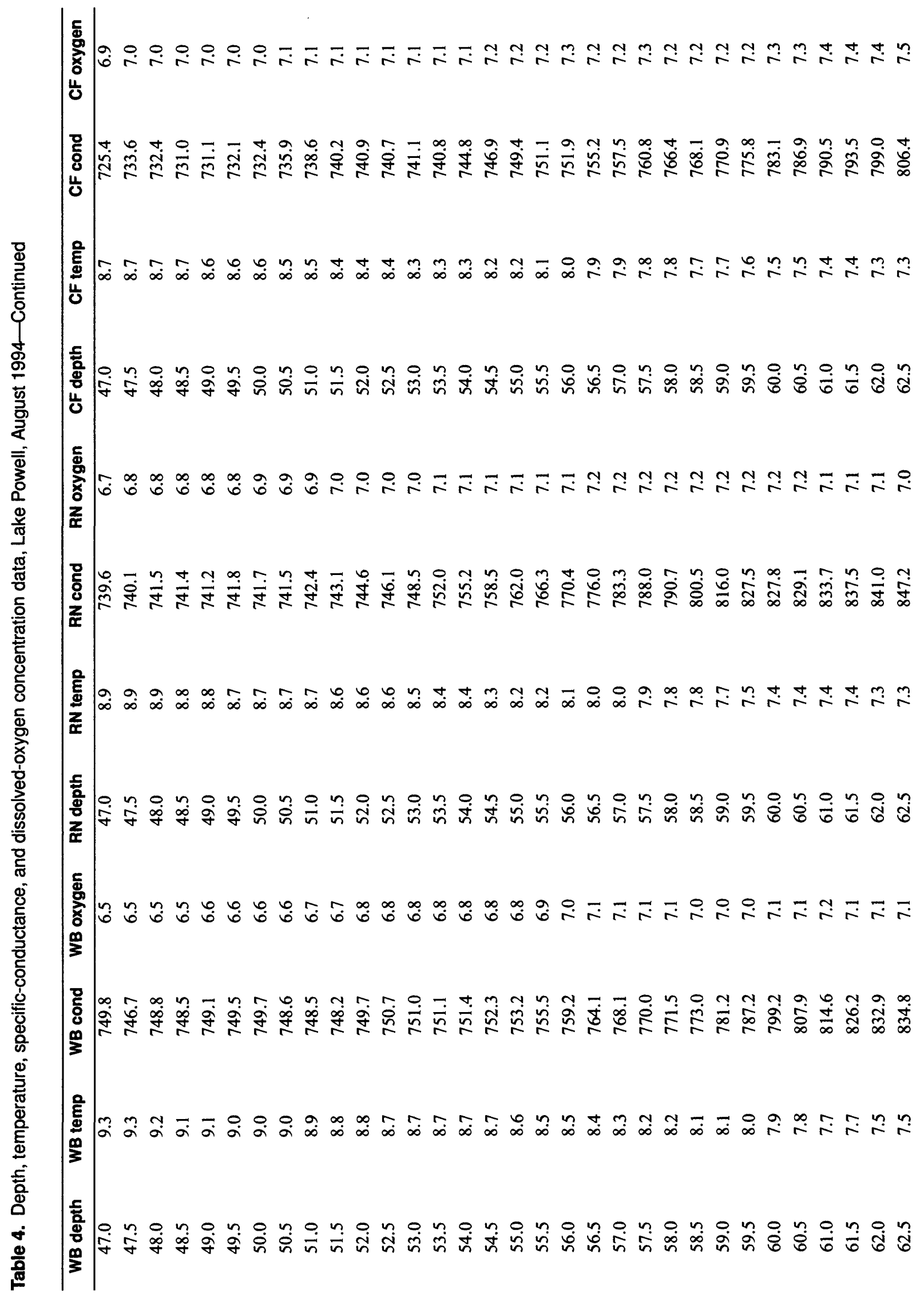




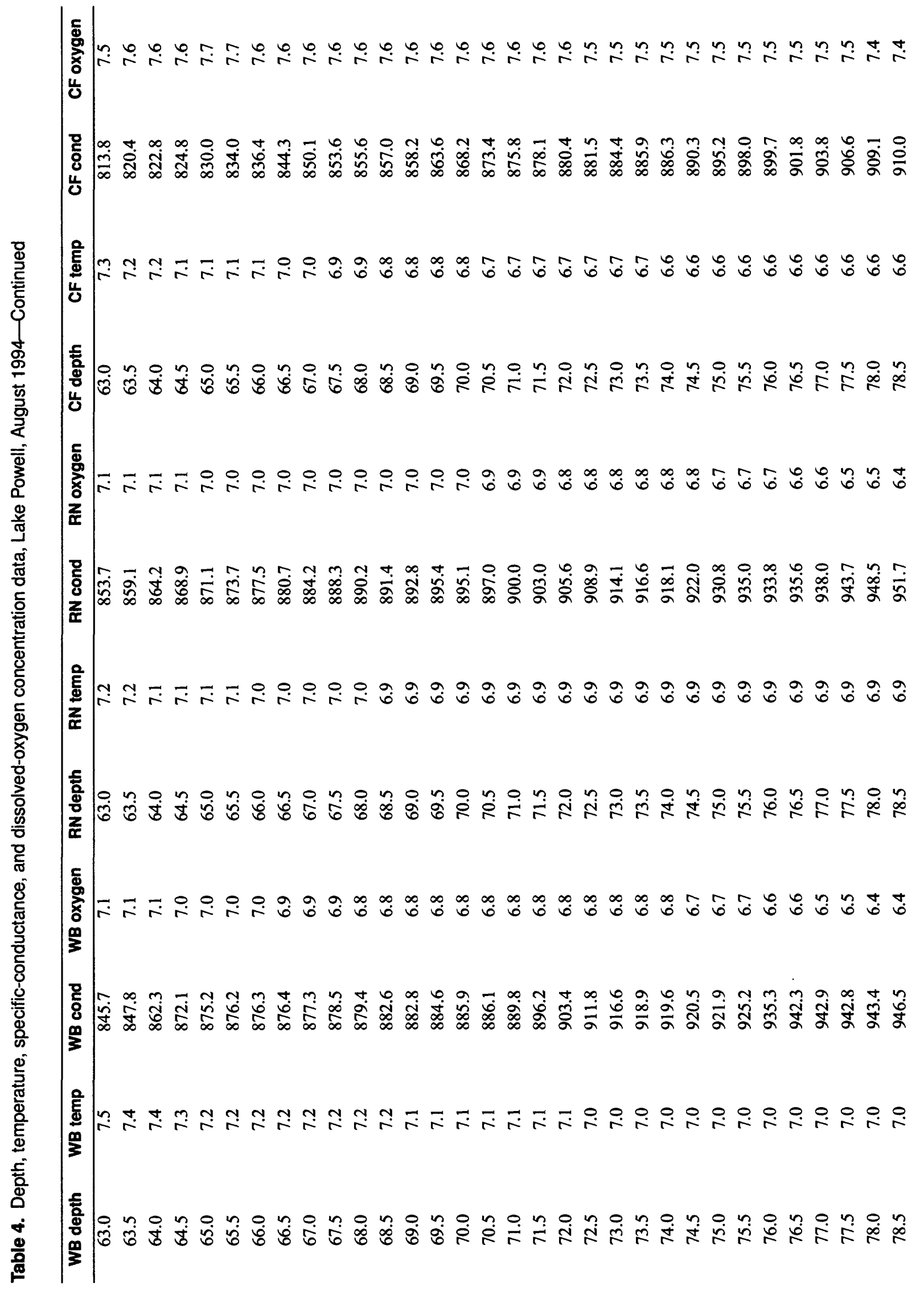

78 Depth Profiles of Temperature, Specific Conductance, and Oxygen Concentration In Lake Powell, Az-Utah, 1992-95 


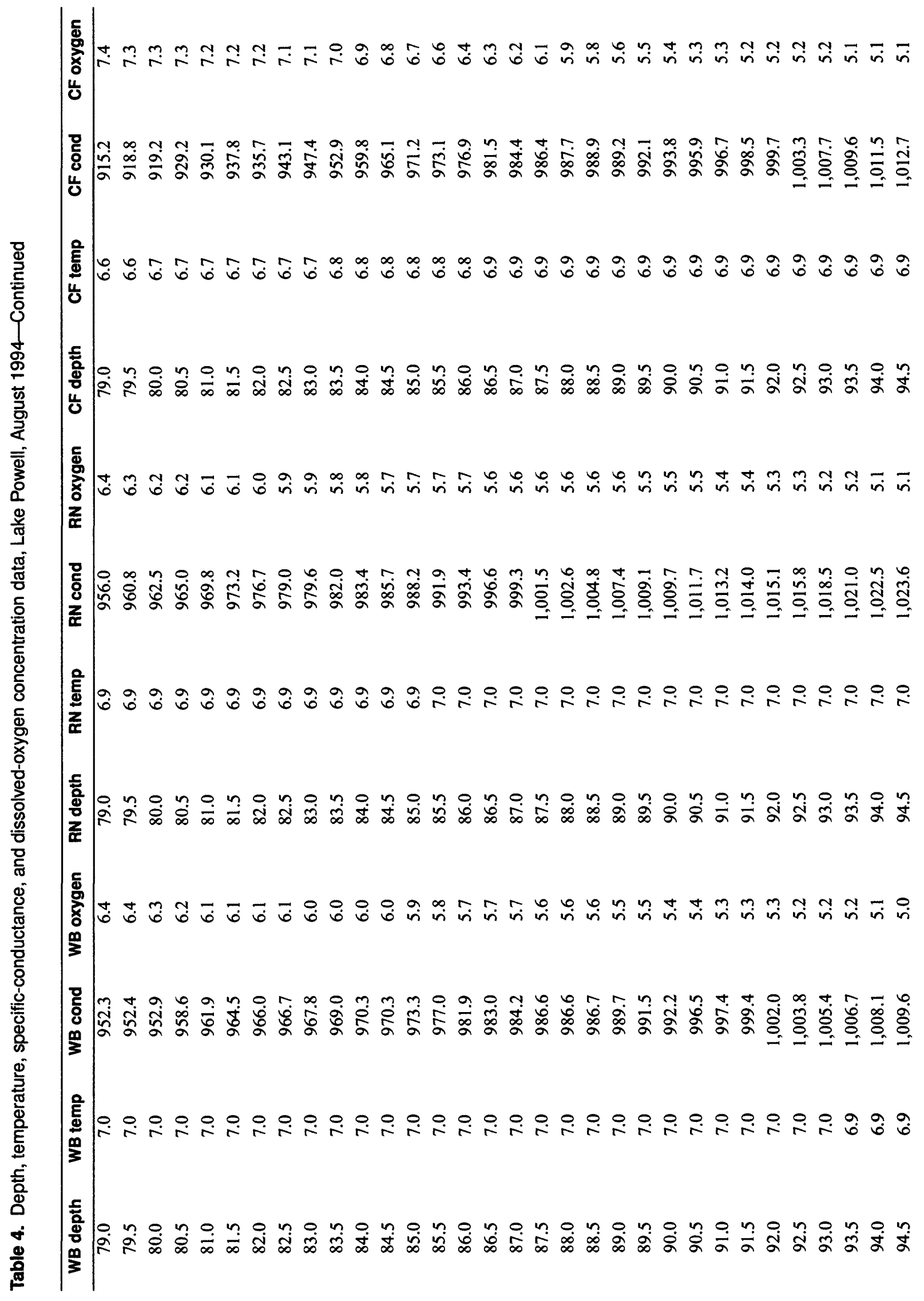




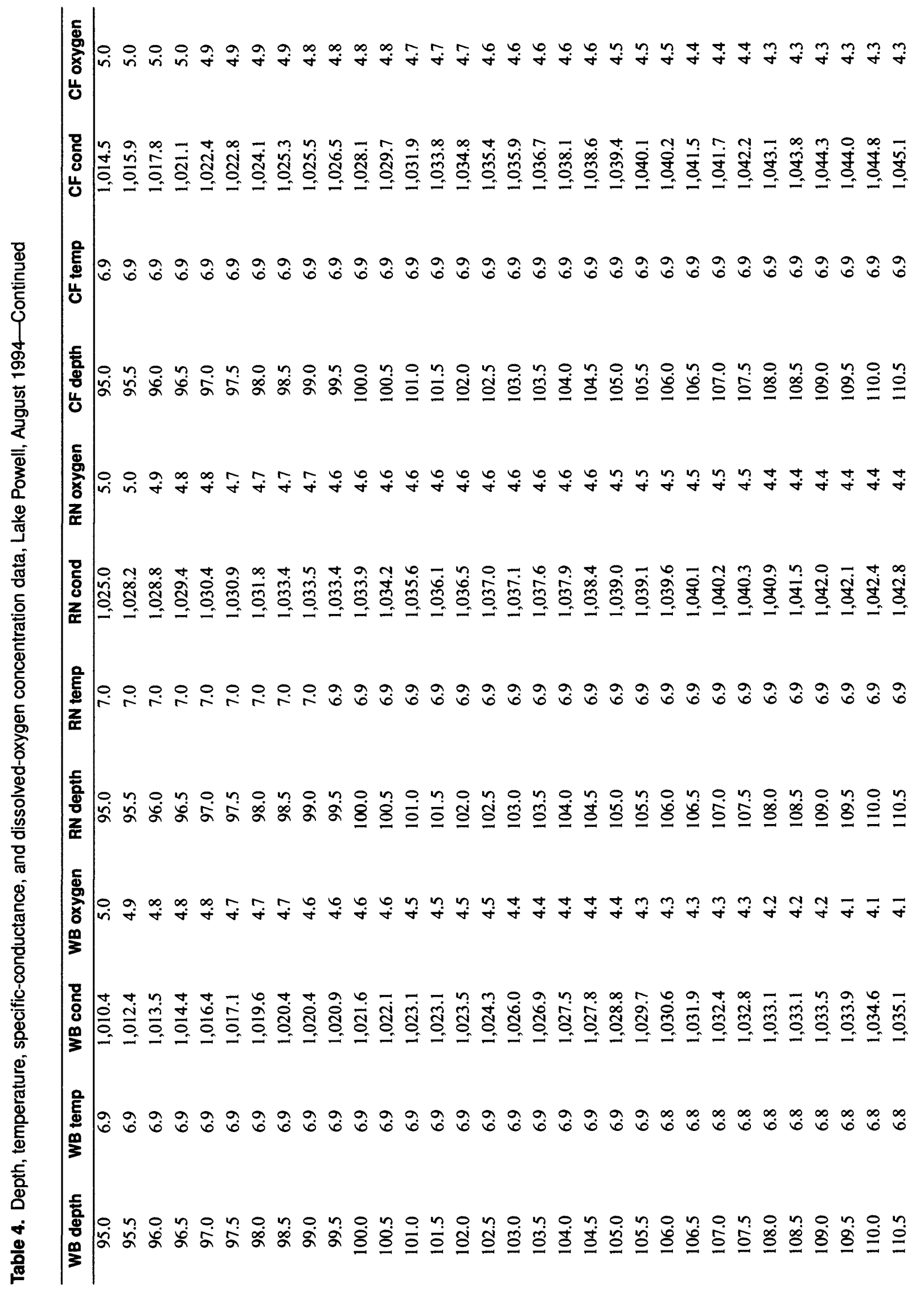

80 Depth Profiles of Temperature, Specific Conductance, and Oxygen Concentration in Lake Powell, Az-Utah, 1992-95 


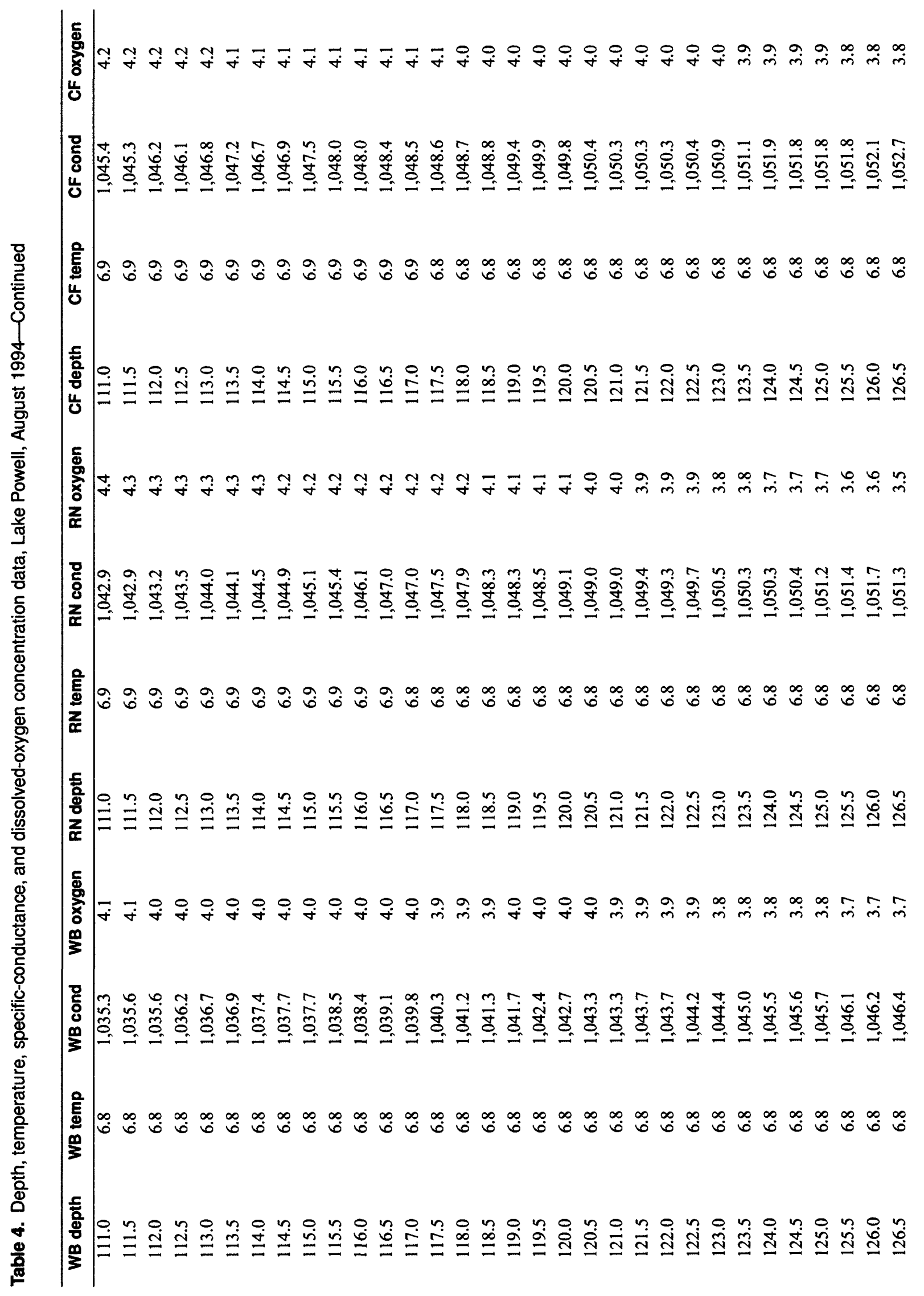




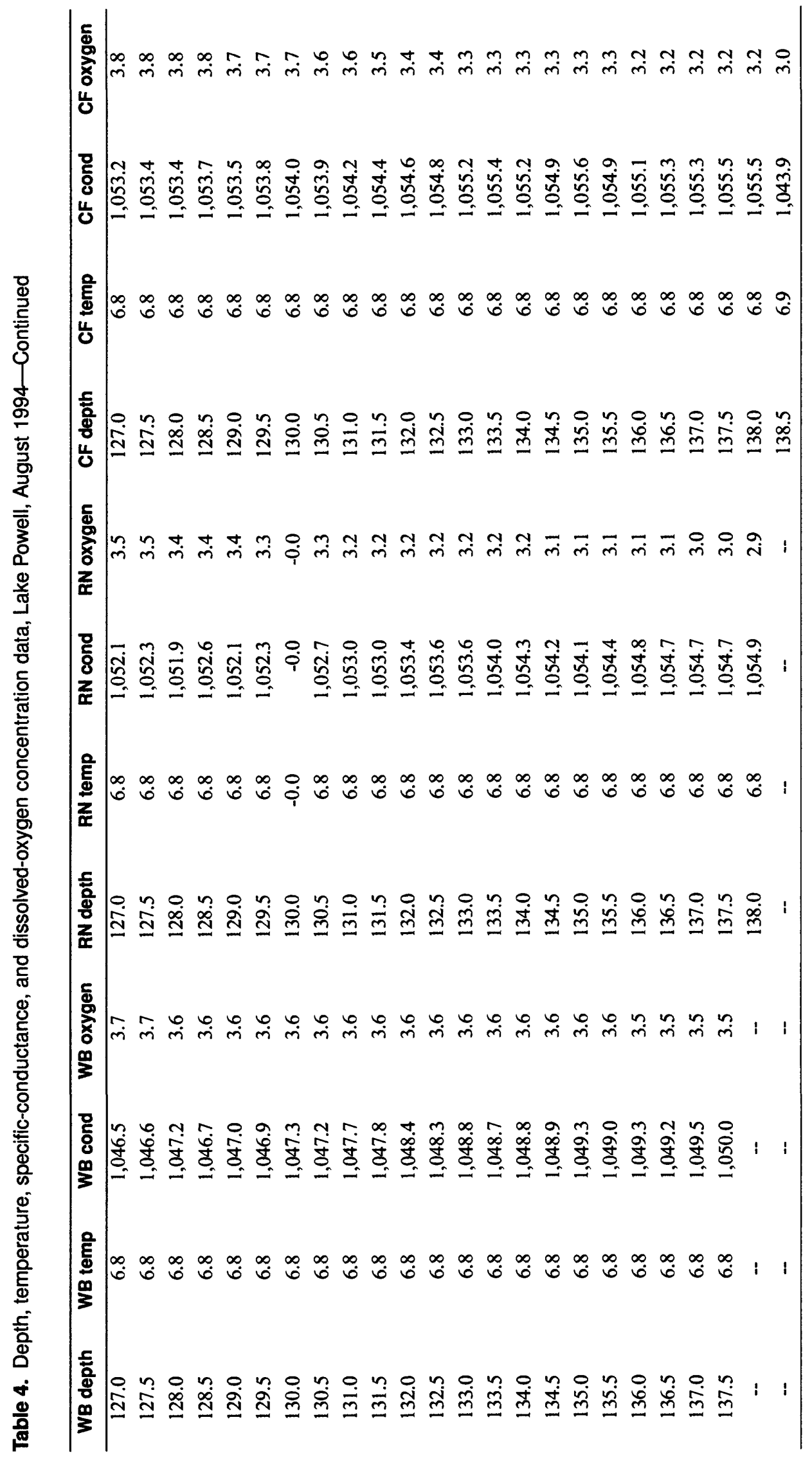




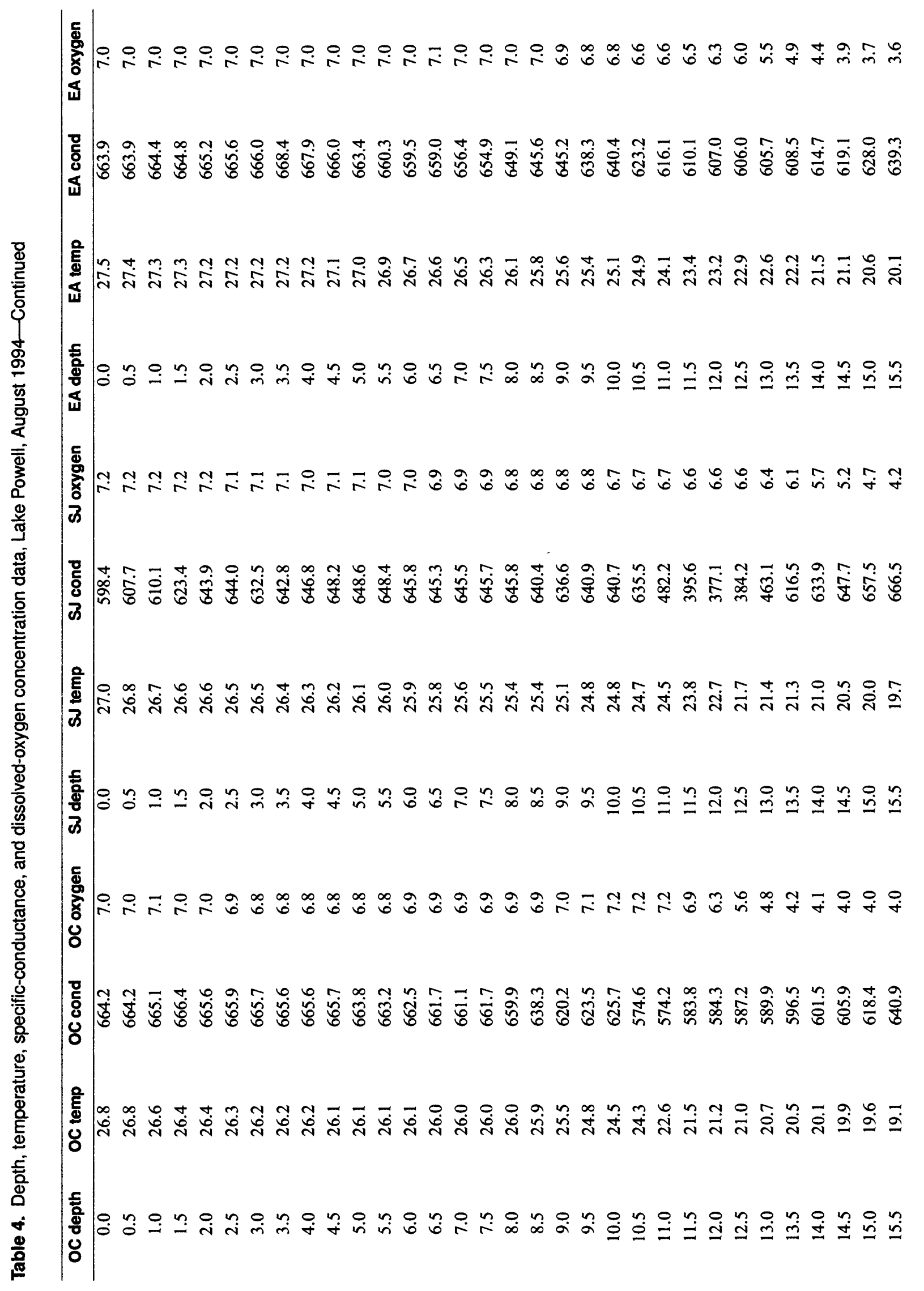




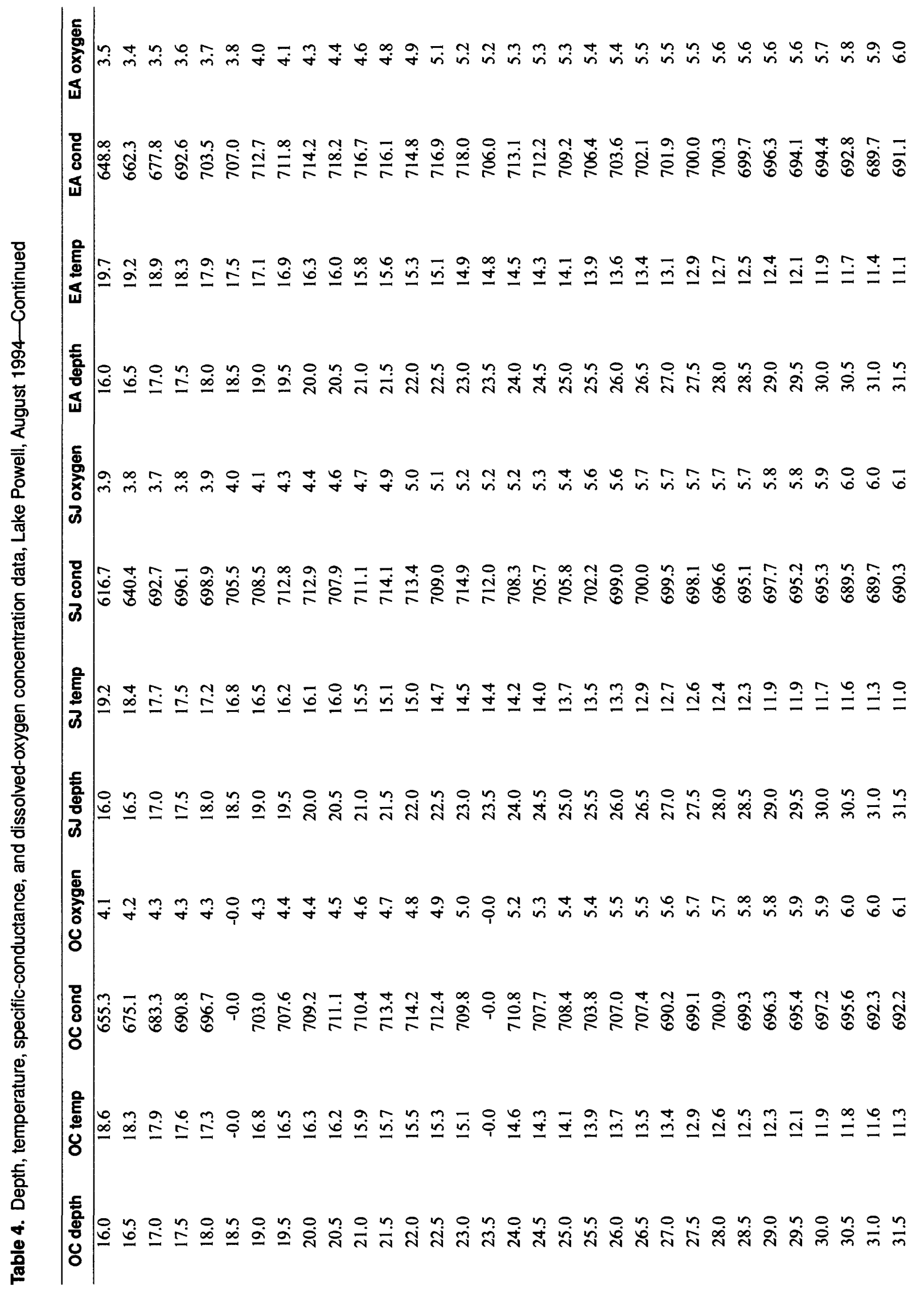

84 Depth Proflles of Temperature, Specific Conductance, and Oxygen Concentration In Lake Powell, Az-Utah, 1992-95 


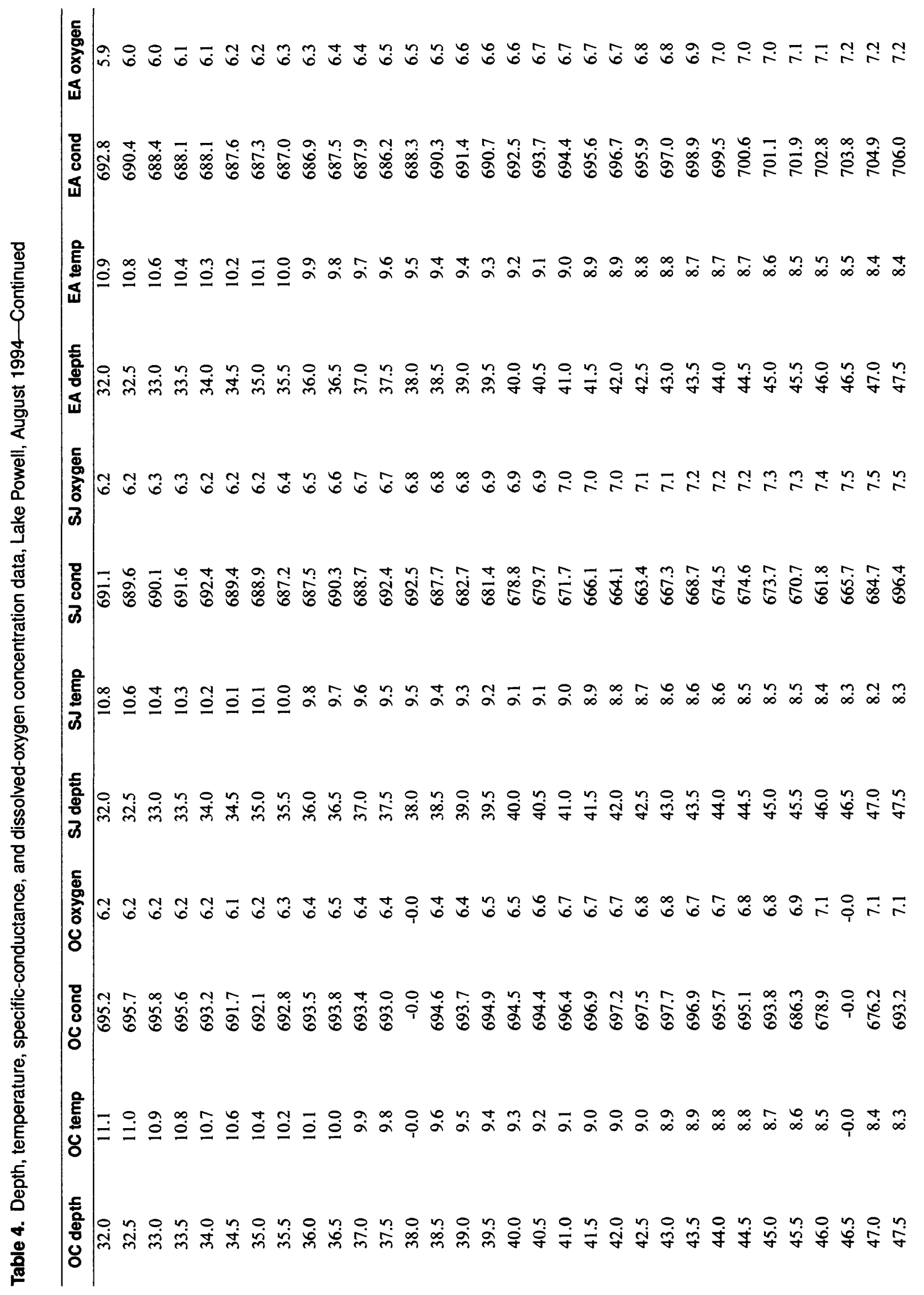




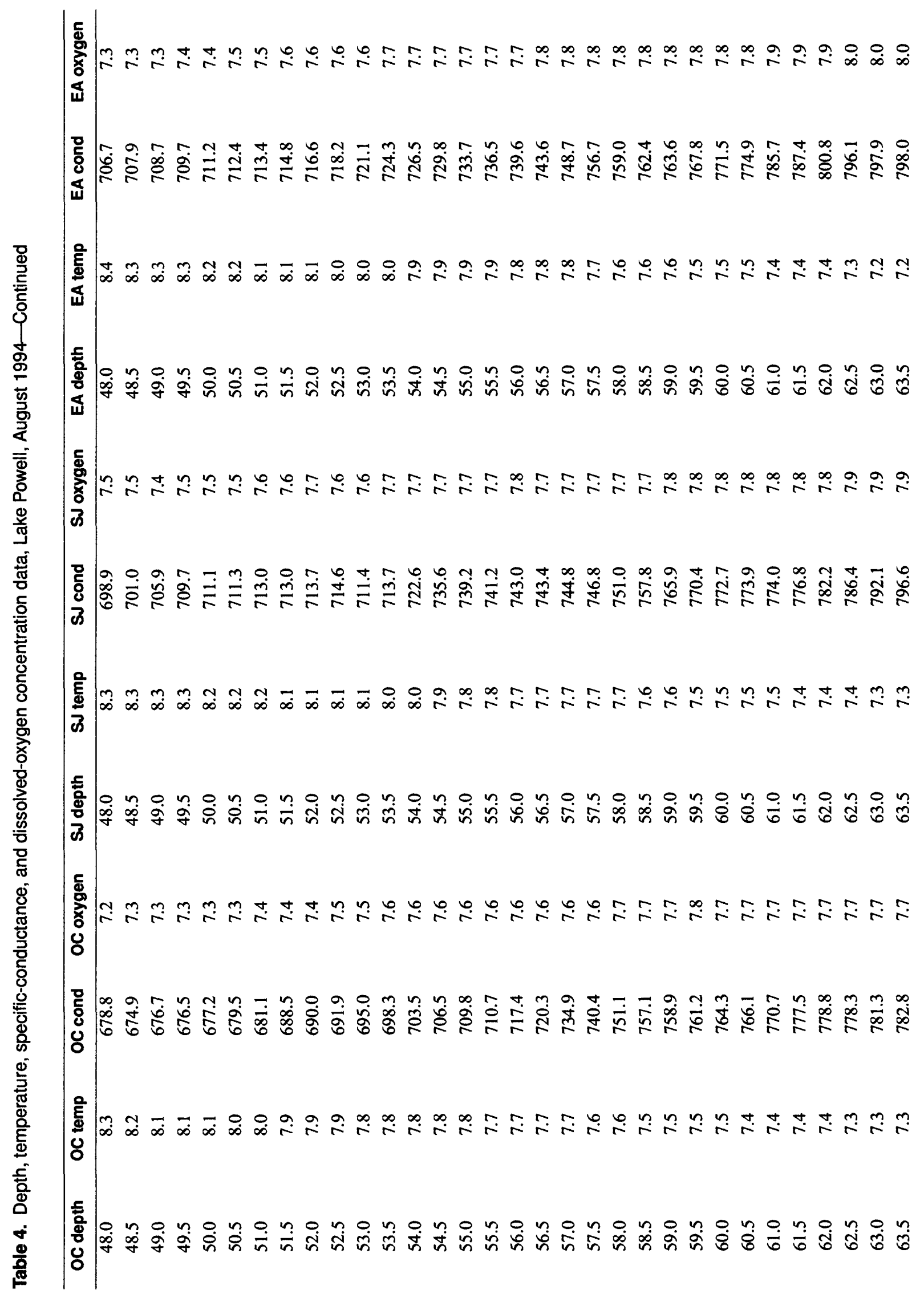




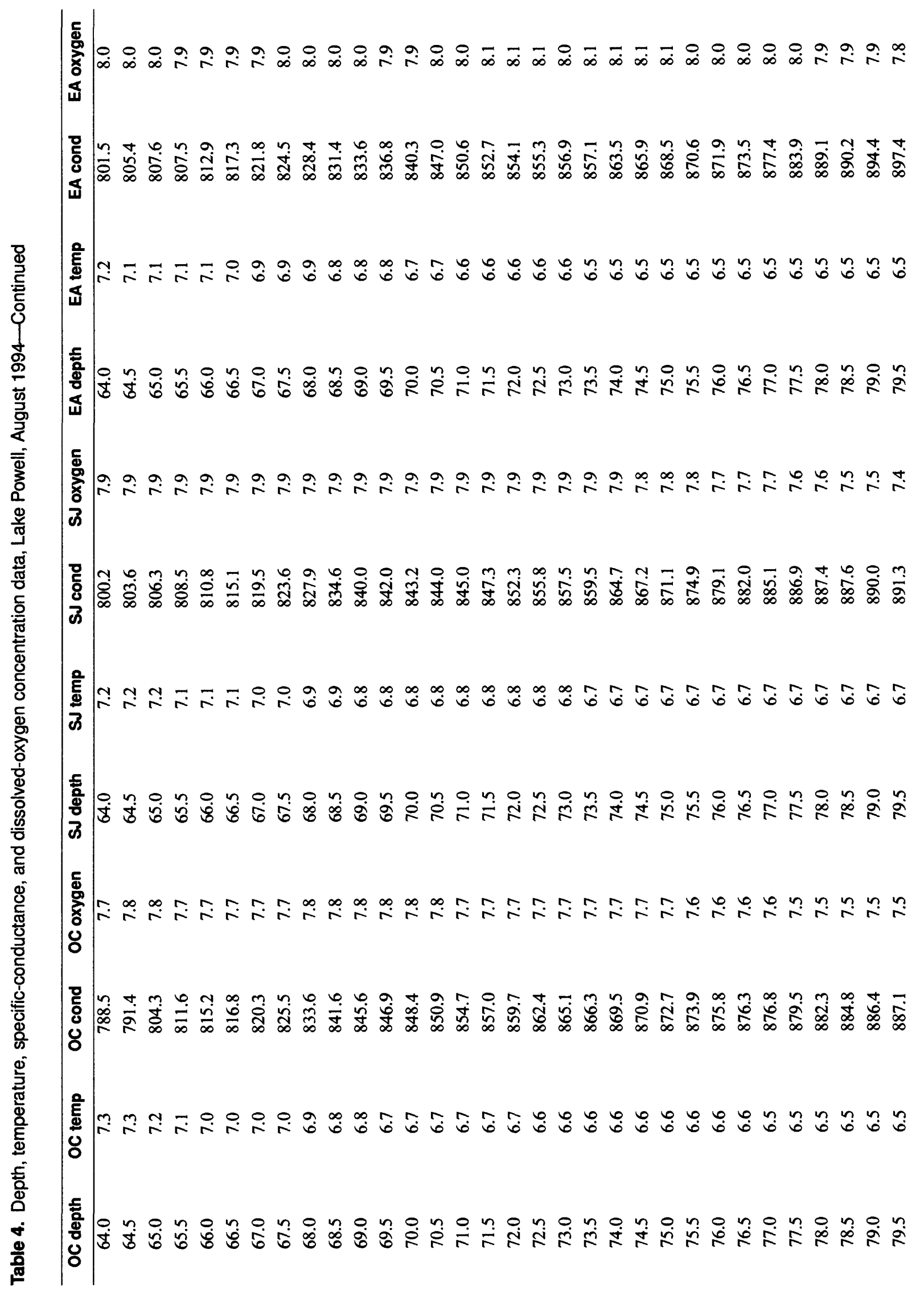




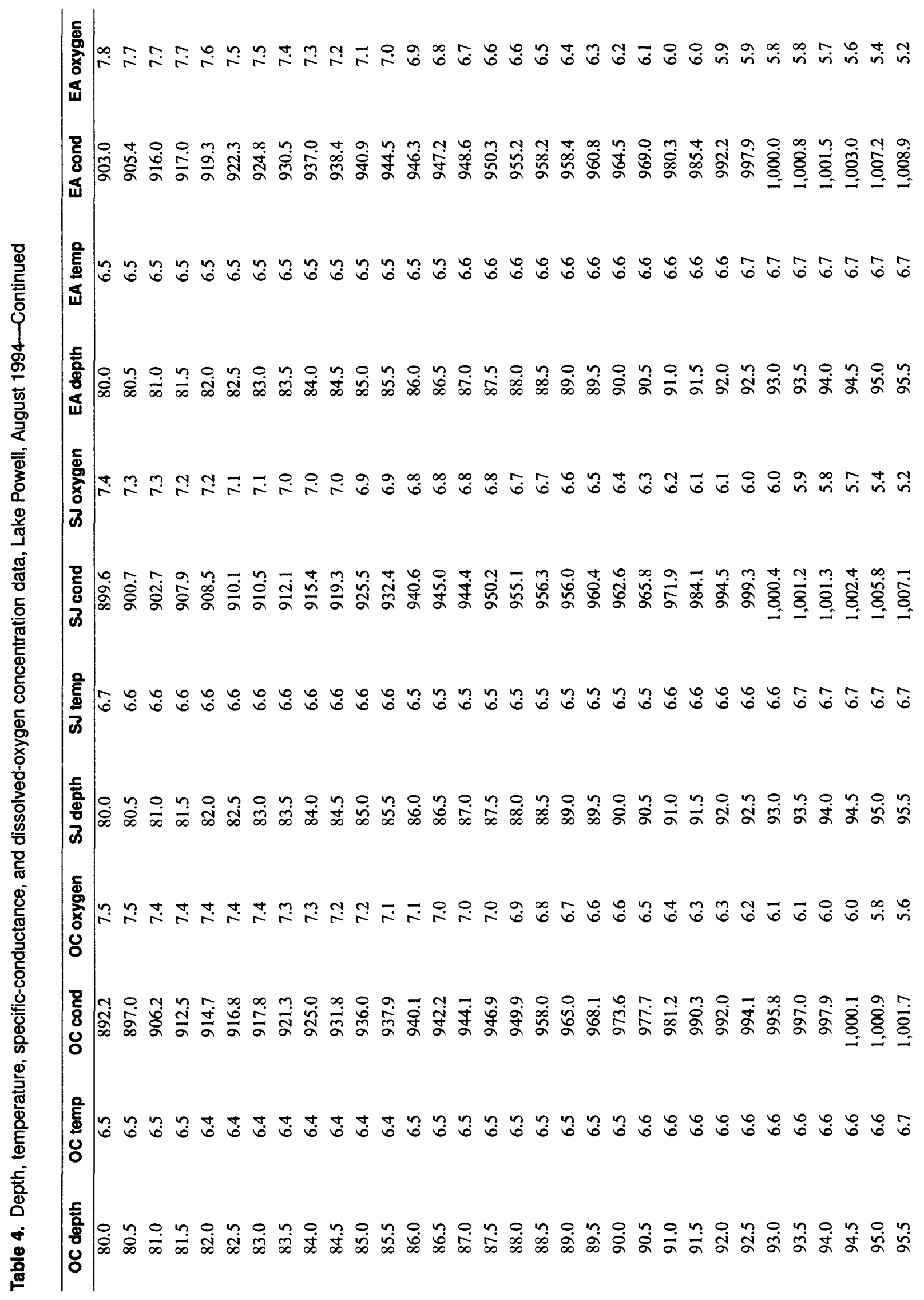




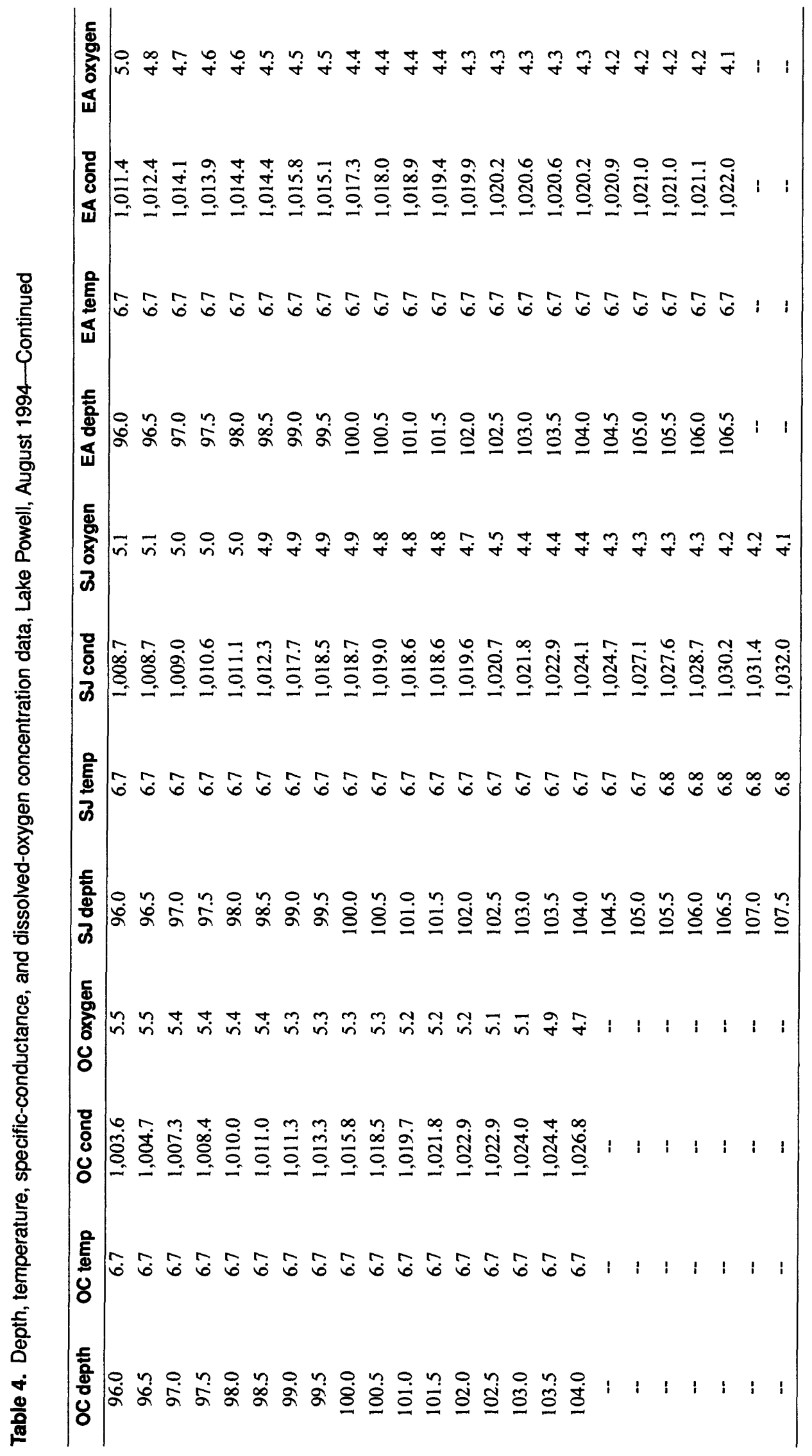




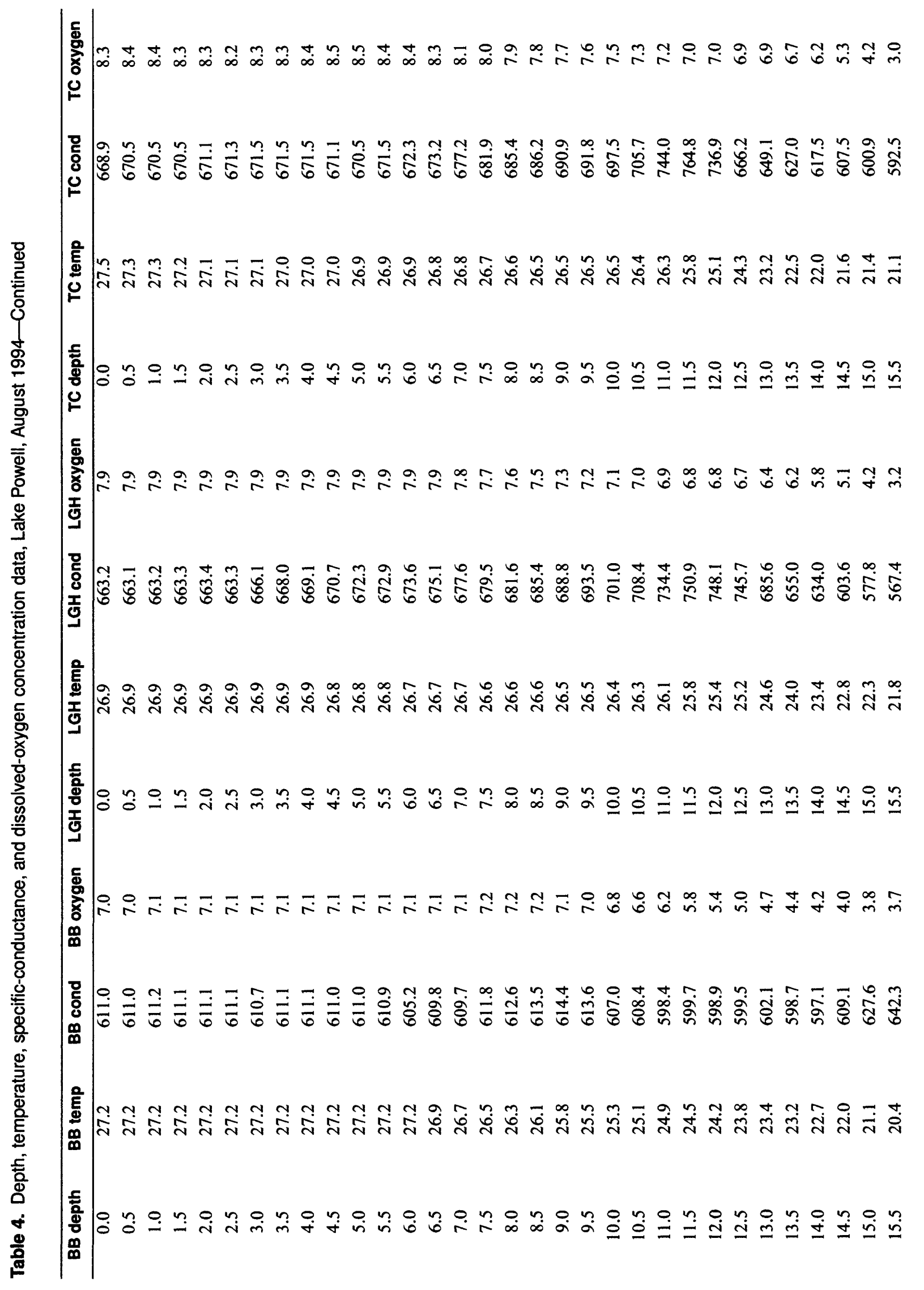




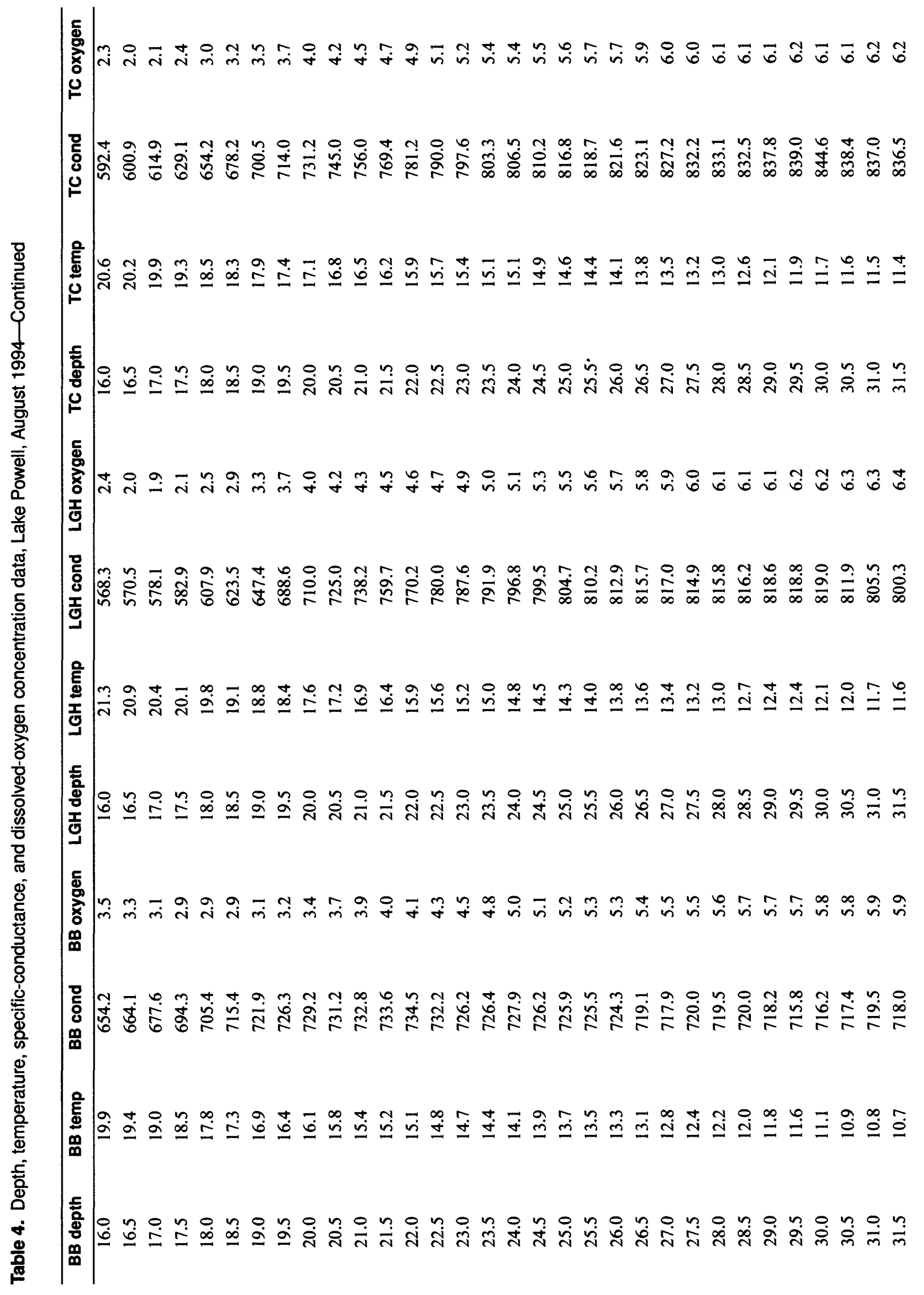




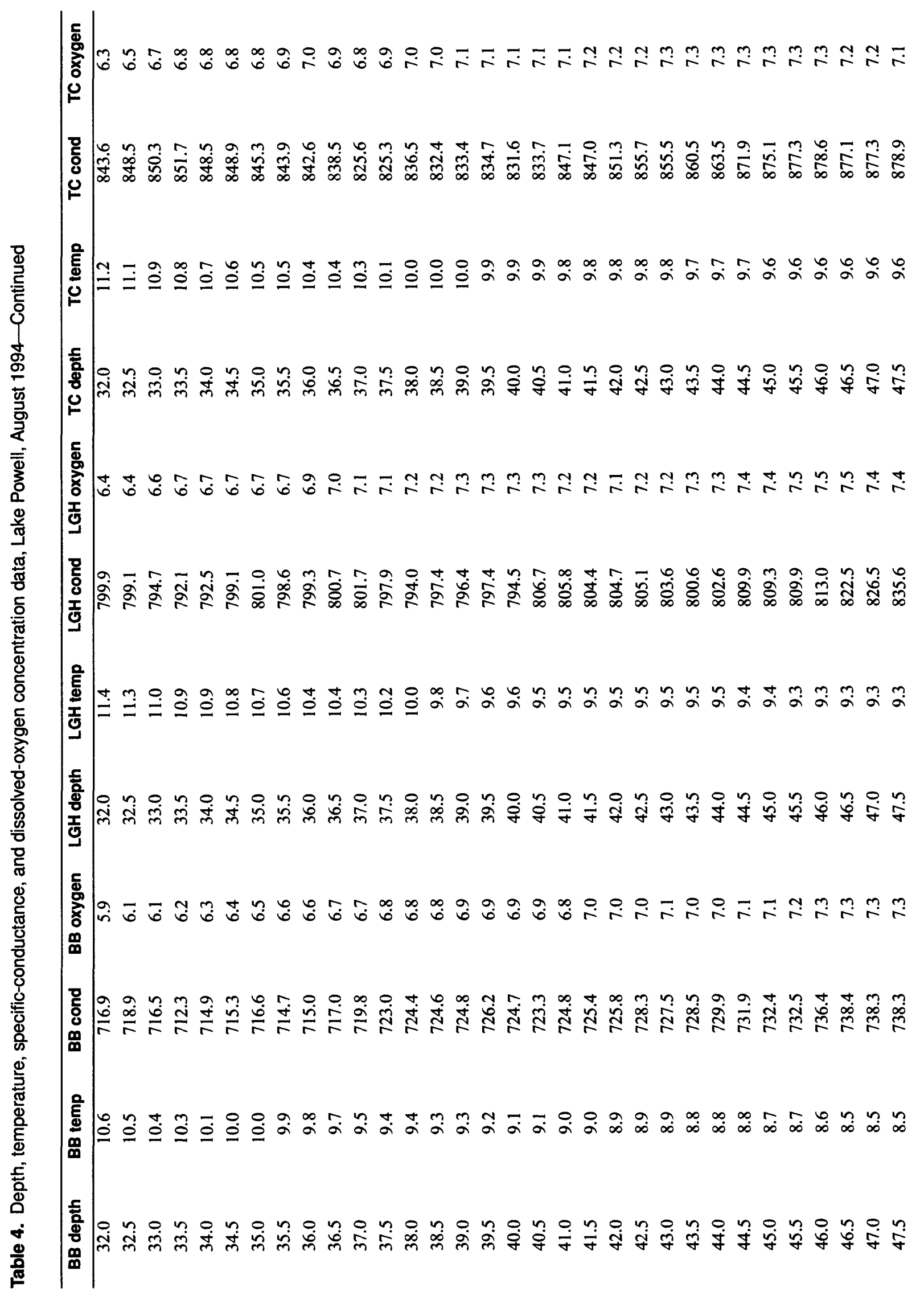




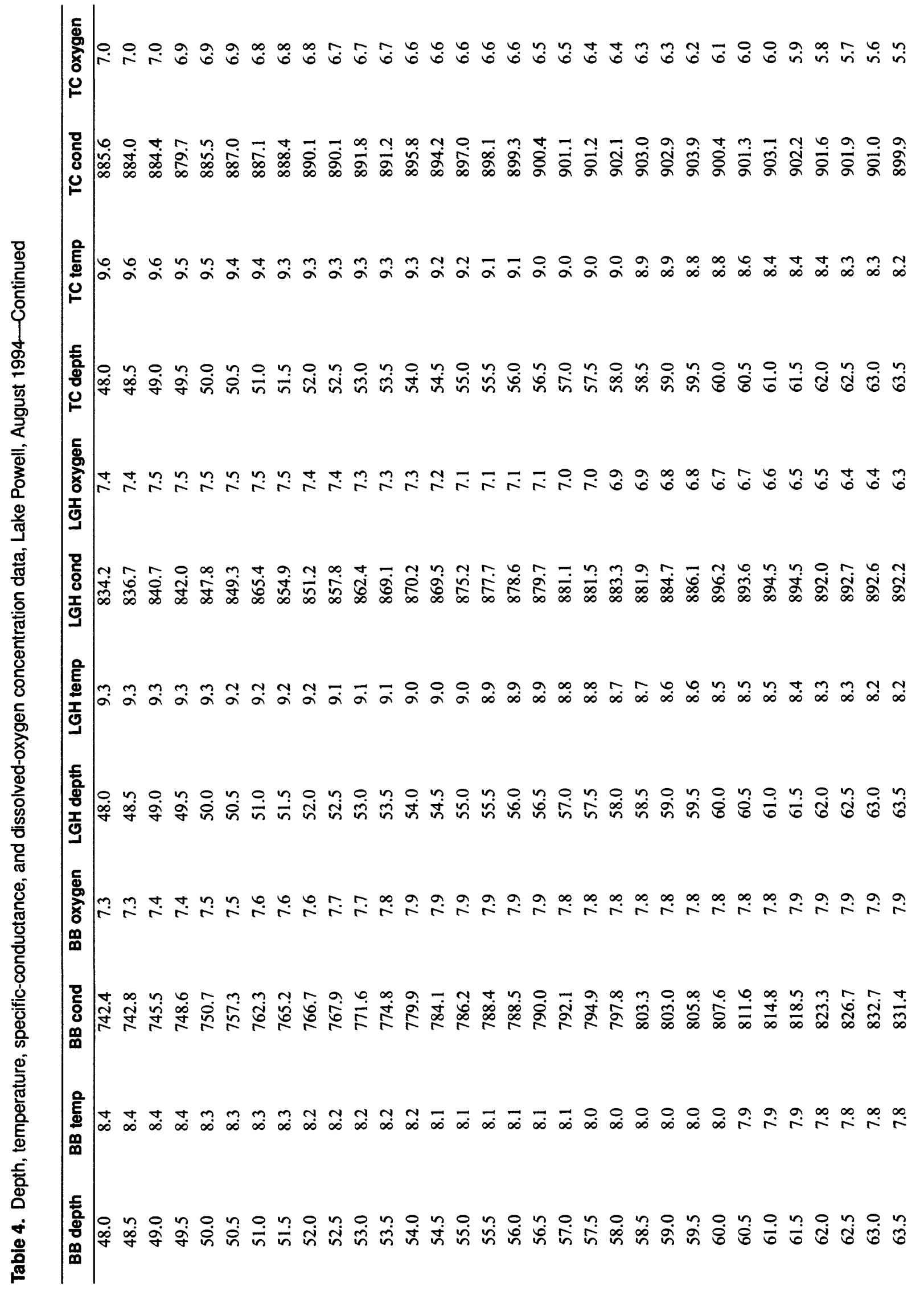




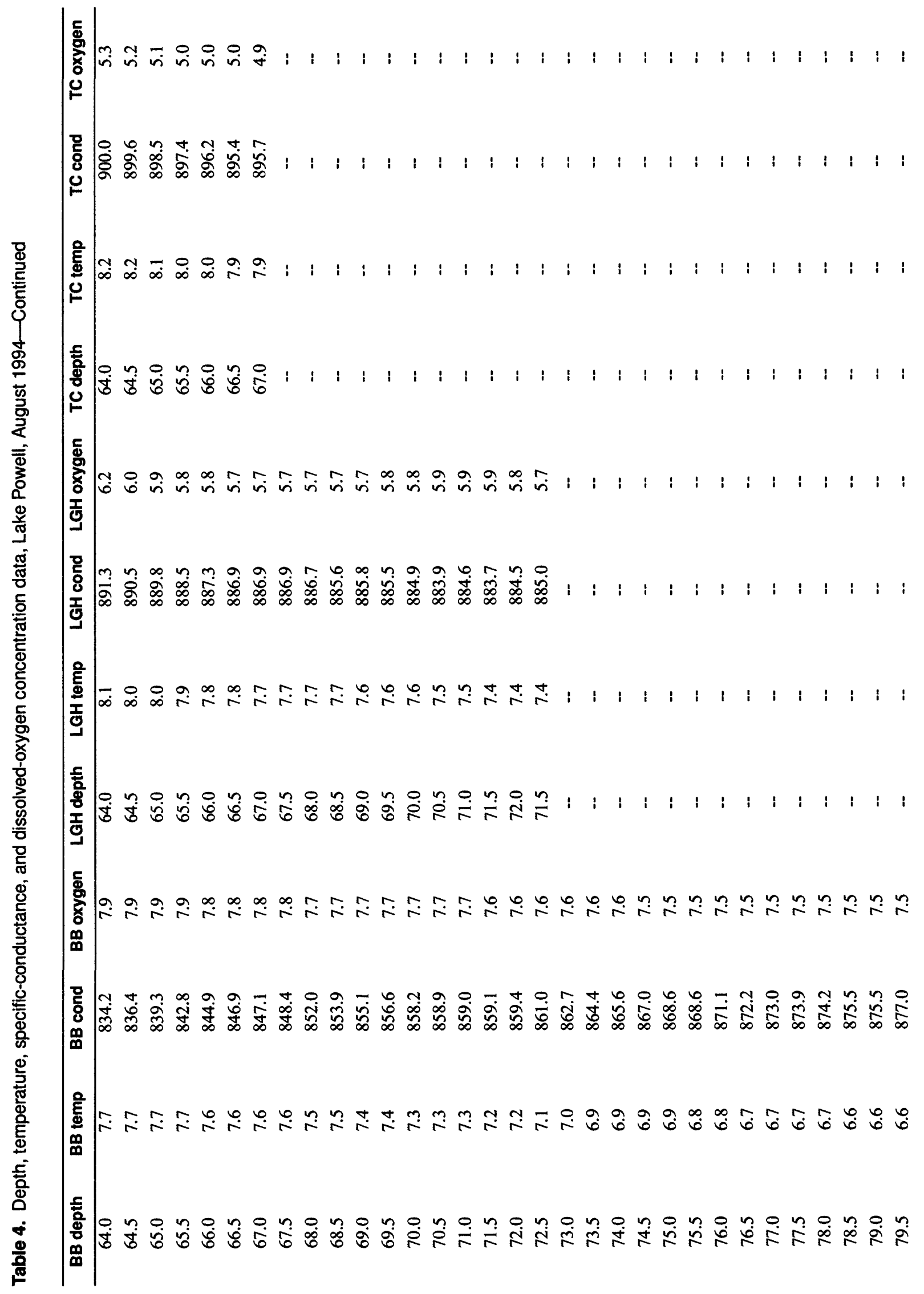




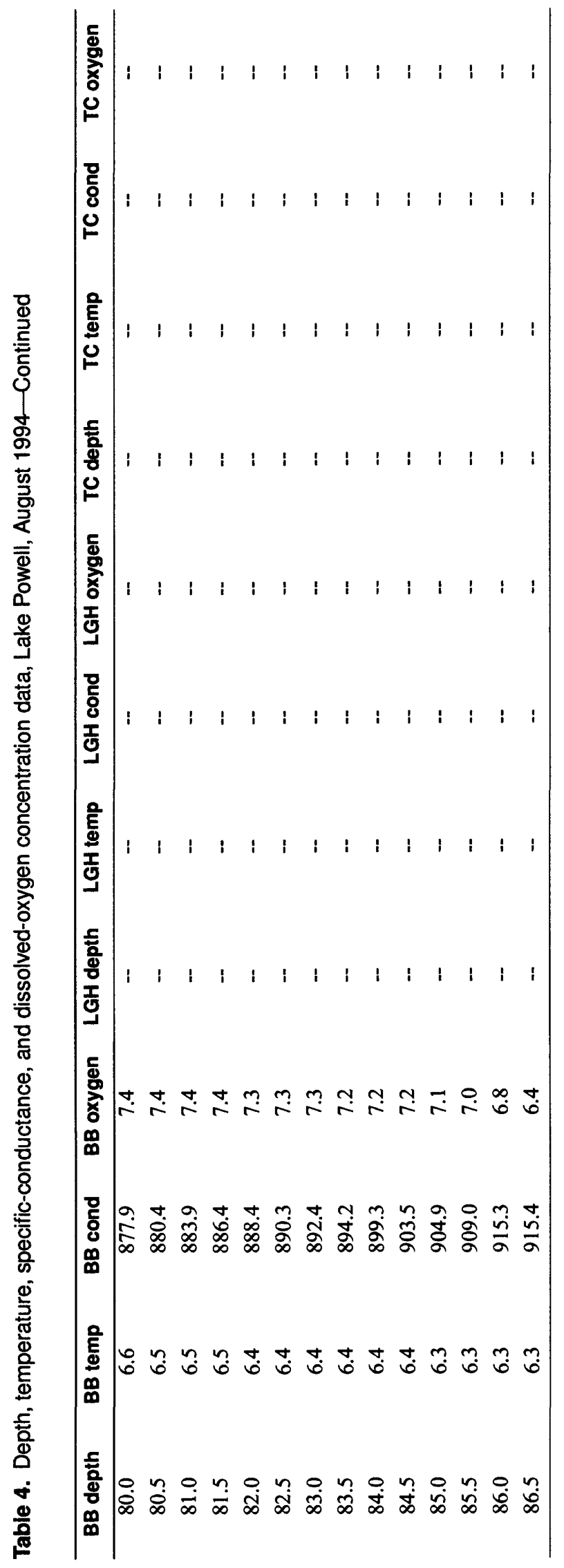




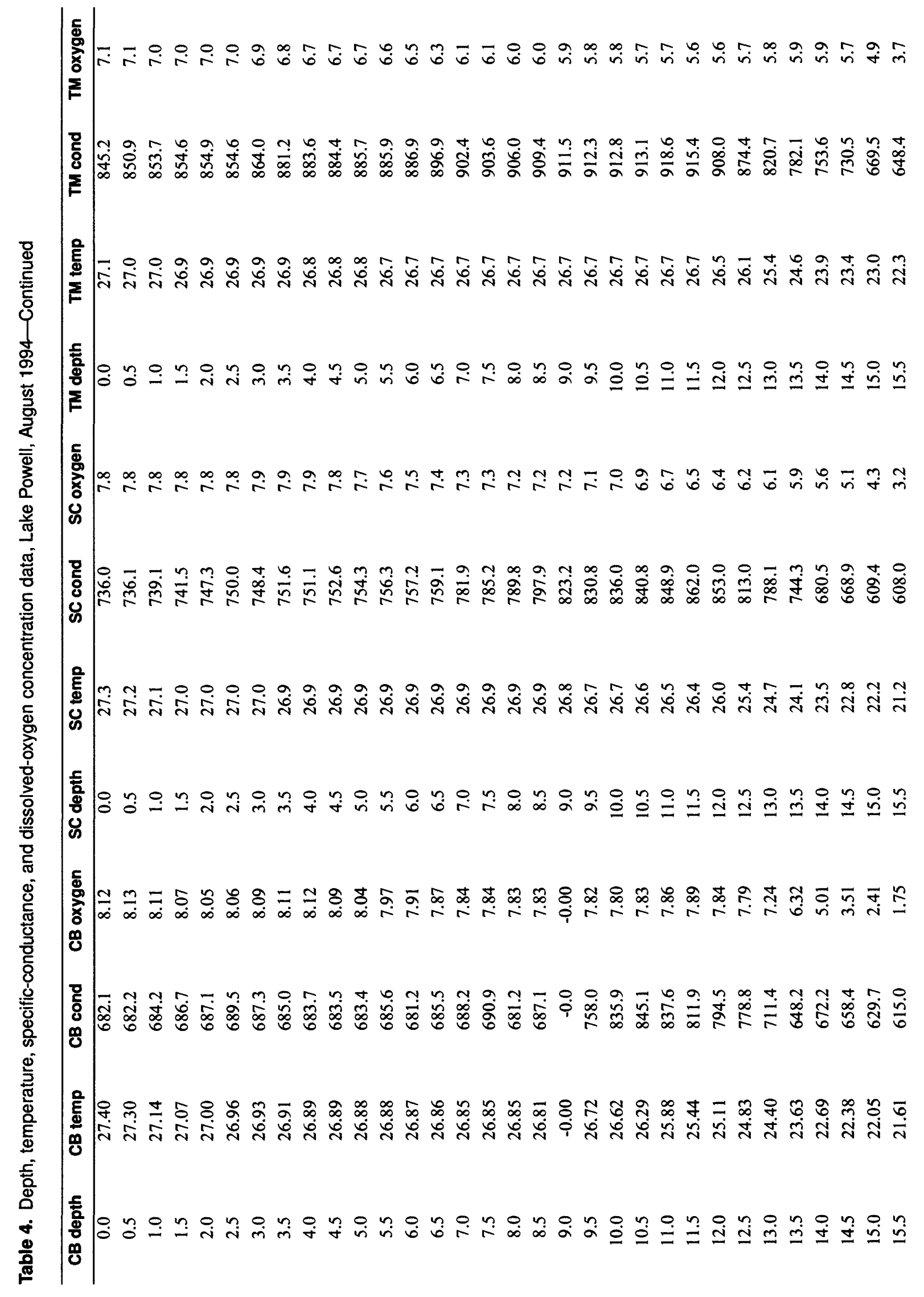




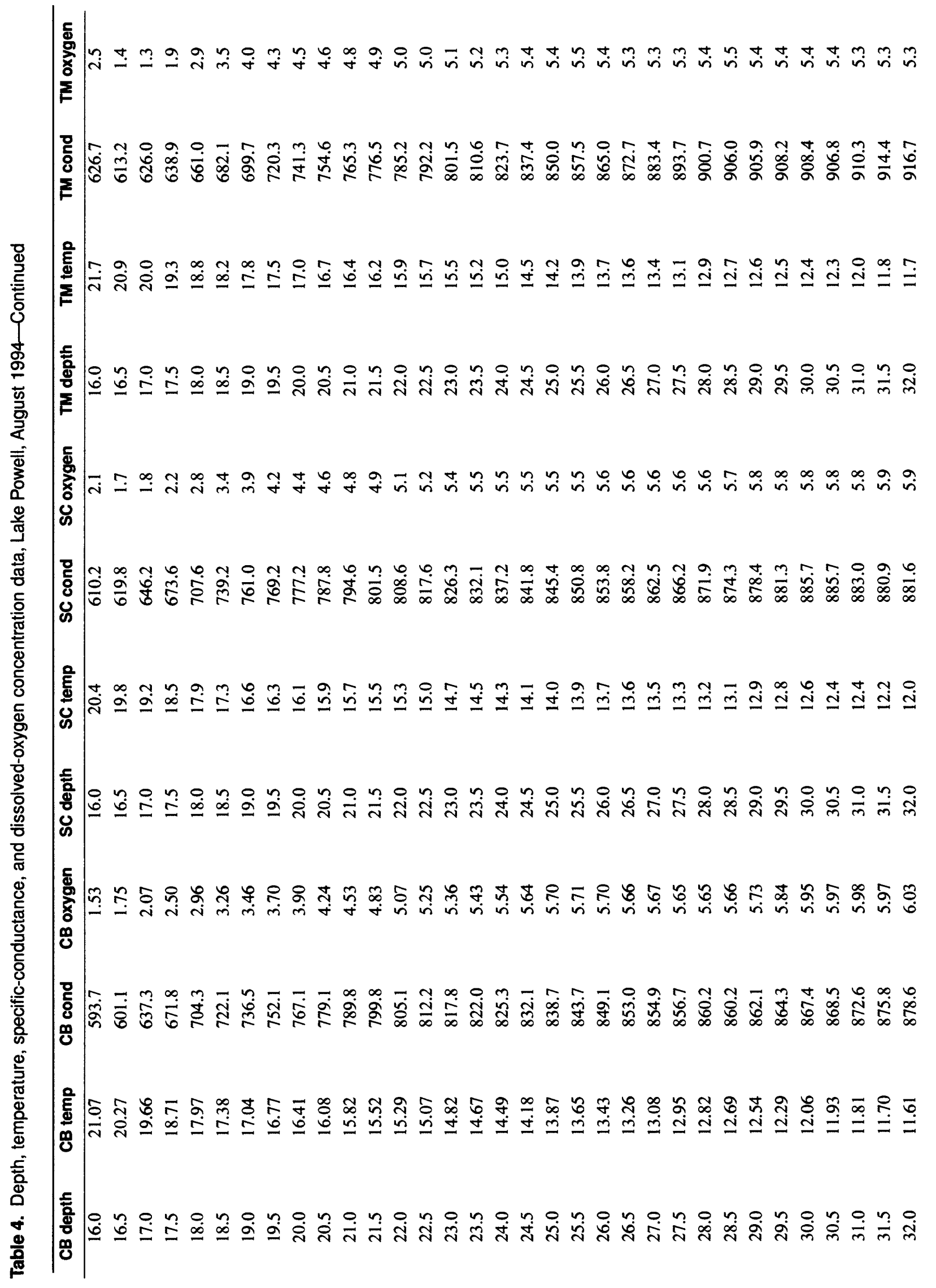




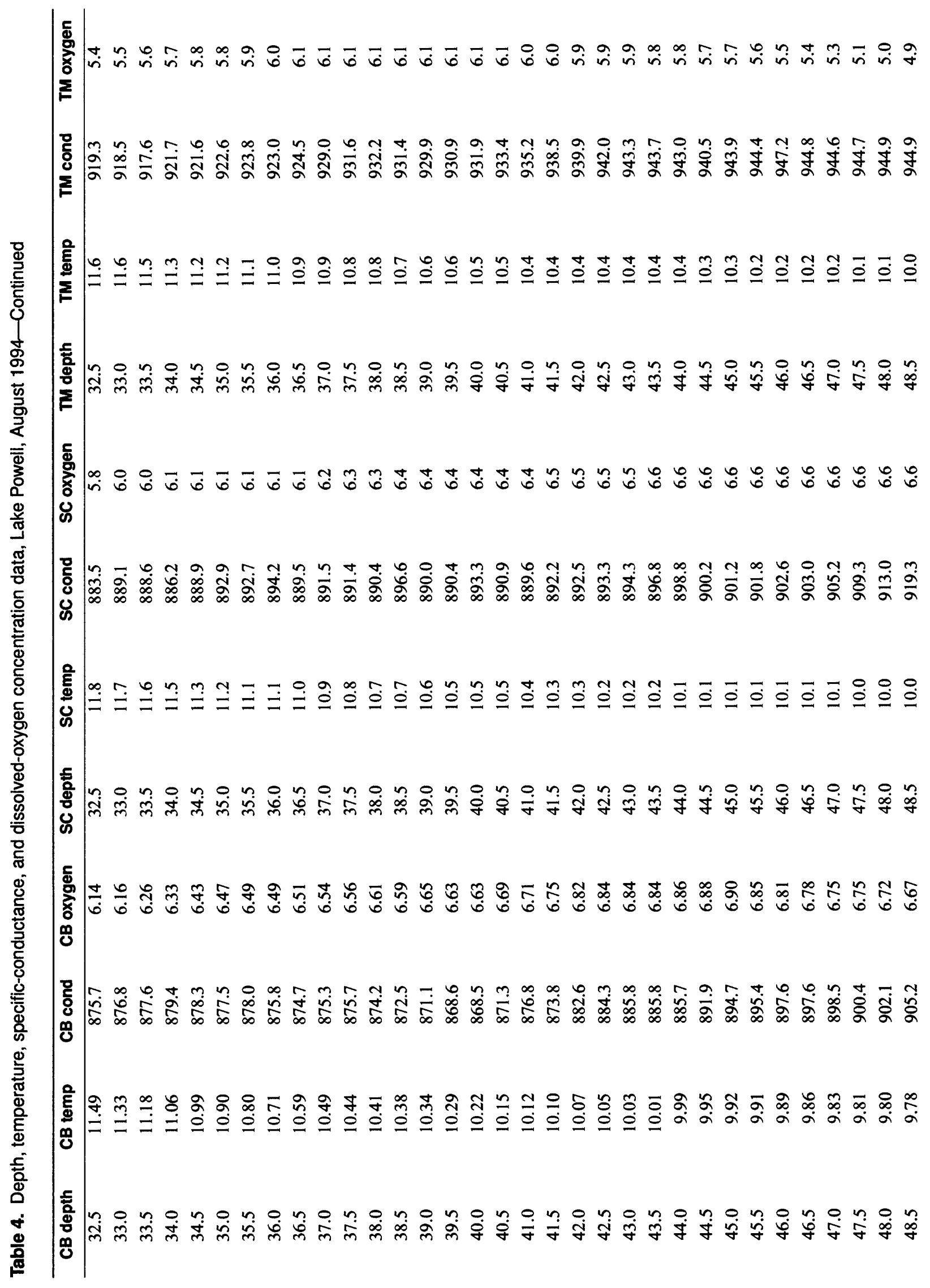




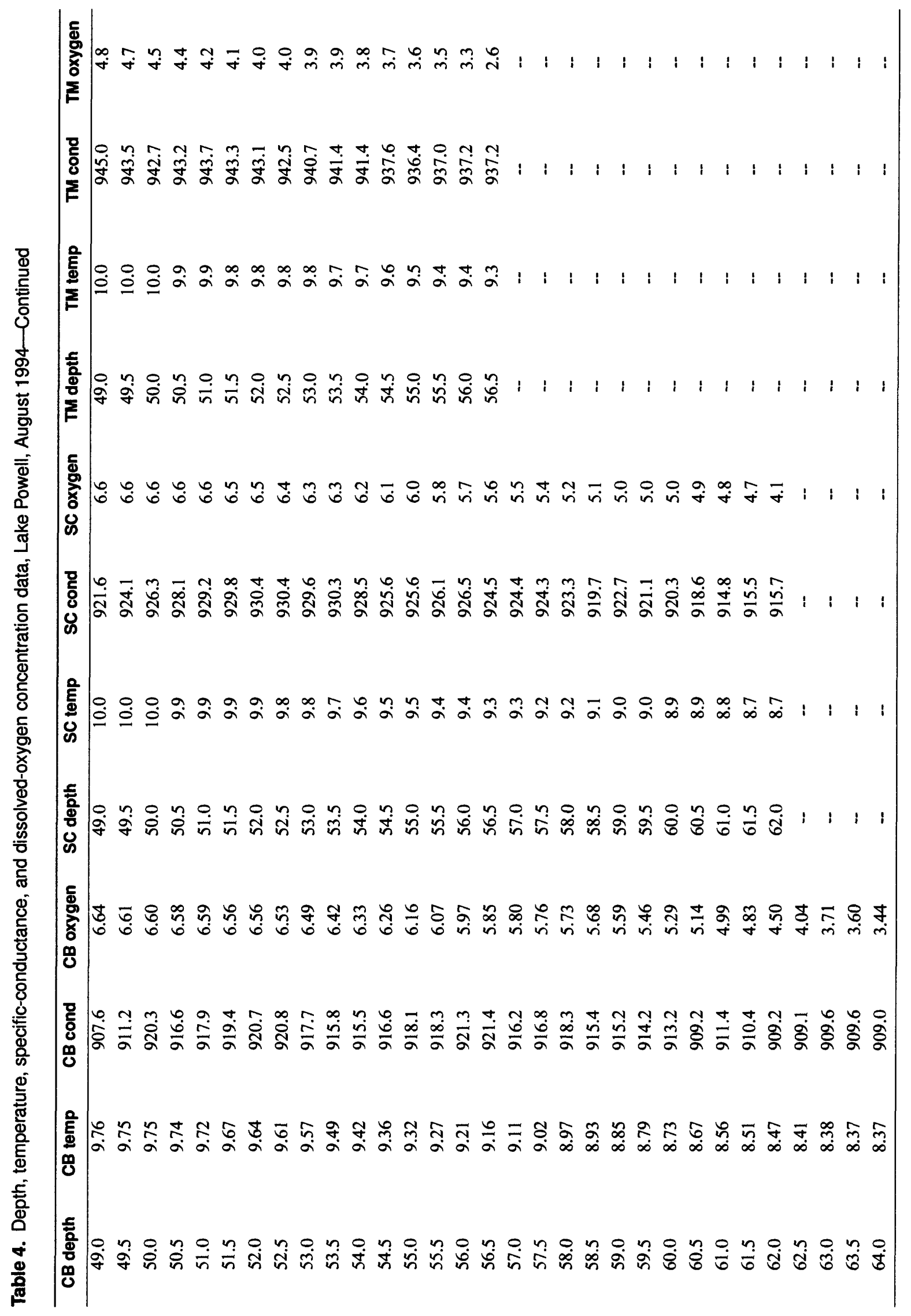




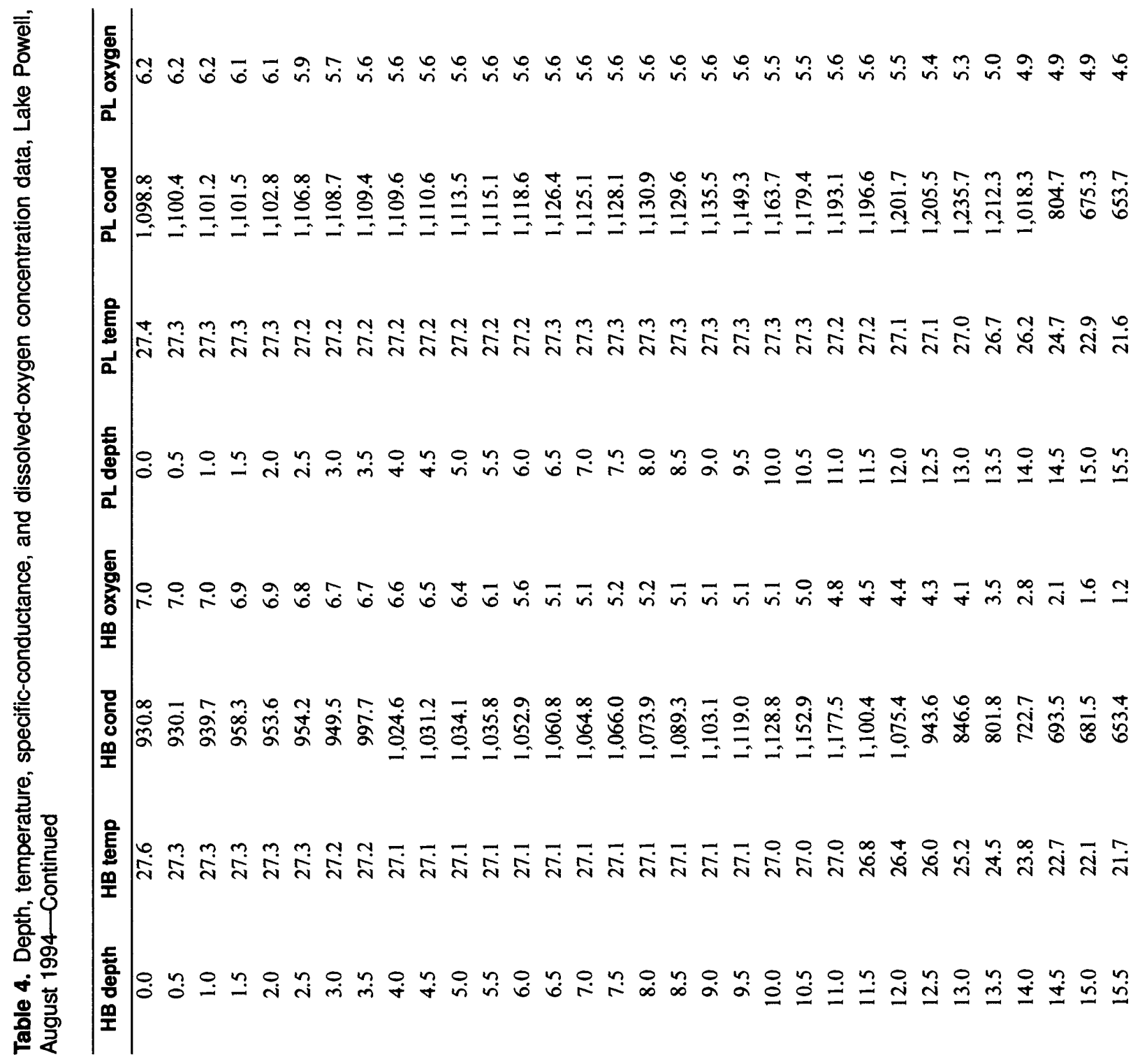




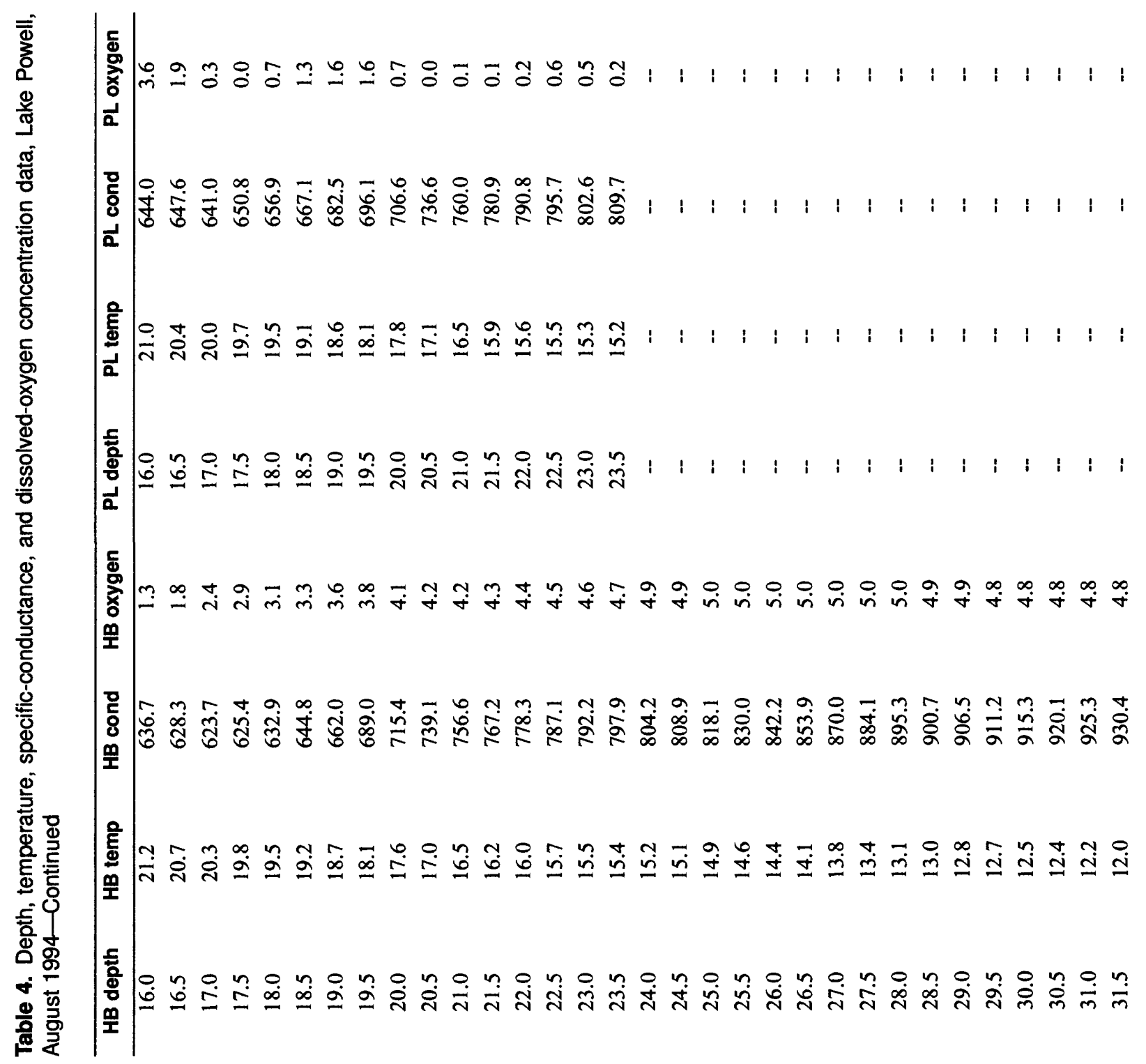




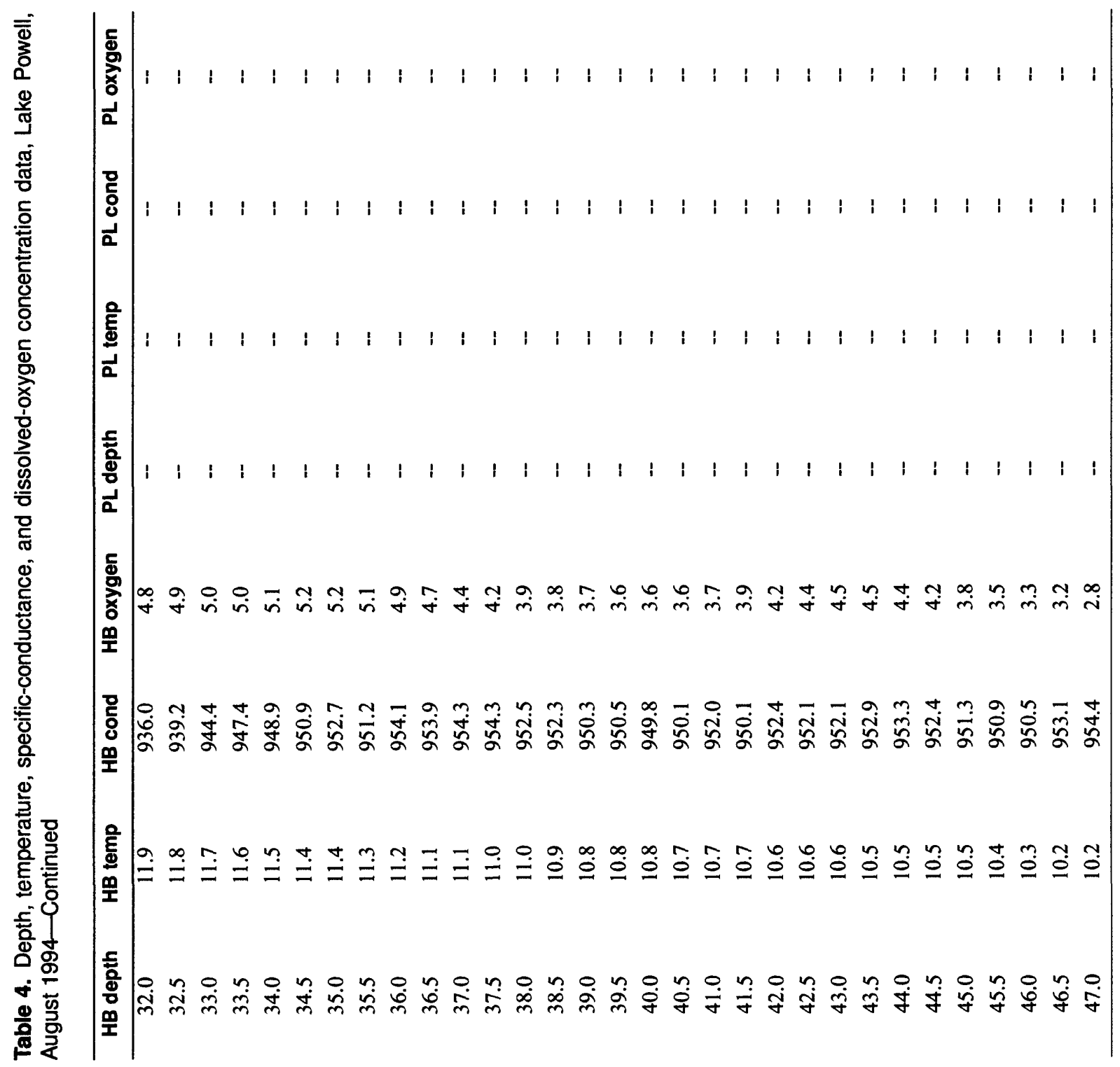




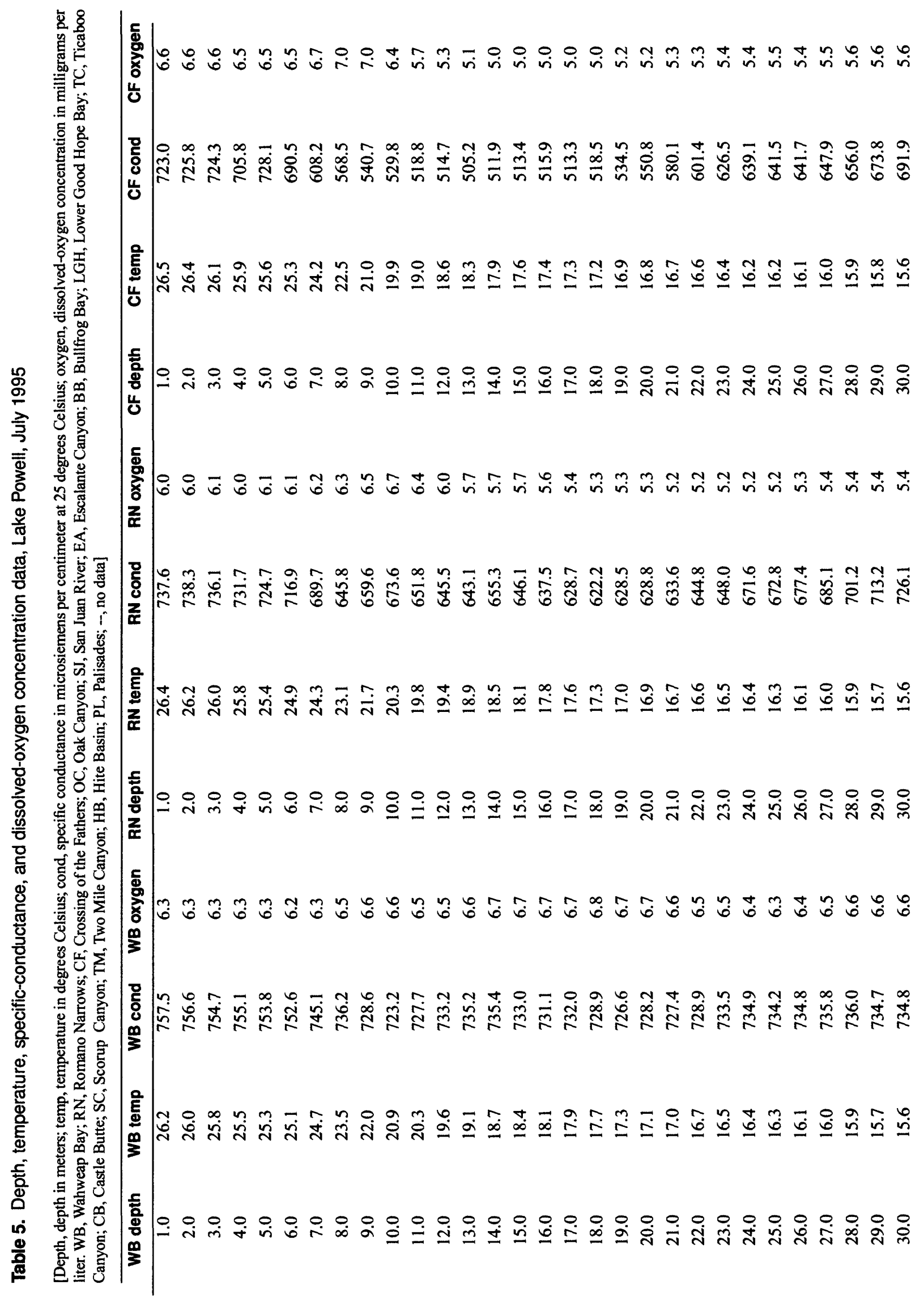




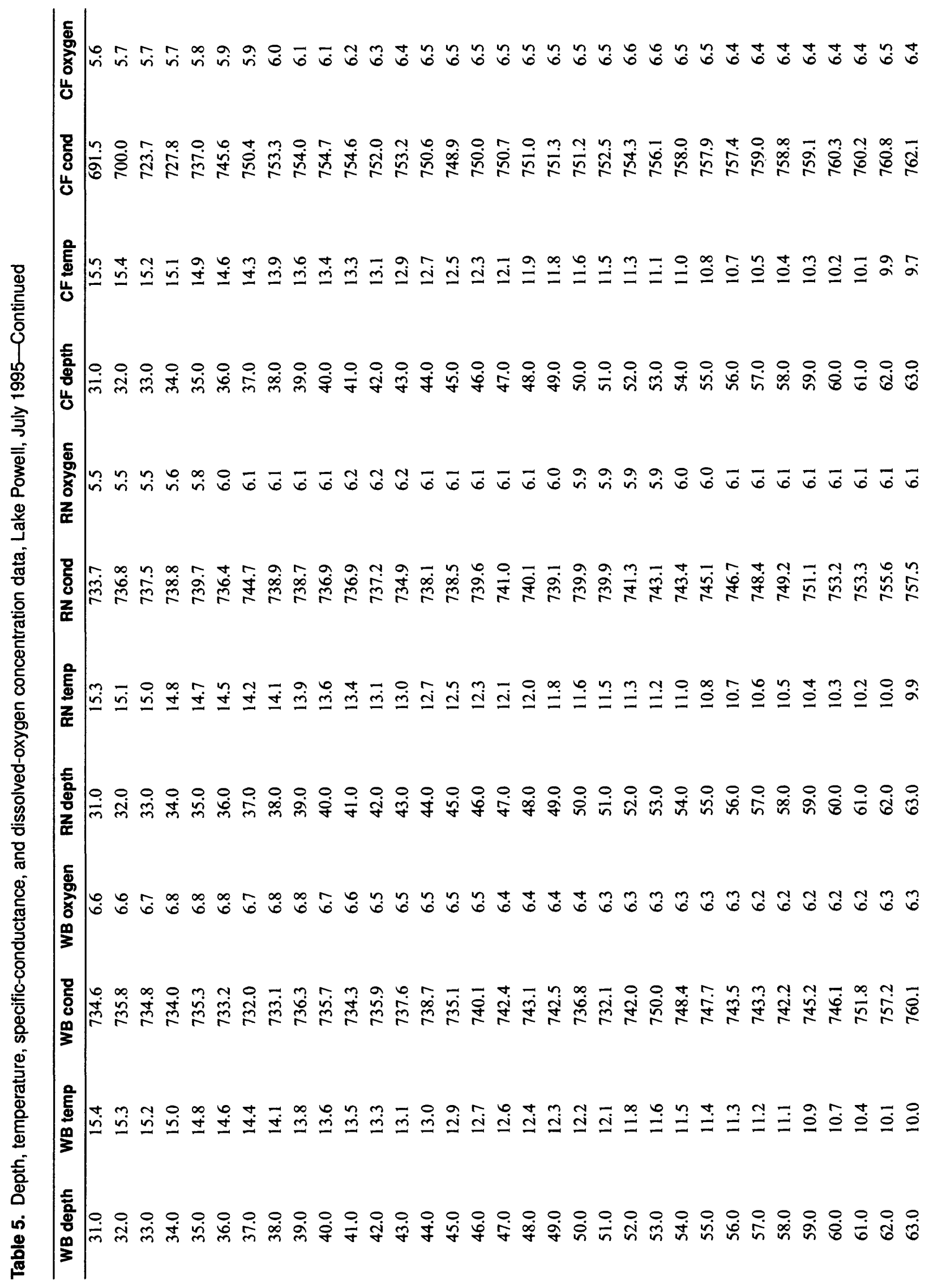




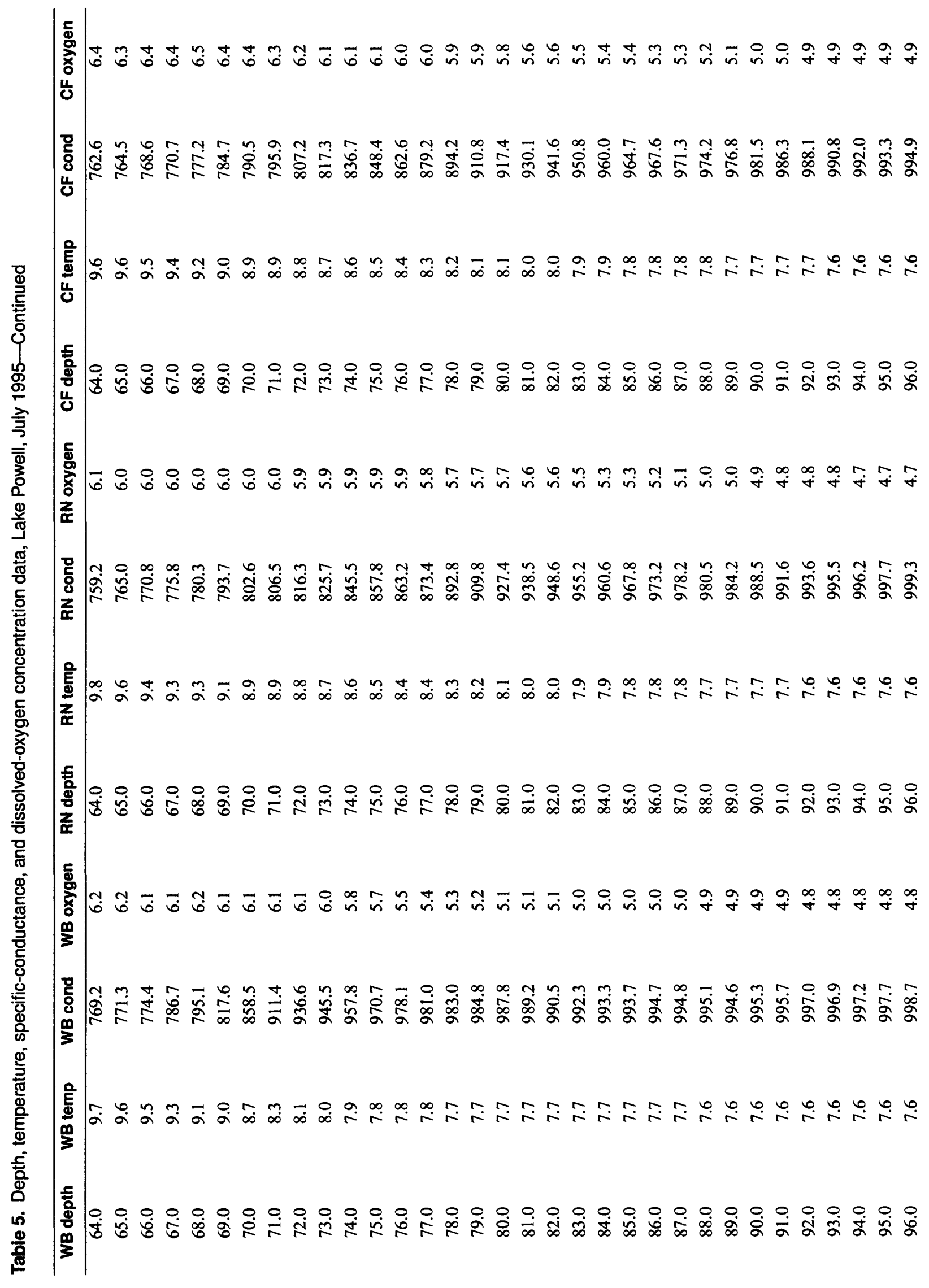




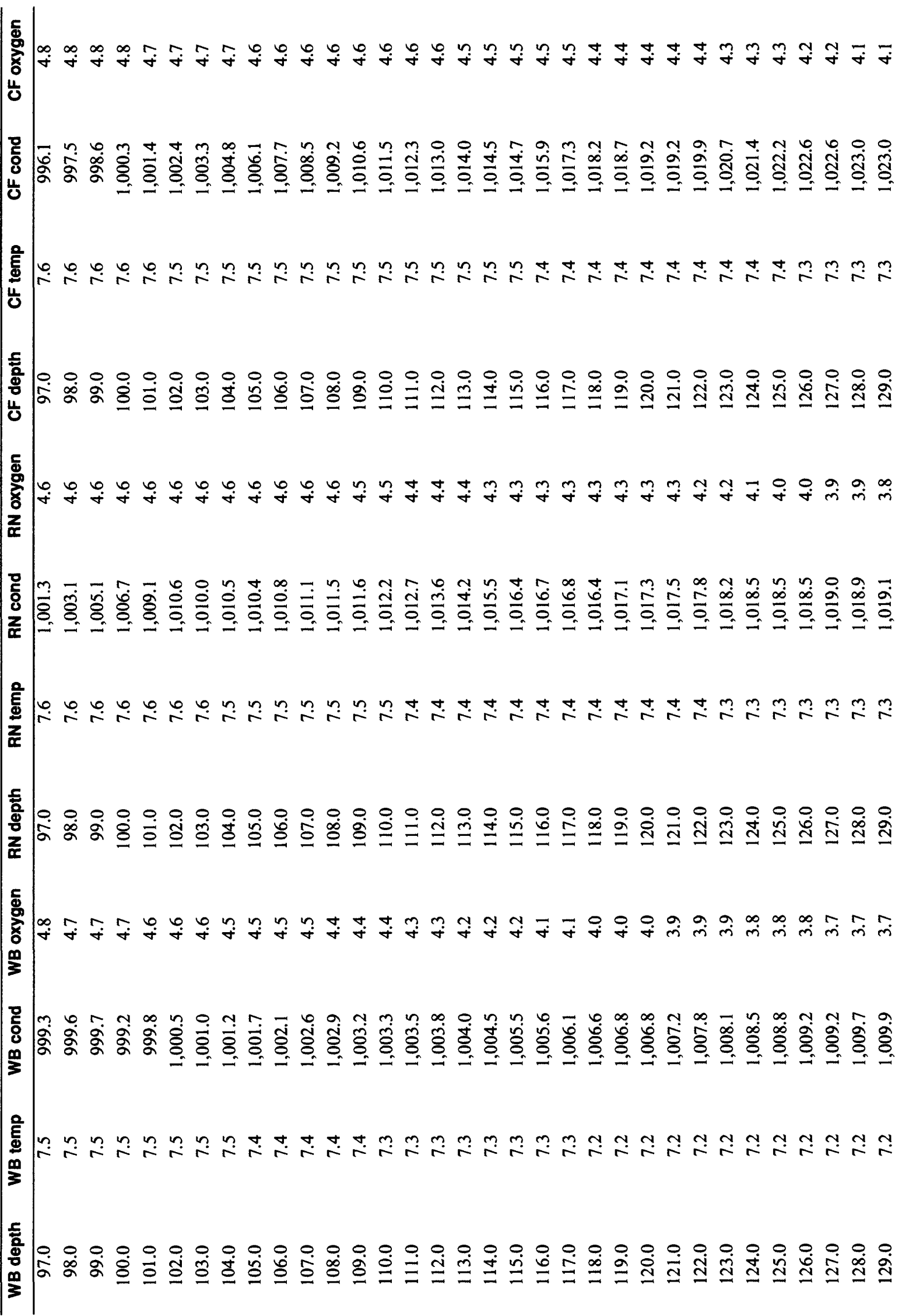




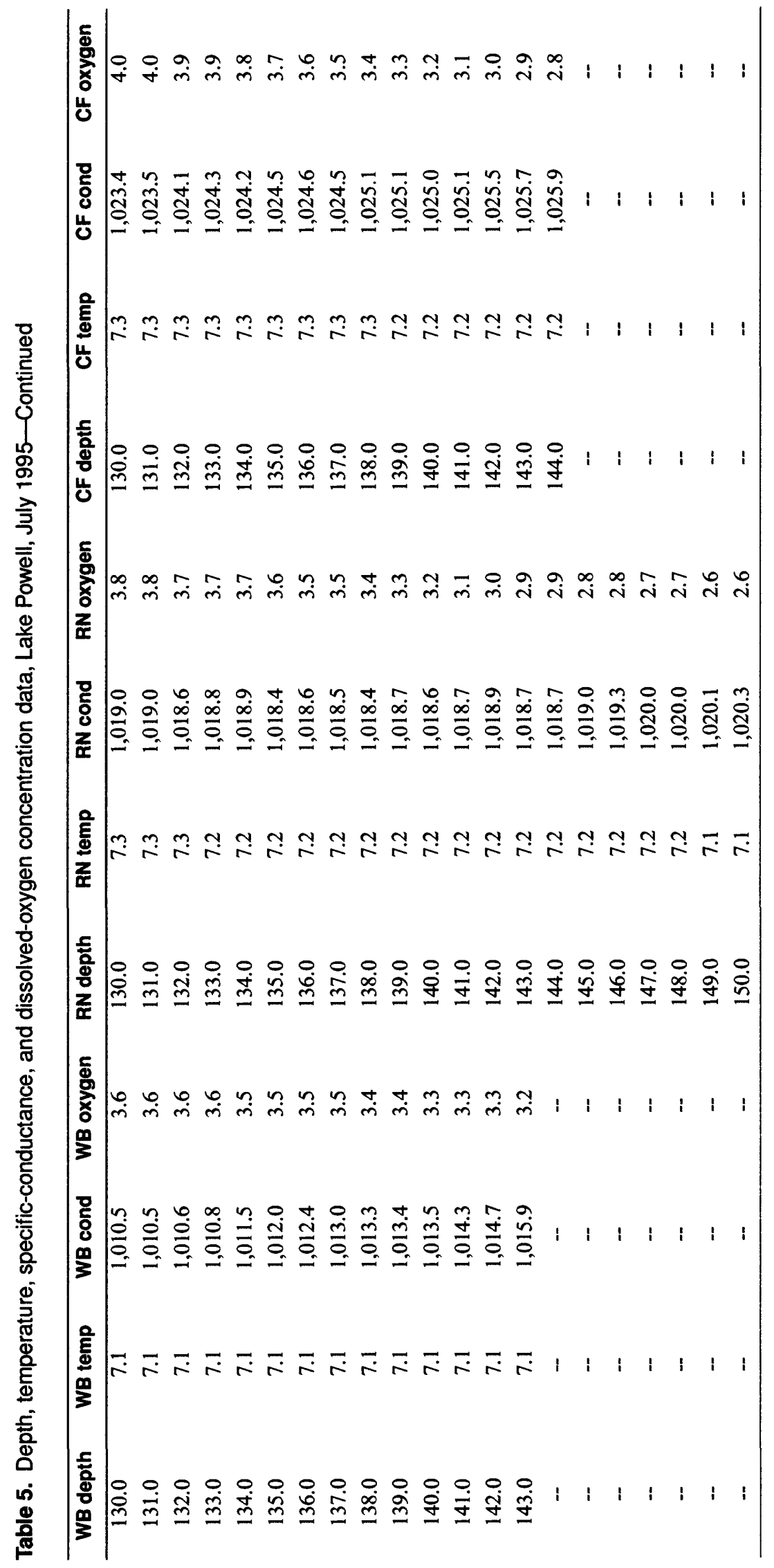




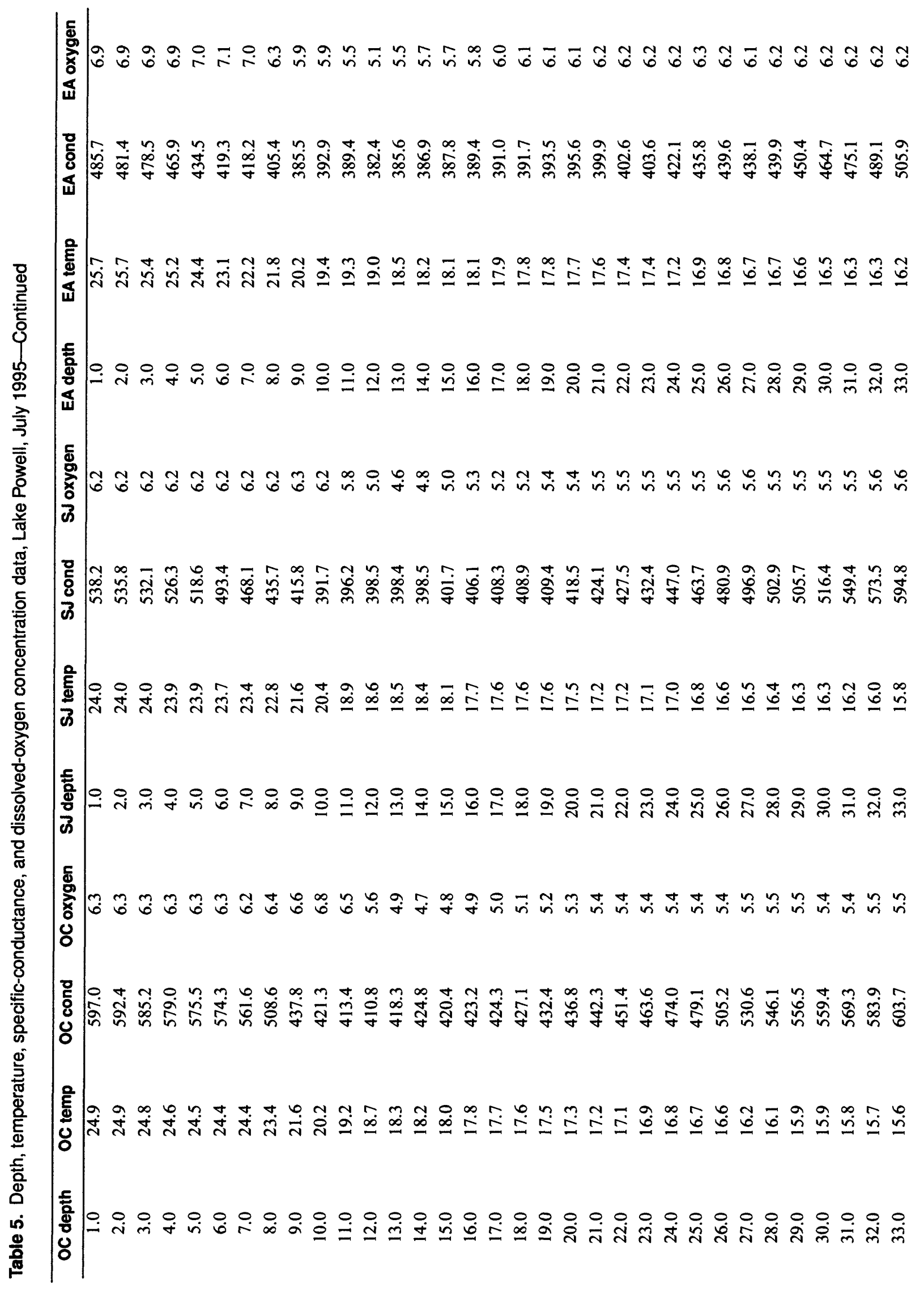




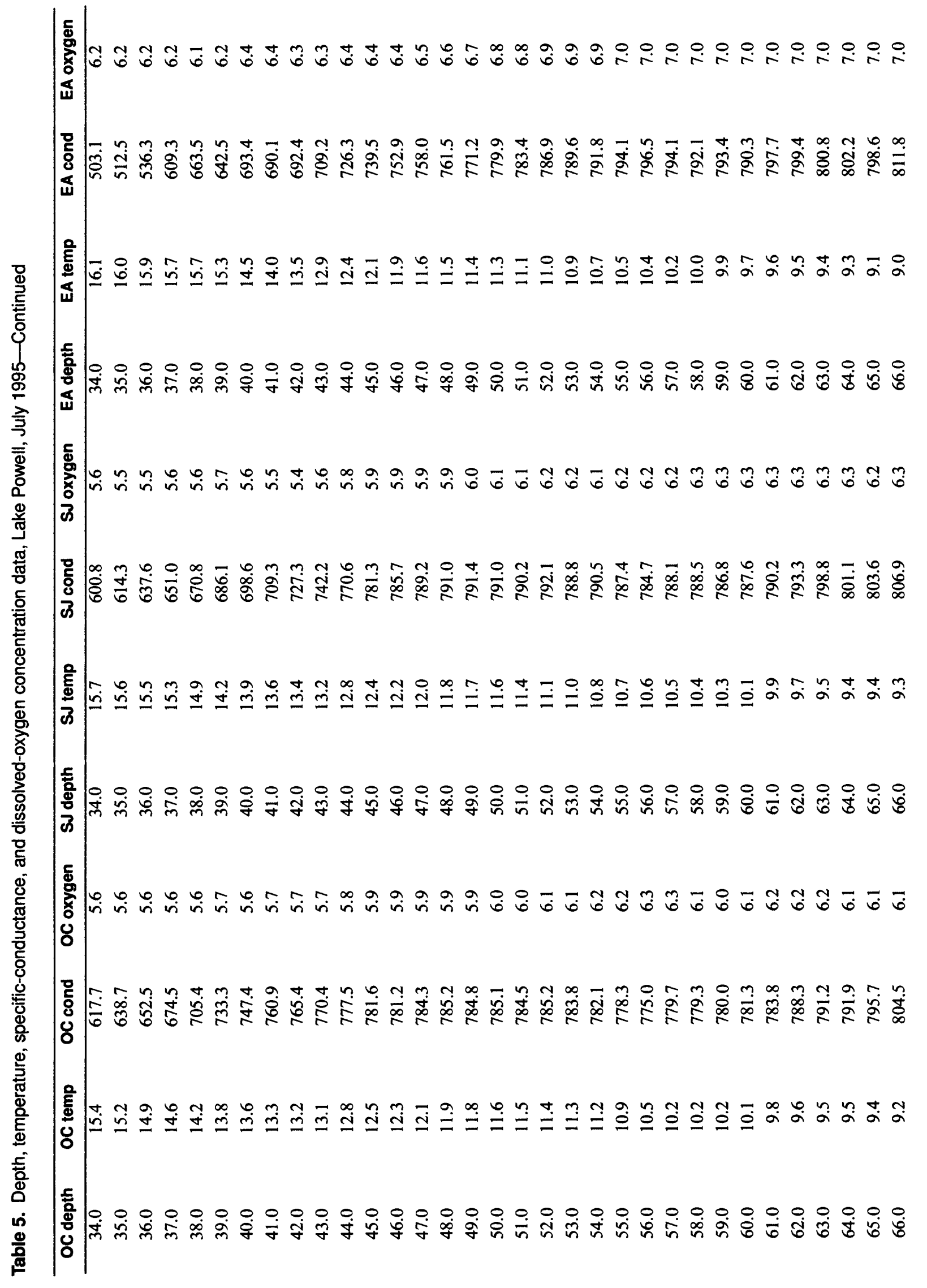




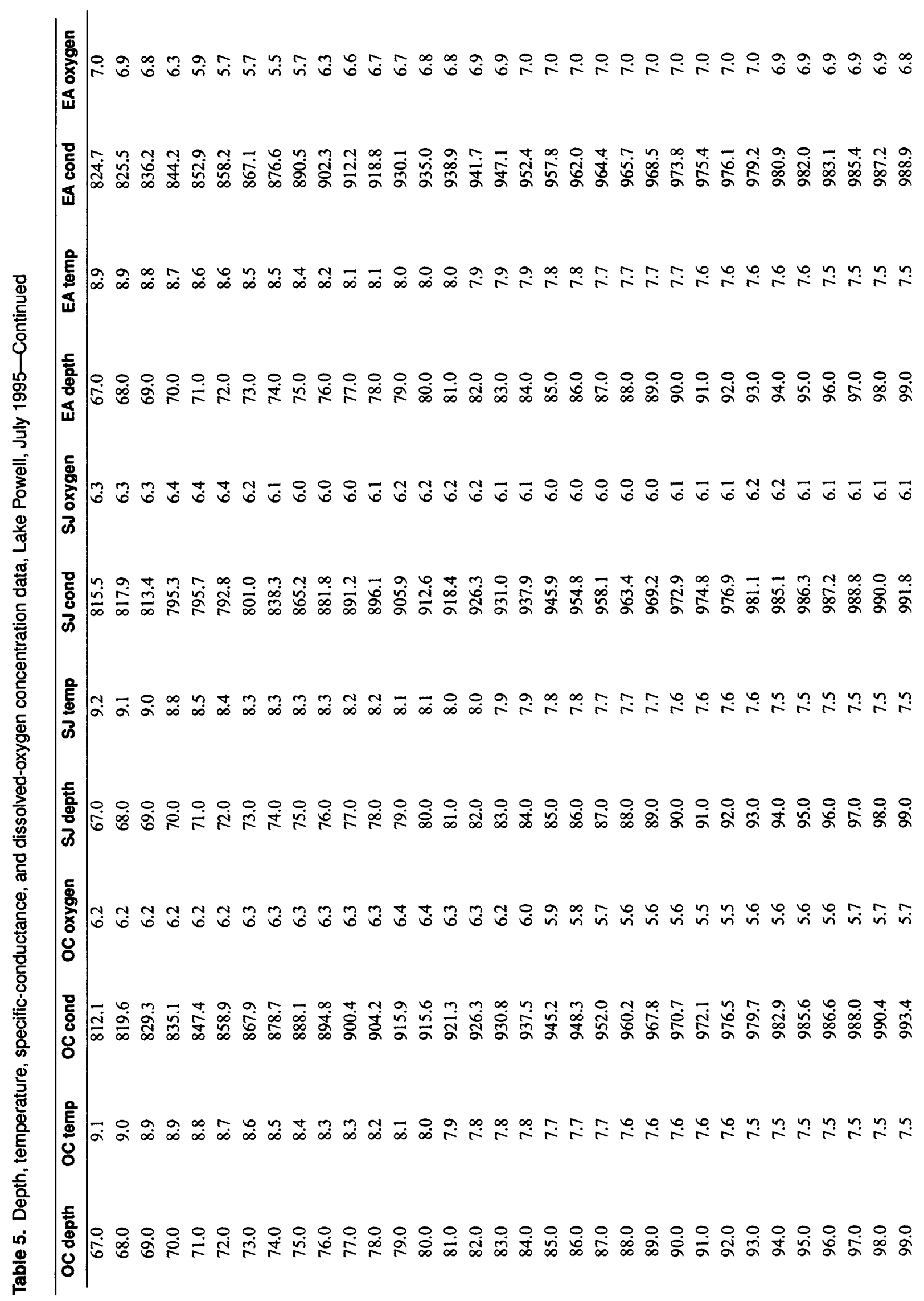




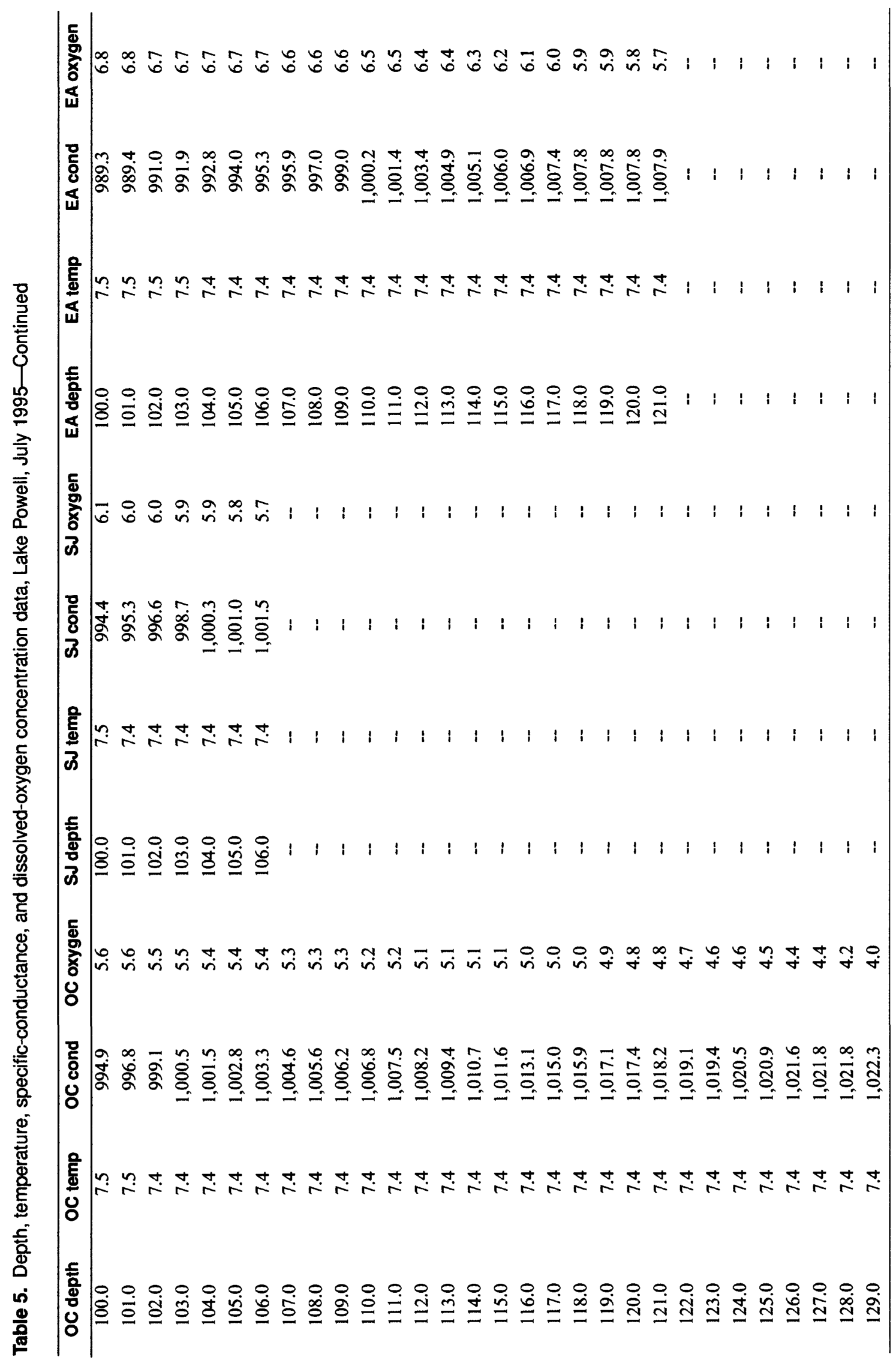




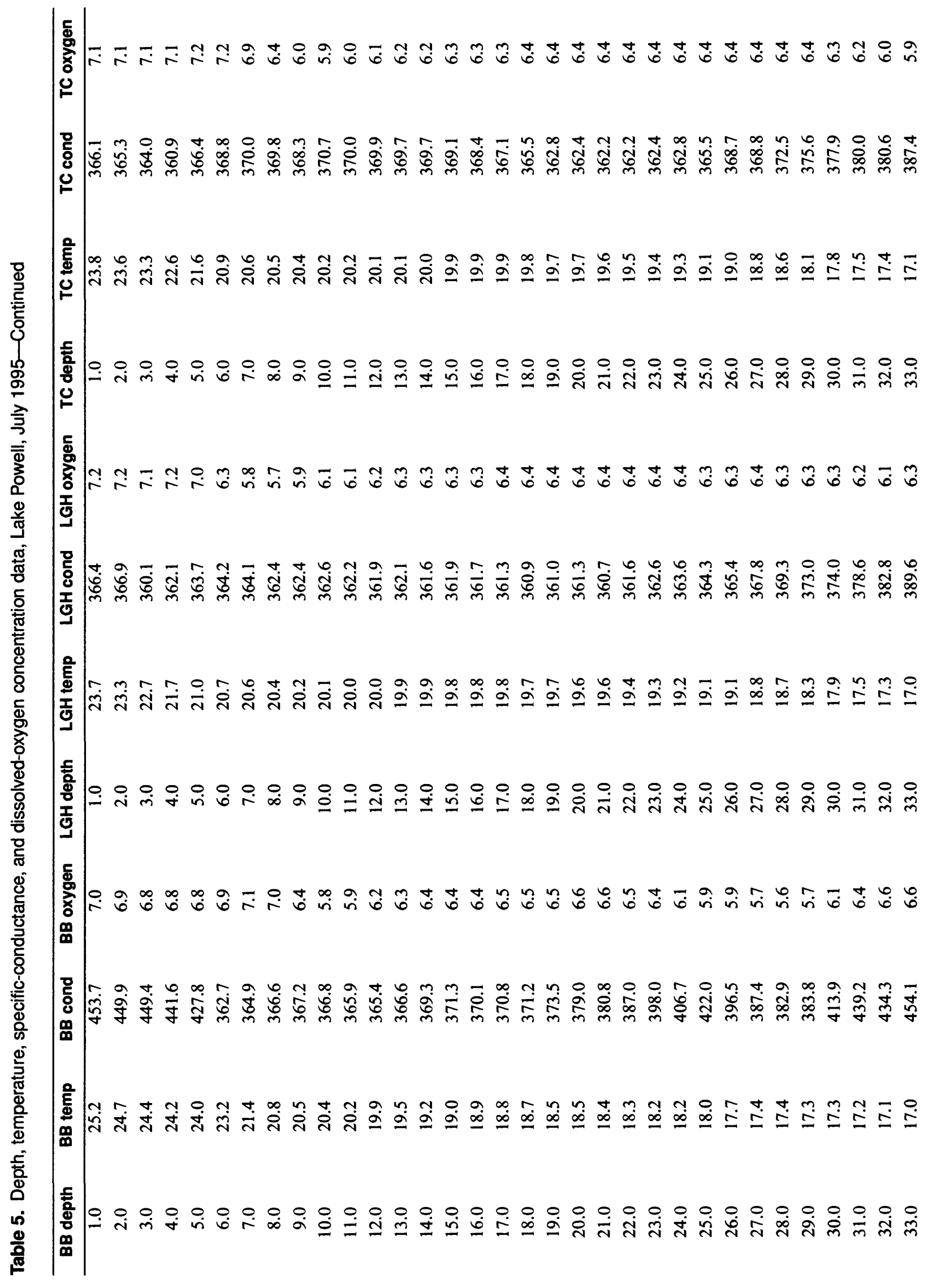




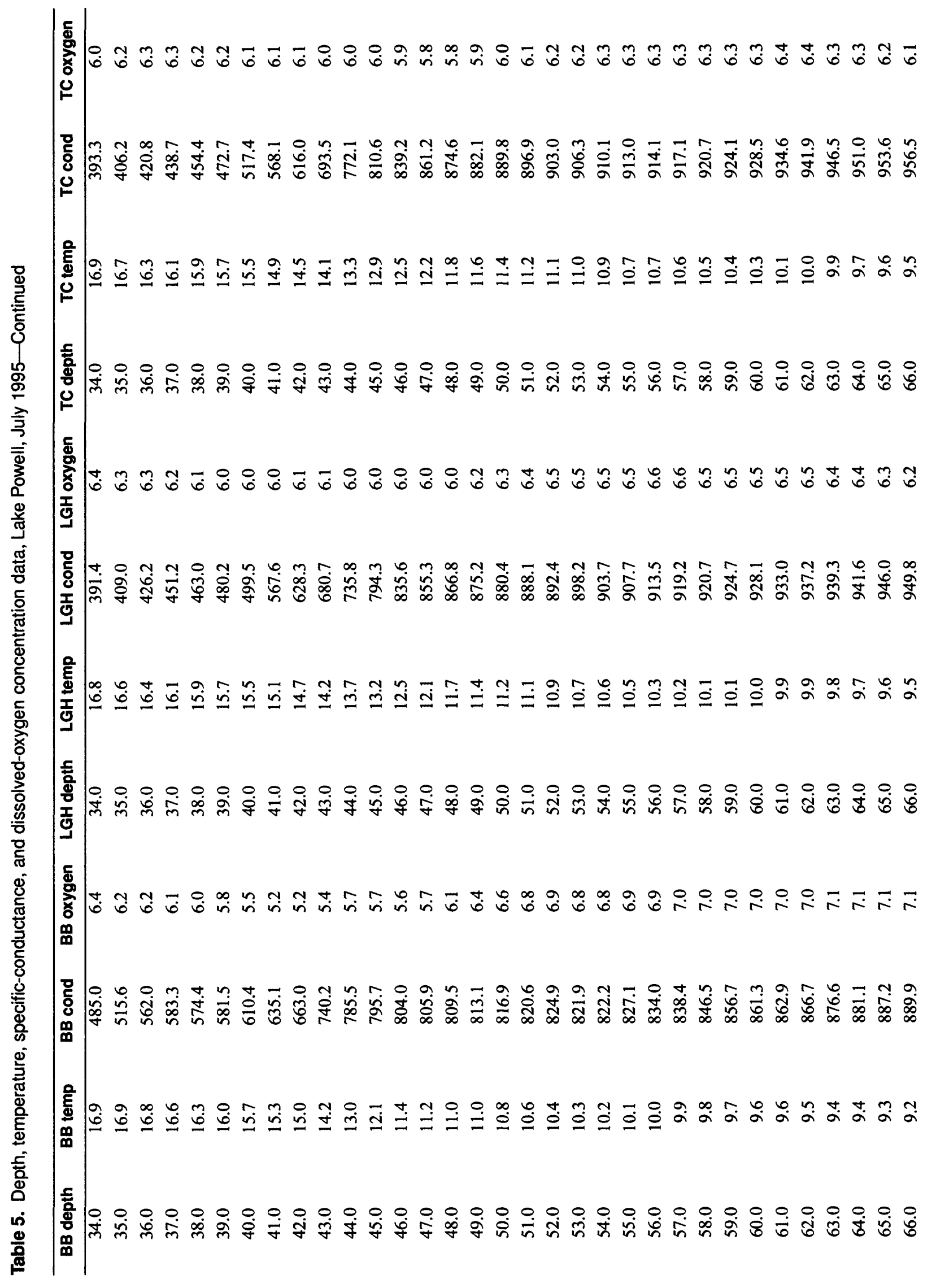




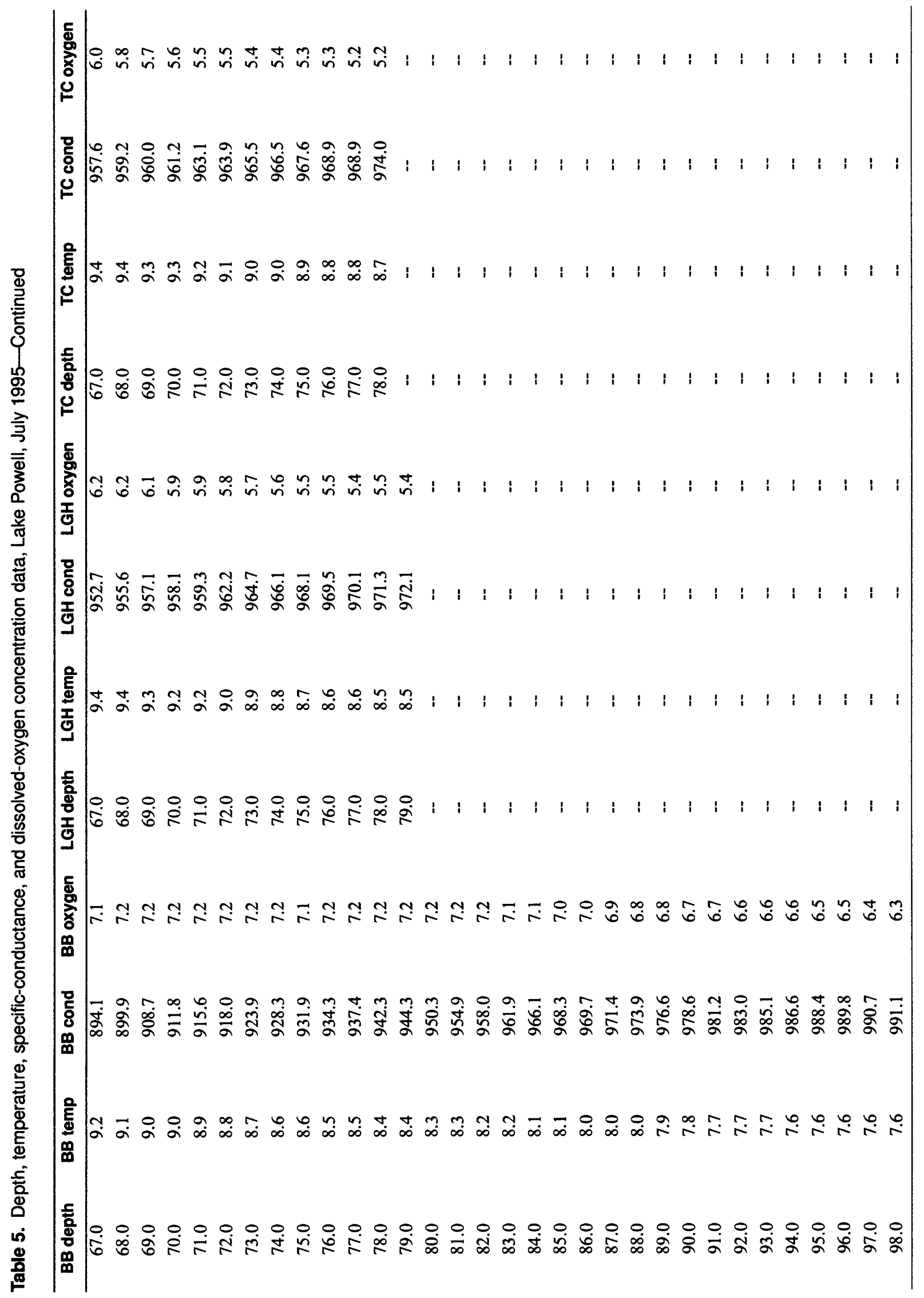




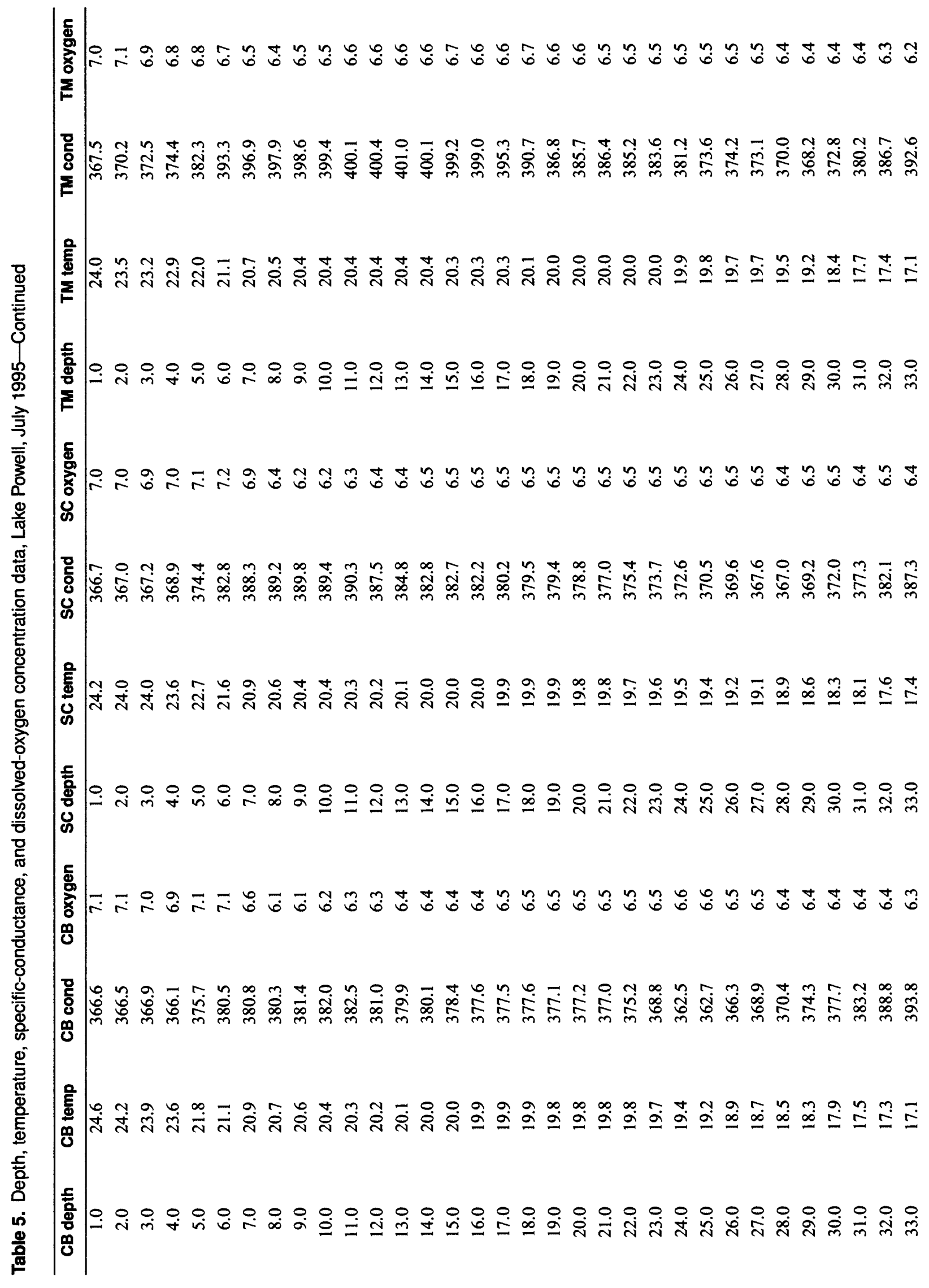




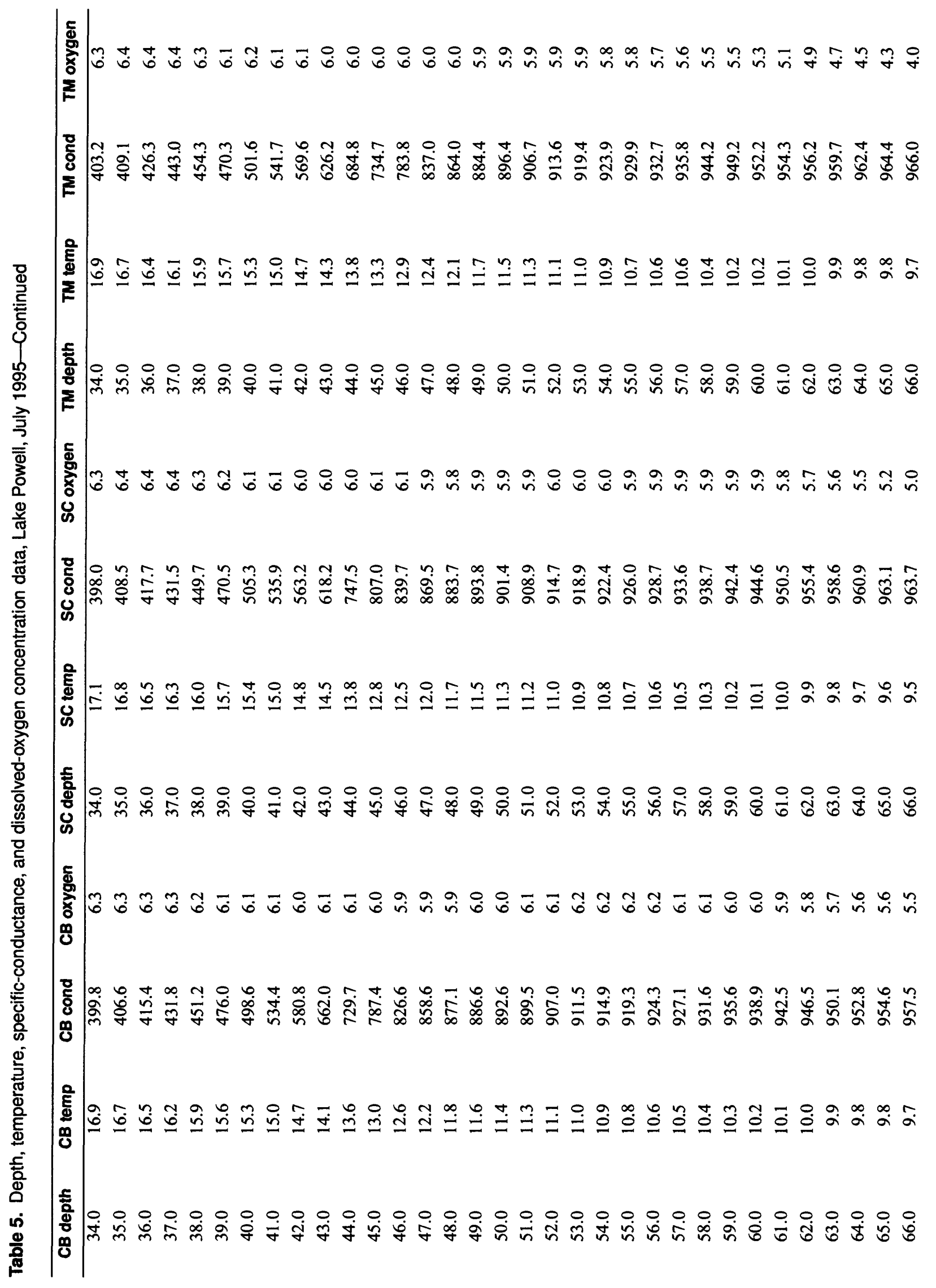




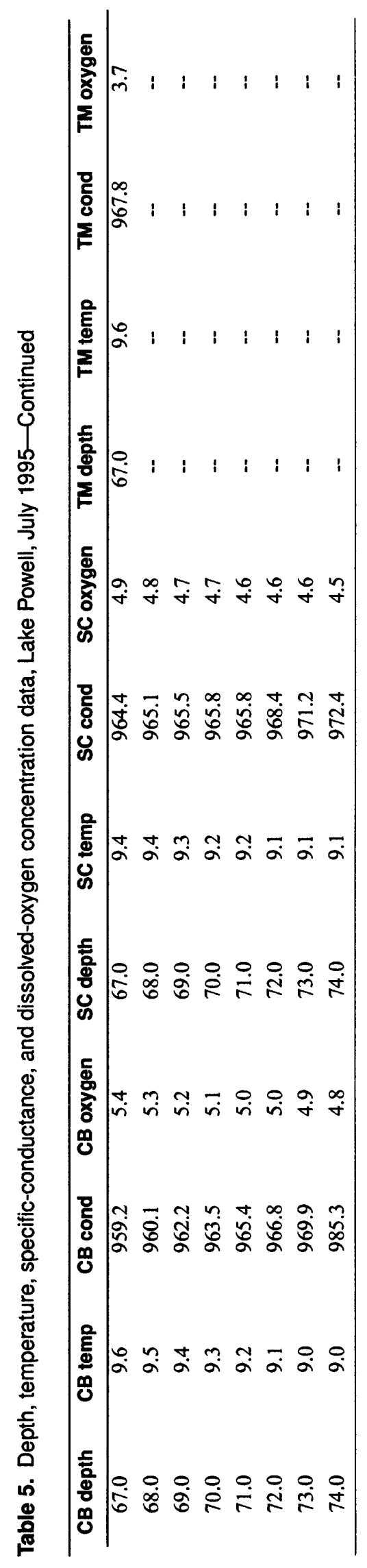




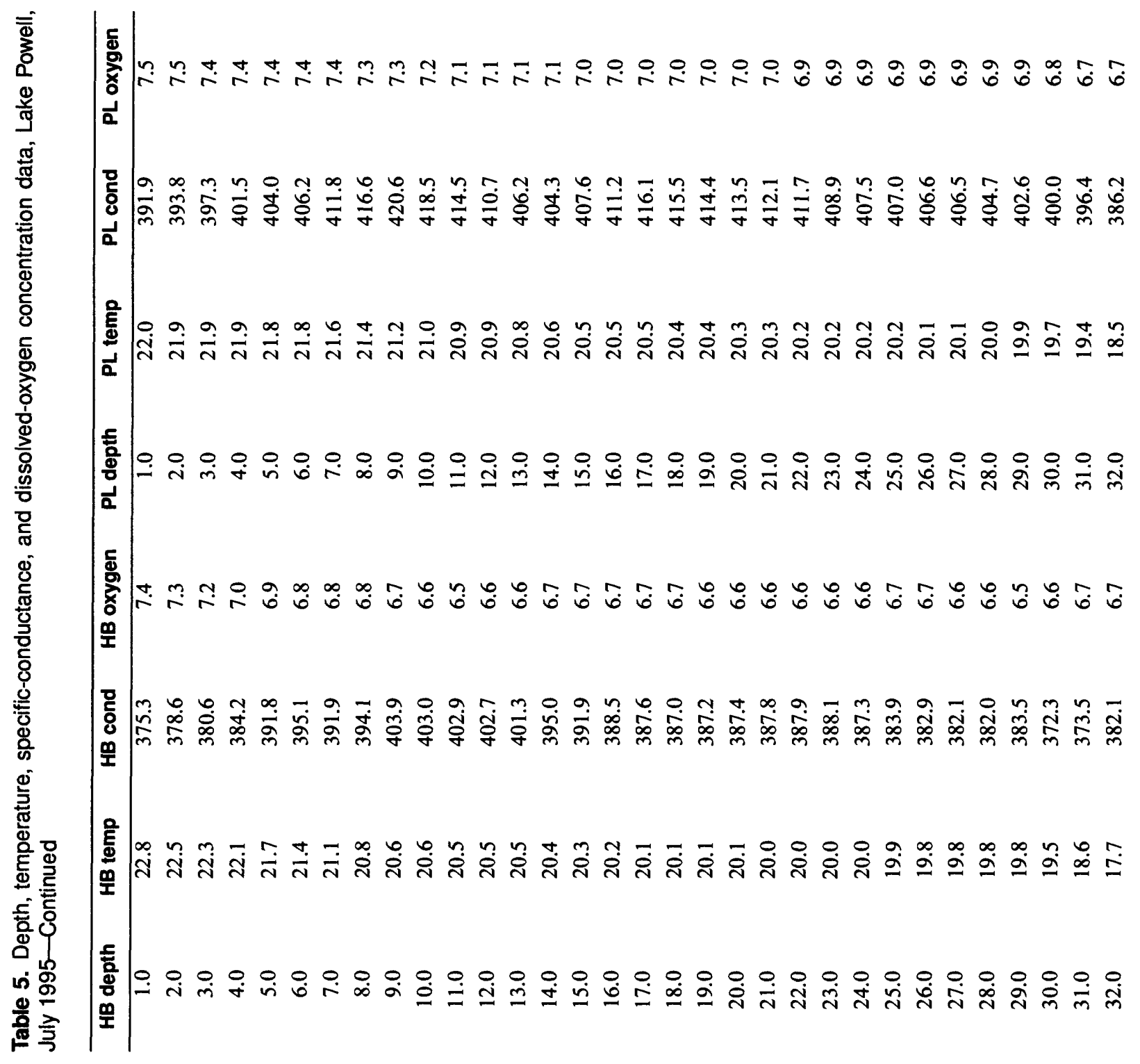




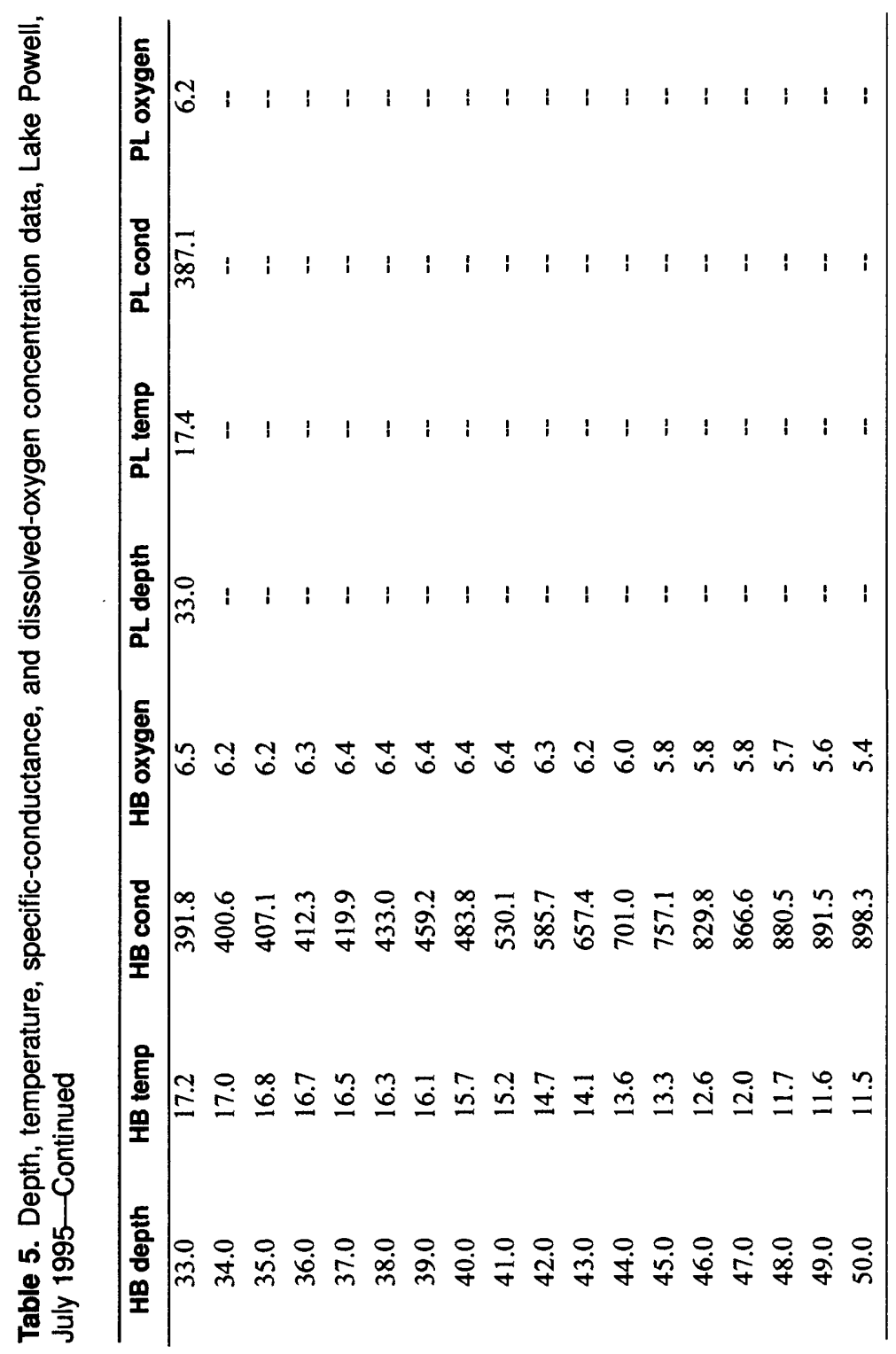

